\title{
Abstracts of presentations at the XXVI Congress of the Italian Phytopathological Society (SIPaV)
}

\section{September 16-17, 2021. University of Verona, Verona, Italy}

Published online: 16 November 2021

○) Società Italiana di Patologia Vegetale (S.I.Pa.V.) 2021

Resistance behaviour to Gnomonia leptostyla (Fr.) Ces. in various species and provenances of Juglans

\section{N. Anselmi ${ }^{1}$, M. Gras ${ }^{2}$}

${ }^{1}$ Department for Innovation in Biological, Agro-food and Forest systems (DIBAF), University of Tuscia, Viterbo (Italy); ${ }^{2}$ CRA (Agricultural Research Council) - PLF (Research Unit for Intensive Wood Production), Rome (Italy).E-mail: anselmi@unitus.it

The aim of this work was to evaluate the response of various species and provenances of Juglans to the anthracnose agent Gnomonia leptostyla. The research was carried out in the 15-year-old experimental plantation Cesurni Farm (CRA) near Tivoli, Rome, during the 2014 vegetative seasons, characterized by a high anthracnose incidence. The considered material consisted of four Juglans species originated from USA, i.e. J. cinerea (8 genotypes), J. microcarpa (18), J. sieboldiana (16) and J. nigra (66) and of J. regia plants of different provenances, from France (27), Russia (16), Israel (28), Iran (9), northern Italy (32), central Italy (36), southern Italy (42). Both the average number of necrosis spots and the percentage of leaf necrotic area were useful tools to evaluate disease susceptibility. J. cinerea and J. sieboldiana showed only small (2-4 mm diameter) necrotic spots, while the other species exhibited necroses larger than $1 \mathrm{~cm}^{2}$, with stronger severity (in descending order) on J. regia, J. nigra and J. microcarpa and, among $J$. regia, for the provenances from France, Russia, Italy, Israel and Iran. J. cinerea, J. sieboldiana, J. microcarpa, J. nigra, resulted more resistant to anthracnose than J. regia. Among J. regia, the genotypes of French origin were discreetly resistant, those from Russia and Israel were tendentially susceptible, those from Iran were very susceptible, whereas the genotypes from Italy ranged from very susceptible to moderately resistant. These results represent an important starting point for the selection and genetic improvement of walnut for fruit and wood production.
Wheat associated microbial community changes due to the activity of Trichoderma gamsii $\mathbf{T 6 0 8 5}$ as a biocontrol agent to mitigate Fusarium Head Blight disease in wheat

A.S. Alukumbura ${ }^{1}$, W.G.D. Fernando ${ }^{1}$, S. Sarrocco ${ }^{2}$, A. Bigi $^{2}$, G. Vannacci ${ }^{2}$, M.G. Bakker ${ }^{3}$

${ }^{I}$ Department of Plant Science, University of Manitoba, 66 Dafoe Road, Winnipeg, MB R3T 2N2, Canada; ${ }^{2}$ Department of Agriculture, Food and Environment, University of Pisa, Via del Borghetto 80, 56124 Pisa, Italy; ${ }^{3}$ Department of Microbiology, 45 Chancellor's Circle, Winnipeg, MB R3T 2N2, Canada. E-mail: matthew. bakker@umanitoba.ca

Beneficial microbes can help mitigate plant diseases through competition with pathogens. Trichoderma gamsii T6085 is a biocontrol agent capable of mitigating Fusarium head blight (FHB) in wheat. This study assessed the impact of $T$. gamsii T6085 on wheat-associated microbiome and on Fusarium graminearum in field. Cultivar Tirex was seeded in a RCBD with four treatments. T. gamsii was applied on: i) crop debris at stalk stage; ii) on spikes at anthesis and iii) on both crop debris at stalk stage and on spikes at anthesis. Untreated plots were used as control with five replicates. Crop residue (wheat from the previous growing season), wheat spikes, and wheat kernels were collected at different time points from T6085 application for DNA extraction and qPCR. The microbial community structure showed an apparent variation over time. The most abundant taxa in wheat spikes and kernels were Pseudomonas, Enterobacter, and Pantoea, while Alternaria and Fusarium were the most abundant fungi. The $F$. graminearum density was significantly higher in crop residue initially and decreased over time. $F$. graminearum density increased over time in wheat spikes, reaching the highest densities at harvest. Application of T. gamsii did not significantly affect the microbial community composition. There was a significant reduction in FHB disease index and severity 28 days post inoculation with $T$. gamsii, the changes 
in $F$. graminearum density due to $T$. gamsii treatment were not significant. The changes in wheat associated microbiome due to the $T$. gamsii colonization are minimum.

Trellis systems of mother vines impact the wood resident microbiome of two grapevine rootstocks cultivars

\section{E. Battiston ${ }^{1}$, L. Borruso ${ }^{2}$, C. Pinto ${ }^{3}$, T. Mimmo ${ }^{2}$, S. $\mathrm{Cesco}^{2}$, S. Di Marco ${ }^{4}$, L. Mugnai ${ }^{1}$}

\begin{abstract}
${ }^{1}$ Department of Agricultural, Food, Environmental and Forestry Science and Technology, Plant pathology and Entomology section, University of Florence, P.le delle Cascine 28, 50144 Firenze, Italy; ${ }^{2}$ Faculty of Science and Technology, Free University of Bozen, Piazza Università 5, 39100 Bolzano, Italy; ${ }^{3}$ Biome Makers, 890 Embarcadero Drive, West Sacramento, CA 95605, USA; ${ }^{4}$ Institute of BioEconomy, National Research Council, Via P. Gobetti 101, 40129 Bologna, Italy. E-mail: enrico.battiston@unifi.it
\end{abstract}

Grapevine nursery industry produces millions of benchgrafted vines starting from the growth of rootstock mother vines. With few exceptions, rootstocks shoots are usually sprawled on the ground, an inexpensive method that may favor infections by trunk disease pathogens, compromising the quality of the propagation material. More rarely, trellis systems are applied to rootstock mother vines to improve the functional leaf area and its exposure to the sunlight. Different trellis system therefore influences the canopy microclimate: this and the lack of contact with the soil occurring by trellising rootstock mother vines may positively shape the dynamics of the epiphytic and endophytic microbial communities. Through a DNA metabarcoding approach, this study investigated the impact of two trellising methods (a trellis system with a transpiring fabric applied to protect sprawled rootstocks from the soil) compared to the traditional sprawled rootstocks (two cultivars: Kober 5 BB and 110 Richter), on the resident fungal and bacterial communities, with a specific focus on wood pathogens. Beta diversity of the bacterial and fungal communities, including epiphytic and endophytic communities, resulted to be affected by the temporal distribution of the rootstock microbiome. Such diversity was more evident when comparing a trellised rootstock (cv. Kober $5 \mathrm{BB}$ ) with the same plant material sprawled on the ground. The results show that the sprawling shoots, compared to vertical-positioned shoots, are more exposed to soilborne microorganisms and pathogens as a consequence of the contact with the inoculum in the soil and the higher temperatures and humidity.

The study was funded by the EAFRD-Rural Development Plan 2014-2020 of the Italian Region Friuli Venezia Giulia (Regional
Decree $\left.n^{\circ} 402 / A G F O R, 21 / 01 / 2020\right)$ and supported by a research fellowship of the International Organization of Vine and Wine (OIV Research Grant Program 2018).

Different grapevine bench grafting methods affect wood necrosis associated with young declines of grafted vines

\section{E. Battiston ${ }^{1}$, S. Falsini ${ }^{2}$, A. Giovannelli ${ }^{3}$, S. Schiff ${ }^{2}$, C. Tani $^{2}$, R. Panaiia ${ }^{2}$, S. Di Marco ${ }^{4}$, L. Mugnai ${ }^{1}$}

${ }^{1}$ Department of Agricultural, Food, Environmental and Forestry Science and Technology, Plant pathology and Entomology section, University of Florence, P.le delle Cascine 28, 50144 Firenze, Italy; ${ }^{2}$ Department of Biology, Biomorphology Laboratory, University of Florence, Via Micheli 3, 50121 Firenze, Italy; ${ }^{3}$ Research Institute on Terrestrial Ecosystems, National Research Council, Via Madonna del Piano 10, 50019 Sesto Fiorentino, Italy; ${ }^{4}$ Institute of BioEconomy, National Research Council, Via P. Gobetti 101, 40129 Bologna, Italy.E-mail: laura.mugnai@unifi.it

Grapevine grafting has become an essential practice in viticulture and over the years various bench grafting techniques have evolved to mechanize the nursery process and to increase the yield in number of viable cuttings. Bench grafting is a fundamental nursery practice that affects the quality of propagation material also in young decline associated to grapevine trunk diseases, and has been recently reported to influence leaf symptoms development associated to diseases of Esca complex. The present study aimed to investigate how three bench grafting methods (omega graft as mechanical technique, whip and tongue graft as manual technique and full cleft graft as semi-mechanical technique) can influence these phenomena, comparing their effect on anatomical development of the grafting point and on functionality of vascular tissue, also considering two factors: cultivar (Cabernet Sauvignon, Glera and Teroldego) and scion/rootstock diameter (thin and large). Light microscopy observations on the anatomical evolution were correlated with the grafting methods and the investigated varieties. Significant differences between cultivars and/or graft type were also detected in terms of necrotic area on the grafted tissues. Statistical analysis of the grapevine vessels suggested differences in xylem parameters between cultivars while graft type had no have significant effects. On the other hand, the intrinsic growth rate was significantly affected by the graft type. The results confirm the potential incidence of lesions and dysfunctionalities correlated with the grafting method applied, which can potentially induce grafted vine declines in vineyard as a result of the necrotic area detected on the grafted tissues.

The study was funded by the EAFRD - Rural Development Plan 2014-2020 of the Italian Region Friuli Venezia Giulia (Regional 
Decree $\left.n^{\circ} 402 / A G F O R, 21 / 01 / 2020\right)$ and supported by a research fellowship of the International Organization of Vine and Wine (OIV Research Grant Program 2018).

Phytopathogenic fungi threaten the Quercus genus in a coastal forest: detection of fungal diversity by Nanopore Sequencing

\section{Beccaccioli, V. Cecchetti, L. Faino, M. Reverberi}

Dept. of Environmental Biology, Sapienza University of Rome, P.le Aldo Moro 5, 00185 Rome, Italy.E-mail: marzia.beccaccioli@ uniromal.it

Molecular characterization of potential fungal pathogens affecting Quercus spp. is the challenge to limit the expansion of the oak decline. The investigation was made on acorns and on Quercus seedlings grown in a forest nursery. The analysis aims to determine pathogens that can potentially infect seedlings and eventually cause plant death. Fungal detection by molecular tools was performed with two approaches: 1) by culture-dependent fungal profiling followed by Sanger sequencing and 2) by culture-independent fungal profiling using Oxford Nanopore Technology (ONT). In both cases, we sequenced the ITS region of ribosomal DNA. Both methods have proven effective, however, culture-independent methodology proved more advantageous; in fact, using culture independent approach, we were able to identify a larger variety of microorganism putatively involved in the oak decline syndrome. Using culture-dependent approach, several saprophytic fungal species were isolated in vitro and subsequently, characterized by ITS sequencing (Sanger). Nanopore ITS sequencing identified a broader variety of fungal species, with few associated to the oak decline such as Diplodia corticola and Discula quercina. Other fungal species identified like Epicoccum nigrum, Alternaria alternata, Alternaria sp., Lophiostoma corticola and Pleosporales sp. could play an important ecological role as they can change their lifestyles from endophytic to pathogenic, or saprobic, depending on the environmental conditions. Our research provides a phytosanitary protocol to rapidly diagnostic the presence of oak pathogens. Diagnosticated microbial genomes may be used to correlate the potential fungal infections to abiotic stresses.

This work was supported by LIFE-PRIMED project (LIFE-17 NAT/GR/000511).

Exploring enniatin B effect and its association with deoxynivalenol on bread wheat tissues and on the development of Fusarium species

\section{G. Beccari, L. Ederli, I. Bergamini, F. Tini, L. Covarelli}

Department of Agricultural, Food and Environmental Sciences, University of Perugia, Borgo XX Giugno 74, 06121 Perugia, Italy.E-mail: giovanni.beccari@unipg.it

Fusarium graminearum (FG) is the main causal agent of Fusarium head blight (FHB) of wheat. However, recently, another pathogen, Fusarium avenaceum (FA), has increased its relevance worldwide. FG biosynthesizes deoxynivalenol (DON), while FA is an enniatin (ENNs) producer. DON is a well-known mycotoxin but little is known about the activity of ENNs on wheat tissues and on fungal competition. For this reason, the present study aims to explore the effect of enniatin B (ENB), and its association with DON, on bread wheat and on Fusarium development. Pure ENB, DON and $\mathrm{ENB}+\mathrm{DON}\left(10 \mathrm{mg} \mathrm{kg}^{-1}\right)$ were applied to bread wheat (cv. A416) seeds, seedlings and leaves to test their impact on germination, shoot/root growth, plant cell death (PCD) induction (trypan blue staining and malondialdehyde, MDA, accumulation methods) and pigmentation. In addition, pure ENB, DON and ENB + DON (10, 50 and $100 \mathrm{mg} \mathrm{kg}^{-1}$ ) were used to assess the in vitro effect on FG and FA growth. A synergistic effect of the two compounds in the reduction of seed germination and shoot/root development was observed. ENB alone induced the highest MDA accumulation in shoot/ root. Conversely, DON, at the tested concentration, did not increase MDA. ENB showed also a higher "protective" effect on pigments in comparison to DON. Starting from $50 \mathrm{mg} \mathrm{kg}^{-1}$ ENB inhibited FG development, while DON promoted FA growth. A synergistic effect was also observed in the reduction of FA/FG development. These results highlight the potential role of ENB in PCD promotion as well as in FA competition with FG.

This work was supported by the "University of Perugia fund for basic research 2018" project title "Study of the antifungal and insecticide activity of enniatins, secondary metabolites biosynthesized by Fusarium avenaceum”.

Signals produced by rhizosphere-living bacteria affect the behaviour of Lysobacter capsici AZ78, a promising bacterial biocontrol agent

\author{
A. Bejarano ${ }^{1,2}$, M. Perazzolli ${ }^{1,2}$, I. Pertot $^{1,2}$, G. Puopolo ${ }^{1,2}$ \\ ${ }^{1}$ Center of Agriculture, Food, Environment, University of Trento, \\ San Michele all'Adige, Italy; ${ }^{2}$ Department of Sustainable Agro- \\ Ecosystems and Bioresources, Research and Innovation Centre, \\ Fondazione Edmund Mach, San Michele all'Adige, Italy. E-mail: \\ ana.bejaranoramos@unitn.it
}

Application of bacterial biocontrol agents (BBCAs) represents a promising strategy for the sustainable management 
of soil-borne pathogens. Nonetheless, their efficacy in field is often inconsistent. This might be due to their difficulty to adapt and integrate within indigenous soil microbial communities. In fact, the establishment of interspecific interactions based on diffusible communication signals (DCSs) produced by the rhizosphere microbiota continuously shapes gene expression of BBCA species, enhancing or hindering their establishment in the rhizosphere. To shed light on the aspects determining rhizosphere competence of BBCAs, we investigated the response of the model BBCA Lysobacter capsici AZ78 (AZ78) to most common rhizosphere DCSs. Functional experiments aimed at assessing changes in AZ78 cell growth and in vitro antimicrobial activity upon exposure to DCSs were carried out in vitro using a growth medium mimicking rhizosphere conditions. Results showed that DCSs did not impair AZ78 cell growth whereas indole and glyoxylic acid influenced AZ78 in vitro inhibitory activity against soil-borne pathogens. Gene expression profiling of AZ78 was carried out by high throughput RNA-Seq. Results revealed that nearly $21 \%$ of all AZ78 genes was modulated by DCSs. 13-methyltetradecanoic acid, glyoxylic acid, and 2,3-butanedione up-regulated genes related to motility and stress tolerance. Indole down-regulated genes related to motility and antibiosis. These findings suggest that manipulating DCSs levels in the rhizosphere could provide efficient means to favour persistence and biocontrol activity of BBCAs in the rhizosphere. Further investigations will be dedicated to the selection of helper-bacterial-strains producing positive signals to obtain functional microbial consortia for field application.

This work was founded by the European Union's Horizon 2020 research and innovation programme under the Marie SklodowskaCurie grant agreements No. 797028.

Using helper bacterial strains to improve the plant protection efficacy of Lysobacter capsici AZ78, a biocontrol agent of soilborne plant pathogens

\section{A. Bejarano ${ }^{1,2}$, G. Puopolo ${ }^{1,2}$}

${ }^{1}$ Center of Agriculture, Food, Environment, University of Trento, San Michele all'Adige, Italy; ${ }^{2}$ Department of Sustainable AgroEcosystems and Bioresources, Research and Innovation Centre, Fondazione Edmund Mach, San Michele all'Adige, Italy. E-mail: ana.bejaranoramos@unitn.it

Microbial based biopesticides have been recognized as a sustainable alternative to chemical pesticides in agriculture. However, environmental factors may negatively impact their viability and limit their efficacy in the field. Moreover, they must survive and thrive within resident soil microbial communities. Nowadays, the use of synthetic microbial consortia is considered as a sound strategy for overcoming these constraints. Herein, we describe a method for designing bacterial consortia with biocontrol activity. A collection of bacterial isolates was preliminary screened in vitro for their ability to coexist with Lysobacter capsici AZ78 (AZ78), a Gram-negative bacterium able to control several phytopathogenic microorganisms. Each strain was tested for enhancement of AZ78 in vitro inhibitory activity against Pythium ultimum. Results showed that some strains belonging to the genera Ensifer, Lysobacter, Stenotrophomonas, and Variovorax particularly enhanced AZ78 biocontrol activity. Strains were also evaluated for their ability to decrease the susceptibility of AZ78 to desiccation and UV light. All the binary combinations showed that extracellular metabolites of Ensifer spp. and Lysobacter spp. enhanced, both, AZ78 resistance to UV light and desiccation. Furthermore, combinations of AZ78 and helper bacterial strains (HBS) were evaluated for their ability to enhance biocontrol activity against Fusarium oxysporum f. sp. radicis-lycopersici in planta. All tested consortia were effective in suppressing Fusarium crown and root rot of tomato in planta. Next steps will focus on the development of protective formulations including AZ78 and HBS and their validation under greenhouse and field conditions.

This work was founded by the European Union's Horizon 2020 research and innovation programme under the Marie SkłodowskaCurie grant agreements No. 797028.

Calcium oxide, potassium phosphite and a Trichoderma enriched compost water suspension protect Capsicum annuum against Phytophthora capsici by priming the immune system

\section{A. Bellini ${ }^{1,2}$, M. Pugliese ${ }^{1,2}$, V. Guarnaccia ${ }^{1,2}$, G.R. Mel- oni $^{1,2}$, M.L. Gullino ${ }^{1}$}

${ }^{1}$ AGROINNOVA - Centre of Competence for the Innovation in the Agro-Environmental Sector, University of Turin, Turin, Italy; ${ }^{2}$ Agricultural, Forestry and Food Sciences Department (DISAFA), University of Turin, Turin, Italy.E-mail: alessio.bellini@unito.it

Proper management of Phytophthora capsici in pepper cultivation is extremely important, since Phytophthora blight is the main disease of this crop worldwide. In the past, the main strategy adopted was the use of fungicides, causing, in some cases, the development of $P$. capsici resistant strains. In this work three different treatments selected from previous studies (potassium phosphite, calcium oxide and a water suspension from Trichoderma sp. TW2 enriched compost) were tested to prove their ability to activate the systemic acquired resistance (SAR) in pepper against $P$. capsici; acibenzolar-s-methyl was used as positive control. Two independent growth chamber pot experiments were performed, spatially dividing the site of treatments application (as radical drench) and the site of inoculation (as agar plug 
on the third leaf). Leaf lesions were measured, showing a significant reduction on all treated plants compared to the untreated control. To further confirm this hypothesis, the expression levels of three SAR key genes ( $\mathrm{CaPBR}$, $\mathrm{CaPOI}$ and $C a D E F 1$ ) were evaluated though RT-Real Time PCR at the three end-point times: T0, T6 and T24. A significant increase of target genes expression was observed in one endpoint time in each treated plant. Eventually, statistical over accumulation of salicylic acid was observed in the upper leaves at the same end-point times, through HPLC-MS/MS analysis. This work confirmed the hypothesis that the three treatments tested have the ability to prime the plant immune system, leading pepper to an alert status able to confer a higher defence against $P$. capsici.

This work was supported by the EU Horizon2020 NUTRIMAN project (GA 818470).

Different sieve-element specific proteins are involved in the immune response of Arabidopsis to phytoplasma infection

\section{Bernardini ${ }^{1}$, A.J.E. van $\mathrm{Bel}^{2}$, R. Musetti ${ }^{1}$}

${ }^{1}$ Department of Agricultural, Food, Environmental and Animal Sciences, University of Udine, via delle Scienze 206, I-33100 Udine, Italy; ${ }^{2}$ Institute of Phytopathology, Justus-Liebig University, Heinrich-BuffRing 26-32, D-35392 Giessen, Germany.E-mail: rita.musetti@uniud.it

Phytoplasmas are strictly dependent on sieve-element resources, thus insight about the fine interaction established with the different sieve-element components are useful in the comprehension of their biology. Sieve elements are living cells in which many organelles (i.e. the nucleus, the ribosomes, the tonoplast, and the Golgi system) are missing, while the plasma membrane remains intact and delimits a narrow parietal cytoplasm, containing smooth endoplasmic reticulum stacks, mitochondria, small plastids and cytoskeleton components. Sieve elements also contain a number of structural proteins and specific sugar membrane transporters and enzymes whose function has to be clarified in relation to phytoplasma infection. In phytoplasma-infected Arabidopsis, sieve-plate plugging by the filamentous sieve element occlusion-related (SEOR) proteins as well as callose accumulation around the sieve pores, under the control of Callose synthase 7 (AtCALS7), have been interpreted as mechanical responses to limit pathogen spread. In addition, synaptotagmins (SYTs) have been described as proteins responsible of the regulation of the host secretion- and endocytic activities in response to different stresses but, even more, in the maintenance of plasma membrane integrity as well as in the movement of pathogens, such as viruses. We report that the above cited proteins, a part their specific local function, are involved, at a different level, in the defense signaling to establish systemic responses to phytoplasma infection, by interfering with defense-related phytohormonal pathways (AtSEOR2 protein), by regulating sugar movement at both symplasmic and apoplasmic level (AtCALS7), and by influencing protein regulation and lipid trafficking at the infection site (SYTA-1 protein).

Management of bacterial wilt disease of tomato and potato: genetic variability of Ralstonia solanacearum strains isolated in Emilia Romagna Region

\section{N. Biondo ${ }^{1}$, E. Biondi ${ }^{1}$, A. Alessandrini ${ }^{2}$, R. Gozzi ${ }^{2}$, G.L. Mazzoli $^{2}$, P. Minardi ${ }^{1}$}

${ }^{1}$ Department of Agricultural and Food Sciences (DISTAL), Alma Mater Studiorum - University of Bologna, Viale G. Fanin 42, 40127 Bologna, Italy; ${ }^{2}$ Emilia-Romagna Regional Plant Protection Service, Via Andrea da Formigine 3, 40128 Bologna, Italy. E-mail: nina.biondo2@unibo.it

Ralstonia solanacearum (Rs), the causal agent of tomato southern bacterial wilt and of potato brown rot, affects more than 250 plant species and it is included in the EPPO list of quarantine pathogens (QP). On tomato, the disease is characterized by a general wilting of the plant due to the colonization of its vascular system. Rs is a species complex with a high genetic variability and, based on the host plants, is currently divided into 5 races. In Emilia-Romagna Region (Northern Italy), during the last 15 years, Rs presence has been detected in potatoes, tomatoes and in superficial waters in nearby cultivated areas. Twenty-seven Rs strains (belonging to races 1 and 3) were characterised by Rep-PCR (BOX, ERIC, REP). The binary matrices from PCR profiles were used for UPGMA analysis in single or concatenated way. PD 2762 Rs and DISTAL 9081 Xanthomonas axonopodis pv. vitians strains were used as race 3 reference and as outgroup, respectively. From the concatenated profiles, the 27 Rs strains were divided in the two macro-groups of races 3 and 1 with a $15 \%$ similarity. The 6 strains race 3 were subdivided in 2 groups with a $50 \%$ similarity and 5 of them were more similar to each other than the PD 2762 strain. The 21 strains race 1 were subdivided into 4 groups with more than $60 \%$ similarity. The high degree of genetic variability particularly among the strains of race 1 (isolated in Parma and Ferrara provinces) suggests the presence of different haplotypes probably due to the movement of non-symptomatic infected material.

Botrytis cinerea cleaves a grapevine chitinase decreasing its enzymatic activity and impairing the detrimental effect on fungal growth 
A. Bolzonello ${ }^{1}$, S. Tundo ${ }^{1}$, R. Marcato ${ }^{1}$, C. Castiglioni ${ }^{1}$, S. Odorizzi ${ }^{1}$, S. Vincenzi $^{2}$, L. Sella ${ }^{1}$, F. Favaron ${ }^{1}$

${ }^{1}$ University of Padova, Department of Land, Environment, Agriculture and Forestry, Legnaro, Italy; ${ }^{2}$ University of Padova, Department of Agronomy, Food, Natural Resources, Animals and Environment, Legnaro, Italy.E-mail: angela.bolzonello@studenti.unipd.it

Chitin represents the main fibrillary component of the fungal cell wall. During plant infection, chitin apposition is counteracted by host chitinases. A chitinase class IV is constitutively contained in grapevine berries and it is expressed in leaves following Botrytis cinerea infection. Early, during fungal growth, the fungus proteolytically removes the chitin-binding domain (CBD). The chitinase without the CBD shows a reduction of activity by about $50 \%$ and louses the detrimental effects on conidia germination and fungal growth. Protease inhibition assays provided evidence that metalloprotease activity is involved in the chitinase cleavage. To ascertain whether the native and cleaved chitinase can differently affect the expression of genes involved in $B$. cinerea cell wall modeling, we analyzed by qPCR the expression of five fungal chitin synthase $(C h s)$ and four chitin deacetylase $(\mathrm{Cda})$ genes. Only one $C h s$ gene decreased its expression in presence of the native chitinase. In conclusion, the removal of the CBD by $B$. cinerea proteases appears as a mechanism preserving fungal growth from plant chitinase activity. Further experiments will better clarify the type of $B$. cinerea protease activity capable to disarm the plant chitinases.

Preliminary observations on a sustainable solution to reduce the impact of Xylella fastidiosa subsp. pauca on olive in the Salento Peninsula

\section{G.L. Bruno ${ }^{1}$, L. Botrugno ${ }^{2}$, C. Cariddi $^{1}$}

${ }^{1}$ Department of Soil, Plant and Food Sciences (Di.S.S.P.A.) Plant Pathology Unit, University of Bari Aldo Moro, Via G. Amendola 165/A, 70126 Bari, Italy; ${ }^{2}$ Salento's Ancient Soapery (Antica Saponeria del Salento), via Turati 17, 73030 Castiglione d'Otranto, Lecce (Italy).E-mail: giovanniluigi.bruno@uniba.it

The xylem-limited bacterium Xylella fastidiosa subsp. pauca is the etiological agent of "Olive Quick Decline Syndrome" (OQDS) in the Salento Peninsula on Olea europaea.

NuovOlivo ${ }^{\circledR}$, a natural bioactive detergent made from plants oils and extracts of multi botanical species (patent $n .102,017,000,109,094)$ was tested in the control of OQDS. The applied protocol associates spray treatments and pruning. Naturally infected 70 to 75 -year-old olive trees of cvs Cellina di Nardò and Ogliarola salentina (三 Ogliarola di Lecce) located in the province of Lecce were used.
McKinney's disease index (MKDI) was calculated using a 0 to 5 rating scale of disease severity. At the beginning of experiments all plants showed a MKDI of $85-95 \%$. Treated olive trees (27 of Cellina di Nardò and 35 of Ogliarola salentina) were pruned in winter and sprayed twice per year in March and October. As untreated control plants were selected 14 and 18 trees of 'Cellina di Nardò' and 'Ogliarola salentina' respectively. After three-years, untreated plants developed leaf scorch and desiccation extending to the whole canopy, MKDI reached $98.85 \%$. On treated plants, MKDI was $2.5 \%$ and plants produced new vegetation, flowers, and drupes. After further two years, treated plants were completely recovered. The leaves of treated plants showed a low total phenolic content and no cell membrane damage associated to lipid peroxidation. In the treated trees of both olive cultivars, qRT-PCR resulted in a $99.2 \%$ reduction of $X$. fastidiosa DNA level. At present, this work represents a basis for further data collection.

Gliotoxin effect on Alternaria sp.: a competitive advantage through the bisdethiobis(methylthio)gliotoxin production

\section{Bulgari ${ }^{1}$, G. Ribaudo ${ }^{2}$, A. Gianoncelli ${ }^{2}$, E. Gobbi ${ }^{1}$}

${ }^{1}$ Piattaforma di Microbiologia Agroalimentare ed Ambientale (Pi. Mi.A.A.), Dipartimento di Medicina molecolare e traslazionale, Università di Brescia, viale Europa, 11, 25123 Brescia; ${ }^{2}$ Piattaforma di Proteomica, Dipartimento di Medicina Molecolare e Traslazionale, Università di Brescia, viale Europa 11, 25123 Brescia. E-mail: emanuela.gobbi@unibs.it

Gliotoxin (GT) is a very ambivalent fungal secondary metabolite predominantly produced by a human pathogen Aspergillusfumigatus and by a plant-beneficial fungus Trichodermavirens. GT showed an antibiotic activity against plant pathogens such as Phytophthora capsici, Pythium ultimum and Cercospora nicotianae. The high tolerance to gliotoxin (up to $30 \mu \mathrm{g} / \mathrm{ml}$ ), shown by Trichoderma spp. in contrast to other fungi either lacking the gli cluster or without a gliT, is due to the activation of a gliA- and gtmA-mediated self-protection system leading to the synthesis of the less toxic metabolite bisdethiobis(methylthio)gliotoxin (BmGT). Few studies were carried out on the role of GT in Alternaria sp. control.

In order to study the antimicrobial activity of GT against Alternaria sp., Alternaria arborescens and Alternaria alternata were grown at different exogenous GT concentration. Both Alternaria spp. were only slightly affected by any GT concentrations up to $30 \mu \mathrm{g} / \mathrm{ml}$. This high tolerance is comparable to that showed by Trichoderma spp. The production of BmGT in Alternaria spp. was analyzed further after adding exogenous GT to their culture media. BmGT were detected in both culture substrate revealing the ability of these strains the produce the less toxic metabolites. In A. fumigatus, GT 
is thiomethylated by the methyltransferase GtmA. Bioinformatics analyses highlighted the presence of a putative $\mathrm{gtm} A$ orthologue in A. alternata and A. arborescens. The ability of Altenaria sp. to produce BmGT could confer them a competitive advantage including against the Trichoderma sp. GT-producers, making them ineffective in the direct control, associated to GT production.

\section{Can Trichoderma harzianum be used to control the aphid transmission of cucumber mosaic virus?}

\section{Caccavo ${ }^{1}$, A. Vitti ${ }^{1,2}$, P. Forlano ${ }^{1}$, V. Trotta ${ }^{1}$, M. Nuz- zaci $^{1}$, D. Battaglia ${ }^{1}$}

${ }^{1}$ School of Agricultural, Forestry, Food and Environmental Sciences, University of Basilicata, Viale dell'Ateneo Lucano 10, 85100 Potenza, Italy; ${ }^{2}$ Department of Pharmacy, University of Salerno, Via Giovanni Paolo II 132, 84084 Fisciano, Salerno,Italy.E-mail: vittoria.caccavo@unibas.it

Fungi Trichoderma spp. are widely used as biocontrol agents and plant growth promoters. It has been showed that tomato plants treated with Trichoderma harzianum (T22) activate their systemic defence responses by modulating the symptoms of cucumber mosaic virus (CMV). Also, feeding behaviour of aphids is altered when they feed on a CMV infected plant. The virus enhances the plant attractivity but reduces its quality as host, promoting the subsequent dispersion of aphids towards healthy plants and, consequently, its diffusion. However, there is no information on the influence of T. harzianum on the aphid attractiveness towards virus-infected plants, nor on the virus transmission through the behavioural changes of the vectors.

In the present study, we investigated the effects of T22 in tomato plants (Solanum lycopersicum var. San Marzano nano) infected with CMV on the feeding behaviour of the green peach aphid, Myzus persicae, the most efficient CMV vector. For this purpose, aphid behaviour was observed in a choice test including tomato plants treated with T22 and then infected by CMV, strain Fny. Although preliminary, the results seem to indicate that $\mathrm{T} 22$, by reducing CMV infection in tomato plants, is able to modify the feeding behaviour of M. persicae because of the host quality enhancement in terms of changes in some produced volatile components. If confirmed, this research represents an important advancement in the knowledge of the biological control induced by T22 against CMV in tomato plants, not only as systemic resistance elicitor, but also by the control of aphid transmission.

The role of CRZ1 transcription factor in Fusarium verticillioides - Zea mays interaction

\section{A. Cacciotti $^{1}$, M. Beccaccioli ${ }^{1}$, V. Scala ${ }^{2}$, M. Reverberi ${ }^{1}$}

${ }^{1}$ Laboratory of Plant Pathology, Dept. of Environmental Biology, Sapienza Università di Roma, P le Aldo Moro 5, 00185 Roma, Italy; ${ }^{2}$ CREA-DC, via C.G. Bertero 22, 00136 Roma, Italy. E-mail: andrea. cacciotti@uniromal.it

Fusarium verticillioides $(\mathrm{Fv})$ is the main maize (Zea mays) pathogen, able to produce fumonisins (FB1 and FB2), dangerous mycotoxins for human health. Our previous studies relate the micotoxin production with the lipid metabolism and suggest the presence of a common transcription factor that possibly allowed their co-regulation: i.e. CalcineurinResponsive Zinc Finger 1 - CRZ1. To understand the connection of so different metabolic pathways in $F$. verticillioides, a set of mutant strains $(F v c r z 1 \Delta ; F v c r z 1 \Delta+c r z 1)$ were generated and tested under artificial infection of maize seedlings. A previous HPLC-MS/MS analysis proves that the absence of $c r z 1$ alters the quantity of fatty acid (FA), oxylipins and fumonisins (FB) in the infected samples. Following this evidence, we wanted to see if these metabolic changes matched even under a transcriptomic level. Transcript profiling was carried out by RNA sequencing of the kernels infected with the wild type and the Fvcrzl inactivation mutant, showing that the absence of the transcription factor led to a change in the expression of the fungal fatty acid related genes and fumonisins genes, suggest a key role in the regulation of this complex and interconnected pathways, especially during the host-pathogen interaction. It is possible to argue that CRZ1, being present upstream of the lipid pathway, controls the FA synthesis, generates the proper conditions for producing oxylipins, and indirectly modulates FB synthesis acting like the main switch of all response mediated by fatty acids (e.g. mycotoxins synthesis) during Zea mays infection.

\section{Biological control approach of Ailanthus altissima in Lombardy}

E. Calastri, G. Gardini, V. Tava, A. Kunova, C. Pizzatti, P. Cortesi, M. Pasquali, M. Saracchi

Department of Food, Environmental and Nutritional Sciences, University of Milan, Italy.E-mail: marco.saracchi@unimi.it

Ailanthus altissima Mill. Swingle, a deciduous tree of Chinese origin, has become invasive in many nations of North America and Europe, spreading worldwide both in urban and natural ecosystems. Neither mechanical nor chemical techniques have demonstrated to be fully effective in its management, therefore, biological control is considered to be a promising approach. With the aim of setting a potential biological control strategy of A. altissima, several fungal strains associated with wilting or decaying 
ailanthus trees grown in different areas of Lombardy were isolated from their woody tissues. Colony characteristics were recorded and presence of reproductive structures was described by optical microscopy observations. Ten morphotypes were finally isolated and purified. A preliminary identification at the genus level was conducted on 34 representative strains by sequencing ITS region confirming morphological observations. Two fungal strains belonging to the genera Fusarium and Verticillium were selected and pathogenicity tests were carried out on A. altissima plants grown in pots from seeds and on more than one-hundred adult trees distributed in five different woody areas of the territory crossed by the Brembo and Adda rivers. Fusarium sp. and Verticillium sp. induced decay symptoms to $35 \%$ and $90 \%$ of treated plants, respectively. Symptoms on seedlings appeared few weeks after inoculation while the decline on adult plants was evident after the new budding in the spring following inoculation. A detailed genomic identification and taxonomic description of the two strains is ongoing.

\section{Machine learning for predicting mycotoxin occurrence in maize}

\section{Camardo Leggieri ${ }^{1}$, M. Mazzoni ${ }^{2}$, P. Battilani ${ }^{1}$}

${ }^{1}$ Dipartimento di Scienze delle Produzioni Vegetali Sostenibili, Area Protezione Sostenibile delle Piante e degli Alimenti Università Cattolica del Sacro Cuore, Via Emilia Parmense 84, 29122 Piacenza, Italy; ${ }^{2}$ Department of Livestock Population Genomics University of Hohenheim, Garbenstrasse 17, 70599 Stuttgart, Germany.E-mail: marco.camardoleggieri@unicatt.it

Meteorological conditions are the main driving variables for mycotoxin-producing fungi and the resulting contamination in maize grain, but the cropping system can considerably mitigate the weather impact. Several researchers have investigated cropping operations' role in mycotoxin contamination, but these findings were unuseful for their use in predictive modelling. Till now, two weather-based mechanistic models were developed, AFLA-maize and FER-maize, predicting aflatoxin $\mathrm{B}_{1}\left(\mathrm{AFB}_{1}\right)$ and fumonisins (FBs), respectively. In this study, a machine learning (ML) approach was considered, which included the output of these models and cropping system data as the input variables. In northern Italy, over the years 2005-2018, the occurrence of $\mathrm{AFB}_{1}$ and FBs was recorded in 30-50 georeferenced maize fields per year; the cropping system data were also collected for all the fields. Two deep neural networks (DNN) models were trained to predict, at harvest, maize fields contaminated above the legal limit with $\mathrm{AFB}_{1}$ and FBs. Both models reached an accuracy $>75 \%$ demonstrating the ML approach added value with respect to classical statistical approaches (i.e. simple or multiple linear regression models). The predictive performance improved around $+25 \%$, compared with that obtained for AFLA-maize and FER-maize, having been $\approx 52 \%$ for both models. These results, coupled with the extensive data set used and the good statistical scores, confirmed the robustness of the models developed.

\section{Genetic variability within an Italian Cercospora popula- tion isolated from soybean}

\section{E. Cappelletti ${ }^{1}$, M. Montanari ${ }^{2}$, R. Paris $^{2}$, A. Prodi ${ }^{1}$, M.T. Senatore $^{1}$, C. Baldin ${ }^{3}$, I. Alberti ${ }^{3}$}

${ }^{l}$ Dipartimento di Scienze e Tecnologie Agro-Alimentari, Alma Mater Studiorum Università di Bologna, Viale Fanin 40, Bologna, Italy; ${ }^{2}$ Consiglio per la ricerca in agricoltura e l'analisi dell'economia agraria, Via di Corticella 133, Bologna, Italy; ${ }^{3}$ Consiglio per la ricerca in agricoltura e l'analisi dell'economia agraria, Viale Amendola 82, Rovigo, Italy. E-mail:e.cappelletti@unibo.it

Soybean (Glycine $\max$ L.) is an annual legume that in Italy covers about 300.000 ha, located principally in the NorthEast region's valleys. Since 2013, some cultivations showed purplish-bronzing necrotic lesions in the upper part of the canopy at the beginning of the seed set. In open field, lesions progressed from upper to lower parts resulting in large defoliations and an unusual red-purple coloration was visible on petioles and pods. Seeds collected from these symptomatic plants, showed pale to dark-purple blotches of variable entity, ranging from a tiny spot to the full coverage of the seed coat. At microscope observation, red-purple petioles and pods showed the presence of conidiophores with conidia belonging to the genus Cercospora. These symptoms were usually associated both with Cercospora Leaf Blight (CLB) and Purple Seed Stain (PSS) of soybean caused by $C$. kikuchii. To confirm the morphological identification, twenty strains collected from 2014 to 2019 were subjected to sequence analysis. The partial sequencing of a single gene was not sufficient for the correct identification of Cercospora species. Therefore, a multilocus DNA sequence dataset, based on the partial sequence of ITS, Histone H3 (H3) and Calmodulin (CAL) genes, was constructed to evaluate phylogenetic diversity within the population. Aligned sequences of the collected isolates were combined with reference strains and then analyzed via maximum likelihood using IQ-TREE software. Statistical support for the branches was evaluated by conducting an ML-BS bootstrap analysis of 1000 replicates. The final combined tree showed a great species variability inside the Italian Cercospora population.

Life Green Grapes Project: limits and advantages of defense support products 
G. Carella ${ }^{1}$, F. Burroni ${ }^{2}$, M. Christoforou ${ }^{3}$, M. Pierucci ${ }^{4}$, D. Tsaltas ${ }^{3}$, R. Perria ${ }^{5}$, P. Storchi ${ }^{5}$, W.A. Petrucci ${ }^{5}$, L. Mugnai $^{1}$

\section{${ }^{1}$ Dipartimento di Scienze e Tecnologie Agrarie, Alimentali, Ambien- tali e Forestali, Sezione Patologia vegetale e Entomologia, Università degli Studi di Firenze, P.le Cascine 28 - 50144 Firenze, Italy; ${ }^{2}$ c/o Prima Forma, Via Palermo 6/A, 00184 Rome, Italy; ${ }^{3}$ Department of Agricultural Sciences, Biotechnology and Food Science, Cyprus University of Technology, PO BOX 50,329, Lemesos, Cyprus; ${ }^{4}$ Stu- dio Associato Agronominvigna, Via de' Buondelmonti 62, 50125 Firenze, Italy; ${ }^{5}$ CREA, Centro di Ricerca Viticoltura ed Enologia, Viale Santa Margherita 80 - 52100 Arezzo, Italy. E-mail: giuseppe. carella@unifi.it}

The Life Green Grapes project arises from the need to find alternative approaches all along the grapevine production chain - from the nursery to wine and table grape production-to reduce the amount of fungicides, in particular to control downy mildew. To this end, the use of DSS has been associated with defense support products included in the category of fertilizers that activate the defense responses of the plant. In wine-grape vineyards the results obtained after three years of trials confirmed the importance and effectiveness of these products in reducing the impact of the disease in years not particularly favorable to the development of the pathogen, as occurred in 2019, when the incidence of the disease did not show statistically significant differences between the IPM treatments (3\%) and the treatments with the use of defense support products (3.5\%). When using DSS, it was possible to decide appropriately both the type of product and the most suitable time for its application, based on the expected pathogen pressure, guaranteeing a 50\% reduction in fungicides. On the other hand, when favorable weather conditions for the pathogen persist for several days, the use of defense support products alone - as to be expected - was not sufficient to control the disease. A correct interpretation of the forecasting model associated with the correct use of plant support products under a high disease pressure alternated or coupled with synthetic fungicides, can guarantee the reduction of them in line with the European directives on the sustainable use of plant protection products.

This work was supported by Life Green Grapes Project LIFE16 ENV/IT/000566, 2017.

Investigations on the molecular diversity of phytobacteria detected by PCR assays intended specific for Xylophilus ampelinus

\section{G. Carminati ${ }^{1}$, G. Bianchi ${ }^{2}$, F. De Amicis ${ }^{2}$, R. Benedetti ${ }^{2}$, P. Ermacora $^{1}$, M. Martini ${ }^{1}$, G. Firrao ${ }^{1}$}

${ }^{1}$ Department of Agricultural, Food, Environmental and Animal Sciences, University of Udine, Udine, Italy; ${ }^{2}$ ERSA, Plant Protection Service, Pozzuolo del Friuli, Udine, Italy. E-mail: carminati. gaia@spes.uniud.it

Xylophilus is a genus of the Burkholderiales comprising only one species that circumscribes a taxon of xylematic bacteria causing bacterial blight of grapevine: $X$. ampelinus. An existing evidence from metagenomic analyses on Arabidopsis leaves and roots suggests, however, that the phytobiome may be the reservoir for an almost unexplored yet large diversity laying within the boundaries of this genus. Recently, we obtained discrepant results when testing grapevines with the two molecular diagnostic protocols for X. ampelinus recognized by EPPO. In fact, we evidenced samples collected from asymptomatic rooted grafted plants which resulted positive only with the PCR protocol targeting the ITS region. The incongruity between the results according to the two solid and well-validated protocols prompted us to start this ongoing study aimed at unraveling the identity of the cross-reacting microorganisms.

With the help of the QuantPrime web service, we developed primer pairs for all the recognized ORFs of the genome of $X$. ampelinus strain CECT $7646^{\mathrm{T}}$ (assembly GCA_003217575.1). By checking the matches of that primer set against a custom database comprising 5878 genomes of the Burkholderiales, we devised a subset of primers targeting only $X$. ampelinus and another one targeting X. ampelinus and its closest relatives. The sequence analysis of the amplicons obtained from the grapevine nucleic acids extracts that were positive only with the ITS protocol, shed light on the diversity of the grapevine microbiota related to the genus Xylophilus. Further genomic analyses are in progress to evaluate the extension of this variedness.

The Friuli Venezia Giulia Region is acknowledged for funding.

The presence of a recognized avirulence gene in Pseudomonas syringae is necessary but not sufficient to trigger a hypersensitive response in Arabidopsis thaliana

\section{E. Caullireau ${ }^{1,2}$, D. Danzi ${ }^{1}$, C.E. Morris ${ }^{2}$, E. Vandelle ${ }^{1}$ \\ ${ }^{1}$ Department of Biotechnology, University of Verona, Strada le Grazie 15, 37134 Verona, Italy; ${ }^{2}$ Plant Pathology Research Unit, INRAE UR407, 84140 Montfavet, France. E-mail: elodiegenevieve. vandelle@univr.it; emma.caullireau@univr.it}

Pseudomonas syringae causes diseases on a wide range of agronomically important crops. Because the prevailing opinion on this bacterium was that it displays a certain host specificity, strains of the $P$. syringae complex had been 
divided into more than 50 pathovars. Considerable research effort has been invested in understanding how $P$. syringae repertoire of virulence effectors, mainly involved in plant immunity suppression, determines the range of plants that a strain can infect. Recently, we showed that the incapacity of $P$. syringae pv. actinidiae to induce ETI in A. thaliana Col-0 is mostly due to its incapability to inject effectors rather than to the absence of a recognized effector.

In this light, here we report results from the comparison of the capacity of different $P$. syringae strains, belonging to different phylogroups and carrying the same plasmidborne avirulence gene, to induce an ETI in A. thaliana Col0 . We show that the response induced by Pto DC3000 is rather unique in consistently triggering high levels of ETI across a range of temperatures. The other strains induced ETI at different intensities and the response was influenced by temperature. Curiously, even strains that were quasiclones did not behave identically. This highlights the necessity to study bacterial virulence in a broader set of strains and supports the hypothesis that the presence/absence of effectors is likely not sufficient to predict the outcome of plant-bacteria interactions. Virulence seems to rely more on the capacity of the bacterium to inject its effectors, with temperature playing a decisive role.

\section{Contrasting approaches to disease control in plants from transgenic plants to endophytic fungi}

\section{D.B. Collinge ${ }^{1}$, E. Rojas ${ }^{1,2}$, M. Latz ${ }^{3}$, S. Sarrocco ${ }^{4}$, H.J.L. Jørgensen $^{1}$, B. Jensen ${ }^{1}$}

\begin{abstract}
${ }^{1}$ Department of Plant and Environmental Sciences and Copenhagen Plant Science Centre, University of Copenhagen, Thorvaldsensvej 40, 1871-Frederiksberg C, Denmark; ${ }^{2}$ Chr. Hansen A/S; ${ }^{3}$ Present address: KTH Royal Institute of Technology, SciLifeLab, 17165 Solna, Sweden; ${ }^{4}$ Department of Agriculture, Food and Environment, University of Pisa, Pisa, Italy.E-mail: dbc@plen.ku.dk
\end{abstract}

We are facing challenges including climate change, urbanization and population growth which require increased food production whilst reducing environmental impact. Plant pathogens alone are responsible for an estimated $20 \%$ losses in our major crops, corresponding roughly to the predicted global population increase for the next 3 decades. Cultural practices such as irrigation, crop rotation, fertilisers etc and spraying with chemical agents represent the major means for disease control. Disease resistance in the host plant is arguably the most effective and sustainable means of disease control, however, 'natural' resistance, obtained by screening within the crop plant species or its close relatives, is unavailable for many diseases. Effective disease resistance has been achieved through genetic engineering using a number of strategies. Historically, the first strategy used single genes encoding antimicrobial proteins such as chitinase. These early studies gave partial resistance but several recent studies have apparently yielded high levels of resistance, even under field conditions. Other approaches exploit our increasingly detailed knowledge of signal transduction and plant immunity. Currently the most promising approaches fall under the headline "New Genomic Technologies" (NGT) where host-induced gene silencing (HIGS) and gene editing of susceptibility genes by, e.g., CRISPR-Cas 9 are most promising, though, no resistant varieties have been released based on NGT.

Biological control is another and, in Europe at least, less controversial approach to disease control. Biological control in the strict sense represents the use of antagonistic microbes to combat the pathogen and as such represents a potentially sustainable approach. Over recent years, biological control has progressed to the stage where a number of products are on the market, and our knowledge of mode action improves continually. Four major modes of action are recognised: competition, antibiosis, hyperparasitism and induced resistance. A weakness of biological control lies in its vulnerability to environmental factors. The endobiome is thought to be a potential source of novel BCAs since once inside, they are likely to be less vulnerable to external environmental influence. Our studies with endophytes to control Fusarium Head Blight (caused by Fusarium graminearum) and Septoria leaf blotch (caused by Zymoseptoria tritici) have given several promising potential BCAs which were isolated using an ecological approach: where they are present in asymptomatic tissues where there was considerable inoculum pressure. RNAseq analysis using two of these, Penicillium olsonii and Acremonium alternatum isolates, respectively in three-way interactions with wheat spikes with $F$. graminearum and leaves Zymoseptoria tritici induces defence mechanisms (pattern-triggered immunity) indicating that induced resistance is an important mechanism in each case.

\section{Metabolomic changes in Xylella fastidiosa-infected olive trees treated with eco-friendly products}

\author{
E. Comite $^{1}$, A. Staropoli ${ }^{1,2}$, S.L. Woo ${ }^{2,3}$, C. Altomare ${ }^{4}$, F. \\ Vinale $^{2,5}$, G. Bleve ${ }^{6}$, A. Gallo ${ }^{6}$, M. Lorito ${ }^{1,2}$ \\ ${ }^{1}$ Department of Agricultural Sciences, University of Naples Fed- \\ erico II, 80055 Portici, Italy; ${ }^{2}$ Institute for Sustainable Plant Pro- \\ tection, National Research Council, 80055 Portici, Italy; ${ }^{3}$ Depart- \\ ment of Pharmacy, University of Naples Federico II, 80131 Naples, \\ Italy; ${ }^{4}$ Institute of Sciences of Food Production, National Research \\ Council, 70126 Bari, Italy; ${ }^{5}$ Department of Veterinary Medicine \\ and Animal Production, University of Naples Federico II, 80137 \\ Naples, Italy; ${ }^{6}$ Institute of Sciences of Food Production, National \\ Research Council, 73100 Lecce, Italy.E-mail: ernesto.comite@ \\ unina.it; claudio.altomare@ispa.cnr.it
}


The Olive Quick Decline Syndrome (OQDS-CoDiRo), caused by the bacterium Xylella fastidiosa, threatens not only olive production but also natural ecosystems, landscapes and tourism, with an economic and social impact for the Apulia Region. In this regard, it is indispensable to develop innovative programs and methods to control the disease and mitigate its impact.

Olive trees affected by $X$. fastidiosa in the Salento area, were treated to test the effect of two eco-friendly products directly in the field: viz. a colloidal formulation of active silver (SILVER) and a bioactive compound (NS; fungal extract) classified as Generaly Regarded As Safe (GRAS) substance. Leaf samples were collected at 3 times (November 2017, May 2018 and November 2018) and analyzed by LC-MS qTOF to evaluate the effects of the treatments on the metabolic profiles. Raw data obtained for each sampling time were subjected to metabolomic analysis and the olive metabolites were identified to determine the differentially accumulated compounds produced from the treatments (SILVER, NS) compared to a control group (CTRL). Apigenin, oleuropein, luteolin and the two glucoside isomeric forms ( $a$ and $b$ ) of luteolin were putatively identified for the last sampling time. Except for luteolin glucoside isomer b, all molecules were more abundant in samples treated with SILVER compared to CTRL; while in plants treated with NS, only apigenin was more abundant, compared to CTRL. The application of the tested eco-friendly compounds exerted a slow change on the metabolome of olive leaves, inducing over time accumulation of phenolic compounds with important antioxidant activity.

This work was financially supported by the Apulia Region Research Program "Sperimentazione Finalizzata alla Prevenzione e al Contenimento del Complesso del Disseccamento Rapido del Olivo (CoDiRO)". Project: Il Silver Bullet contro Xylella fastidiosa (SIX).

Plant beneficial microbial consortia (BCA - PGPR) and biopolymers influence sweet basil productivity, photosynthesis and metabolome

E. Comite ${ }^{1}$, C. El-Nakhel ${ }^{1}$, Y. Rouphael ${ }^{1}$, V. Ventorino ${ }^{1}$, O. Pepe $^{1}$, A. Borzacchiello ${ }^{5}$, F. Vinale ${ }^{2,3}$, D. Rigano ${ }^{4}$, M. Lorito $^{1}$, S.L. Woo ${ }^{3,4}$

${ }^{1}$ Department of Agricultural Sciences, University of Naples Federico II, 80055 Portici, Italy; ${ }^{2}$ Department of Veterinary Medicine and Animal Production, University of Naples Federico II, 80137 Naples, Italy; ${ }^{3}$ Institute for Sustainable Plant Protection, National Research Council, 80055 Portici, Italy; ${ }^{4}$ Department of Pharmacy, University of Naples Federico II, 80131 Naples, Italy; ${ }^{5}$ Institute for
Composite Polymers and Biomaterials, National Research Council, 80125 Naples, Italy. E-mail: ernesto.comite@unina.it

Increasing attention is being given to the development of innovative formulations to substitute the use of synthetic chemicals in agriculture. Alternatives can include products containing beneficial microorganisms and bioactive metabolites able to inhibit plant pathogens, induce systemic resistance and promote plant growth.

The efficacy of such bioformulations can be increased by the addition of polymers as adjuvants or carriers. The aim of this work is to evaluate the use of two beneficial microorganisms, BCA Trichoderma afroharzianum T22 and PGPR Azotobacter chroococcum 76A, and 6-pentyl-a-pyrone (6PP, a Trichoderma secondary metabolite), singly or in consortia, with or without a carboxymethyl cellulose based biopolymer (BP), in the cultivation of sweet basil (Ocimum basilicum L.). Parameters evaluated included productivity, photosynthetic activity/efficiency, disease and metabolome of plants grown in the greenhouse.

The applications of $\mathrm{BP}+6 \mathrm{PP}$ and $\mathrm{BP}+\mathrm{T} 22+76 \mathrm{~A}$ bioformulations to the rhizosphere increased the total fresh weight of basil by $26.3 \%$ and $23.6 \%$, respectively; and augmented the photosynthetic efficiency. No diseases were observed on the plants during the experiments. Untargeted LC-MS qTOF analysis demonstrated that the plant metabolome was significantly modified by the treatments. Profiles of the major phenolic compounds indicated that the treatment with $\mathrm{T} 22+76 \mathrm{~A}$ consortium increased rosmarinic acid content by $110 \%$. The use of applications containing microbes, their compounds and a biopolymer modulated the response of basil that improved yield and quality. Such innovative bioformulations provide the opportunity to develop farm management systems to minimize the environmental footprint of the agricultural production.

Induction of resistance and enhancing agronomic performance in grapevines under greenhouse and in open fields by applications of plasma activated water

N. Contaldo ${ }^{1}$,Y. Zambon ${ }^{1}$, R. Laurita ${ }^{2,3}$, M. Gherardi ${ }^{2,3}$, V. Colombo ${ }^{2,3}$, A. Bertaccini ${ }^{1}$

${ }^{1}$ Department of Agricultural and Food Sciences \& ${ }^{2}$ Department of Industrial Engineering, ${ }^{3}$ Industrial Research Centre for Advanced Mechanics and Materials, Alma Mater Studiorum, University of Bologna, Bologna, Italy. E-mail: nicoletta.contaldo2@unibo.it

The exposure of water to a cold atmospheric pressure plasma (CAP) enables the production of plasma activated water (PAW), having high content of reactive species, whose applications were tested on grapevine plants, both in greenhouse 
and in vineyard conditions. Two different CAPs were used for PAW production, evaluating their effectiveness as a possible mean to control plant diseases. Grapevines infected with yellows associated with the presence of phytoplasmas were treated evaluating qualitative and quantitative yield parameters, phytoplasma presence, and gene expression. The results show the capability of PAW to enhance plant defence mechanisms and, as demonstrated in the field trials, confirmed its ability to improve the health status of the treated plants. Quantitative (q)RT-PCR analyses allowed to determine the transcription level of genes involved in the plant defence response (phenylalanine ammonia-lyase, pal) and in the plant phytoalexin metabolism of PAW-treated materials. The number of symptomatic grapevine plants in vineyards was significantly reduced by the treatments. Transcriptional and post-transcriptional molecular analyses highlighted the PAW ability to enhance the expression of genes encoding the main enzymes involved in the phytoalexin biosynthetic pathway (flavonoids and stilbenes). The PAW ability to enhance some of the plant defence mechanisms also improving the health status of the treated plants was therefore experimentally demonstrated. After three years of trials the overall results demonstrated the possible use of PAW to reduce the disease severity, induce plant resistance both in open field and greenhouse, improving plant healthy status and grapevine yield production.

\section{RT-qPCR through an optoelectronic Lab-on-Chip: from plant virus to SARS-CoV-2 detection}

F. Costantini ${ }^{1}$, N. Lovecchio ${ }^{2}$, L. Iannascoli ${ }^{2,3}$, A. Manglli $^{1}$, F. Faggioli ${ }^{1}$, P.F. Roversi ${ }^{1}$, M. Biasin ${ }^{4}$, G. de Cesare ${ }^{2}$, A. Nascetti ${ }^{3}$, D. Caputo ${ }^{2}$

${ }^{I}$ CREA-DC Research Centre for Plant Protection and Certification, Rome, Italy; ${ }^{2}$ Department of Information, Electronic and Telecommunication Engineering, Sapienza University of Rome, Rome, Italy; ${ }^{3}$ School of Aerospace Engineering, Sapienza University of Rome, Rome, Italy; ${ }^{4}$ Department of Biomedical and Clinical Science L. Sacco, University of Milan, Milan, Italy. E-mail: francesca. costantini@crea.gov.it

In recent years, Lab-on-Chip (LoC) technology has revolutionized several diagnostic assays. The success of this technology relies on miniaturization of the standard analytical methods leading to portable systems that often showed higher throughput and improved sensitivity. In this work, we report on the development of a LoC systems for RT-qPCR, which would allow direct in-field amplification and early detection of pathogens. The device was first optimized in detecting watermelon mosaic virus (WMV) and subsequently applied for the detection of SARS-CoV-2.
The LoC system here presented shows the integration of different units such as heating system, temperature control and sample detection, based on thin film optoelectronic, together with a chip for sample handling, to achieve a portable system for performing RT-qPCR of RNA virus. The whole device is included in a metallic box, which permits portability of the system.

Total RNA of WMV and the relative negative control were extracted from infected and healthy zucchini leaves, respectively; while SARS-CoV-2 and the relative negative control were obtained from infected and healthy cells, respectively. RT-PCR was performed in the LoC system using $1 \mu \mathrm{L}$ of extracted total RNA in a total volume of $10 \mu \mathrm{L}$. The LoC showed an analytical sensitivity of $10^{-6}$ in analyzing tenfold dilutions of RNA solutions for both extracted viruses and a $100 \%$ of analytical specificity in testing different non target plant viruses. The LoC is under investigation also for the detection of plant pathogenic bacteria.

Essential oils at the nanosize: a nano-formula(tion) to achieve plant protection

D. Danzi ${ }^{1}$, S. Cremonesi ${ }^{1}$, S. Lampis ${ }^{1,2}$, M. Bonaconsa ${ }^{3}$, M. Bovi $^{3}$, L. Tosi ${ }^{4}$, F. Spinelli ${ }^{5}$, A. Polverari ${ }^{1}$, E. Vandelle ${ }^{1}$

${ }^{1}$ Department of Biotechnology, University of Verona, Strada Le Grazie 15, 37134 Verona, Italy; ${ }^{2}$ Bactory srl, Strada le Grazie 15, 37134 Verona, Italy; ${ }^{3}$ Nanomnia srl, Viale Archimede 25, 37059 Zevio, Italy, ${ }^{4}$ AGREA srl, Via Giuseppe Garibaldi 5, 37057 San Giovanni Lupatoto, Italy; ${ }^{5}$ Department of Agricultural and Food Sciences, Alma Mater Studiorum-University of Bologna, 40127 Bologna, Italy.E-mail: elodiegenevieve.vandelle@univr.it

Crop pathogen management is a priority for sustainable agriculture development. Indeed, the large use of pesticides is threatening both human and environmental health, while simultaneously, pushing antimicrobial resistance occurrence. Moreover, synthetic compounds suffer from low biodegradability leading to their accumulation into soil and freshwater. This led to many restrictions regarding the application of available products, including copper, that make difficult the management of plant diseases. Among the different practices included in integrated pest management, the biological control, usually referred to the use of organisms to influence the activities of a plant pathogen, has been extended to the use of natural biomolecules in the control of plant diseases. However, natural molecule application suffers from their poor persistence in the field or penetration into plant tissues. Our objective is thus the development and application of innovative nanocompounds based on nanoemulsions to convey essential oils (EOs), as an alternative to the use of traditional 
treatments. Indeed, most EOs display a broad-spectrum antimicrobial activity, thanks to their diverse combinations of terpenoids, phenols and volatile components. Despite their application in food industry and the well-recognized antimicrobial activity against plant pathogens, little is known about their efficacy in a poorly controlled environment such as open fields. We are thus currently investigating the possibility of using EOs as natural crop protection agents, focusing on the improvement of EO solubility in water and stability in a natural environment, through their specific nanoformulation, to enhance their bioavailability and efficacy in a real agricultural context.

In silico and in vitro screening of the potential for biocontrol of bacteria of the Pseudomonas corrugata subgroup

\section{G. Dimaria ${ }^{1}$, S. Musumeci ${ }^{1}$,F. Modica ${ }^{1}$, G. Venticinque ${ }^{1}$, M.C. Bazzano $^{2}$, M. Russo ${ }^{2}$, V. Catara ${ }^{1}$}

\footnotetext{
${ }^{1}$ Università degli Studi di Catania, Dipartimento di Agricoltura, Alimentazione e Ambiente, Via Santa Sofia 100, 95123 Catania, Italy; ${ }^{2}$ Agrobiotech Soc. Coop., Stradale V. Lancia 57, 95131 Catania, Italy. E-mail:vcatara@unict.it
}

The Pseudomonas fluorescens complex includes plants associated bacteria characterized by metabolic and physiological properties with potential biotechnological applications. Bacteria in the $P$. corrugata subgroup ( $P$. corrugata, $P$. mediterranea, $P$. brassicacearum, $P$. thivervalensis, $P$. kilonensis), show plant growth promotion traits and biocontrol activities against several phytopathogenic agents. This activity is largely attributable to the production of secondary metabolites with antimicrobial activity. This study covered the in silico genome mining of secondary metabolites gene clusters in the $P$. corrugata subgroup using 15 complete genomes available in genomic databases. The analysis was performed with the antiSMASH pipeline which integrates tools such as NCBI BLAST + , HMMer 3, Muscle 3, FastTree, PySVG, JQuery SVG, ClusterFinder and ClusterBLAST that allow the identification of clusters of genes of secondary metabolites and their comparison with those already identified and characterized experimentally. The results obtained show that some pathways are highly conserved among the various species (e.g. fragin, aryl polyenes, fengycin, etc.), others averagely conserved (e.g. ornibactin, thanamycin, nunapeptin) and others are not very frequent (e. g. bicornutin, rhizomide), with percentages of similarity extremely variable, with respect to the known clusters. Many 'orphan' clusters waiting to be studied have been identified and highlight the potentiality for future biotechnology developments. Laboratory tests performed to study the biological activity of strains of $P$. corrugata and $P$. mediterranea, have allowed to evaluate their antifungal activity, as result of metabolites diffusible in agar and volatile substances.

\section{Plenodomus tracheiphilus colonization in Citrus auran- tium and effect on the microbiome}

\section{G. Dimaria ${ }^{1}$, A. Mosca $^{2}$, A. Anzalone ${ }^{1}$, G. Paradiso ${ }^{1}$, A. Pulvirenti $^{3}$, M. Russo ${ }^{4}$, V. Catara ${ }^{1}$}

${ }^{l}$ Department of Agriculture, Food and Environment, University of Catania, Catania, Italy; ${ }^{2}$ Department of Physics and Astronomy University of Catania, Catania, Italy; ${ }^{3}$ Department of Clinical and Experimental Medicine, University of Catania, Catania, Italy; ${ }^{4}$ Agrobiotech Soc Coop Srl, Catania, Italy. E-mail: vcatara@unict.it

'Mal secco' is a vascular disease of citrus trees caused by the mitosporic fungus Plenodomus tracheiphilus (Pt). Pathogen penetration occurs due to wounds in the above- and below-ground part of the tree. Sour orange (Citrus aurantium), the most popular rootstock for lemon, has been used in many studies on this pathosystem. In this study, sour orange seedlings $P t$ wound-mediated inoculations were accomplished in both roots and leaves. Six months postinoculation the fungal colonization and the microbial communities of the rhizosphere, endosphere and xylem were evaluated. As expected, inoculated leaves started to show symptoms ten days post-inoculation and then later many of them fell. Only a few root-inoculated plants showed yellowing of the midveins after four months. The presence of $P t$ was detected by real-time PCR in the rhizosphere, endorhizosphere and xylem of the root-inoculated seedlings, including those that were asymptomatic. The fungus was detected only in the xylem of leaf-inoculated seedlings. The fungal and bacterial communities of the three plant compartments, assessed by amplicon-based metagenomics, partly reflect the microbial composition identified in other species belonging to the genus Citrus. However, the three plant compartments were clearly distinguishable. Amongst them the highest microbial richness and diversity were observed in the rhizosphere. The most abundant bacterial and fungal phyla were Proteobacteria and Firmicutes, and Ascomycota respectively. Bacterial communities OTUs were either enriched or depleted in samples of inoculated plants, although to a different extent in the various compartments. Pt was enriched in inoculated plants and the results correlated with those of real-time PCR. 


\section{Characterizaztion of an effector gene in Fusarium} oxysporum

\author{
A. $\operatorname{Doddi}^{1}$, M. Rep $^{2}$, M. Reverberi ${ }^{1}$, L. Faino ${ }^{1}$ \\ ${ }^{1}$ Department of Environmental Biology, University of Rome "La \\ Sapienza”, Piazzale Aldo Moro 8, 00185 Roma, Italy; ${ }^{2}$ Molecular \\ Plant Pathology, Swammerdam Institute for Life Sciences, Uni- \\ versity of Amsterdam, The Netherlands.E-mail: doddi.1710387@ \\ studenti.uniromal.it; luigi.faino@uniromal
}

Fusarium oxysporum is a soilborne ascomycetous fungus. It is apparently asexual and includes non-pathogenic and pathogenic species. Pathogenic strains of Fusarium oxysporum cause wilt-disease, infecting xylems vessel to subtract nutrients from plant cells, while non-pathogenic strains show endophytic behavior, sometimes even inhibiting the growth of Fusarium pathogenic species. Previous studies shed light on how each species of Fusarium oxysporum is able to infect only one or a few related species, for this reason they are subsequently divided in what is called "formae speciales" based on their host-range specificity.The aim of this project is to identify new effectors protein which are essential for virulence in Cucurbitaceae. Our candidate has been identified in Verticillium dahliae and after a preliminar bioinformatic analysis it is clear its presence among different species of fungi including different formae speciales of Fusarium oxysporum, to understand its role in the infection a deletion mutant of the potential effector has been made in Fusarium oxysporum f. sp. radicis cucumerinum who is able to infect melon, cucumber and watermelon plants. In this way we can infect a variety of Cucurbitaceae to see if this gene is really involved during infection. It has also been observed that there is a mimp (transposable element) present in the promotor of D gene in Forc016 but not in other strains of other formae speciales. In further studies we want to investigate the influence of the mimp on the effector expression.

\section{Morphological, physiological and molecular characteriza- tion of Monostichella coryli, the causal agent of hazelnut anthracnose}

\section{M.I. Drais, A. Faluschi, S. Turco, L. Varvaro, V. Cristo- fori, A. Mazzaglia}

Dipartimento di Scienze Agrarie e Forestali, Università degli Studi della Tuscia, Via S. Camillo de Lellis snc, 01100 Viterbo, Italy. E-mail:drais@unitus.it

During 2019 and 2020, repeated field surveys were carried out in hazelnut orchards located in the Viterbo province, in Lazio region (Italy). Dry rot of buds, desiccation of twigs, and necrosis of leaf lamina were diffusely observed on hazelnut trees, particularly on cv. Nocchione. As result of fungal isolation from symptomatic tissues, one morphotype was persistently obtained from the margin of lesions of collected samples. The analysis of morphological features of the fungus grown on malt extract agar (MEA), potato dextrose agar (PDA), corn meal agar (CMA) and oatmeal agar (OA), provided for the attribution to the species Monostichella coryli. This initial identification was molecularly confirmed by sequencing the partial large subunit rDNA, the internal transcribed spacer region and partial beta-tubulin region and blasting the sequences in the NCBI database. Pathogenicity tests proved that the fungus is able to multiply and systematically invade artificially inoculated hazelnut tissues and incite disease symptoms on both Nocchione and Tonda Gentile Romana cultivars. In vitro assays demonstrated that environmental conditions, such as temperature and relative humidity influence growth rate, sporulation and conidial germination and allowed the definition of mathematical functions describing optimal, suboptimal and critical condition for these biological facets. Findings in this study provide useful information for epidemiology studies on hazelnut anthracnose and will help to choose the appropriate control strategies for the management of the disease.

This work was supported by the European Commission under the Grant Agreement number 774571 (project PANTHEON - 'Precision farming of hazelnut orchards').

\section{Garden fungi that can protect horticultural plants from root rot caused by Armillaria mellea}

\author{
J. Drakulic ${ }^{1}$, H. Rees ${ }^{2}$, N. Bashir ${ }^{1}$, M. Cromey ${ }^{1}$, G. Fos- \\ ter $^{2}$, A. Bailey ${ }^{2}$ L. Beal ${ }^{1}$ \\ ${ }^{1}$ Royal Horticultural Society, Wisley, GU23 6QB, UK; ${ }^{2}$ University \\ of Bristol, School of Biological Sciences, BS8 1TQ, UK. E-mail: \\ jassydrakulic@rhs.org.uk
}

Armillaria root rot is a destructive root disease caused by soilborne fungi and is extremely difficult to eradicate. It causes aboveground dieback and death in an extensive range of horticulturally important plants. Armillaria mellea is an aggressive pathogen which, according to 5 years of survey data obtained over a period of more than 10 years, causes most disease cases in gardens. A. gallica is preferentially saprotrophic and occurred in $15 \%$ of samples. We have hypothesised that both species compete for the same niche in gardens and that if present first, A. gallica may be able to exclude A. mellea and prevent outbreaks of the serious disease it causes. An outdoor pilot and an indoor study using potted privet both showed that fewer plant deaths occurred when A. gallica had colonised a pot 6 months before A. mellea was added compared to $A$. mellea attack on its own. Additionally, endophytic Trichoderma spp. isolates have been collected from plants that had escaped infection in RHS Garden Wisley and inoculated into 
experimental strawberry and privet plants to assess their ability to protect plants from A. mellea attack. Two isolates of $T$. atrobrunneum were protective in both hosts, enabling plant survival despite high infection pressure over a 9 month period. These isolates are putative generalists that could be used to prepare protected planting stock to reduce or eliminate the fallow period required before replanting into infected sites.

\section{A tomato-Trichoderma-Phytophthora model system for studying plant-microrganisms interactions}

\section{S. El boumlasy ${ }^{1,2}$, F. La Spada ${ }^{1}$, E.I. Rovetto ${ }^{1}$, A. Pane ${ }^{1}$, M. Riolo $^{1,3,4}$, F. Aloi ${ }^{1}$, R. Parlascino ${ }^{1}$, M. Franco ${ }^{1}$, S.O. Cacciola ${ }^{1}$}

${ }^{1}$ Department of Agriculture, Food and Environment (Di3A), University of Catania, Via Santa Sofia 100, 95123 Catania, Italy; ${ }^{2}$ Laboratory of Materials-Catalysis, Chemistry Department, Faculty of sciences, University Abdelmalek Essaadi, B.P. 2117 Tetouan, Morocco; ${ }^{3}$ Council for Agricultural Research and Agricultural Economy Analysis, Research Centre for Olive, Citrus and Tree Fruit-Rende CS (CREA-OFA), 87036 Rende, Italy; ${ }^{4}$ Department of Agricultural Science, Mediterranean University of Reggio Calabria, 89122 Reggio Calabria, Italy. E-mail:olga.cacciola@unict.it

This study aimed at (i) evaluating the effectiveness of two selected strains of the species, Trichoderma asperellum and Trichoderma atroviride, in both the promotion of growth of tomato (Lycopersicon esculentum cv. Cuor di bue) and the biological control of root and crown rots caused by Phytophthora nicotianae, and (ii) defining the modulation in the expression levels of the genetic pathways activated in any player of the experimental model system tomato-Trichoderma-Phytophthora. The beneficial effects in both the promotion of the growth and the biological control were tested in planta and in vitro. In this respect, T. atroviride demonstrated to be more effective than T. asperellum. Additionally, the expression profile of several plant defense-related genes, pathogen effectors and mycoparasitism-related genes in tomato, P. nicotianae and Trichoderma spp., respectively was evaluated during a simultaneous three-component interaction. Results support the hypothesis that Trichoderma spp. elicit the expression of plant-defense related genes. A marked overexpression of two necrosis-inducing effectors was observed in P. nicotianae-infected and Trichoderma-colonized tomato plants. Finally a mycoparasitism-related gene was significantly overexpressed in Trichoderma colonizing $P$. nicotianae-infected tomato plants. This study contributed to understand the genetic pathways related with the ability of Trichoderma spp. to counteract the challenge of $P$. nicotianae infections on tomato; additionally, it revealed the beneficial effects in tomato growth promotion of a new $T$. atroviride strain and its good antagonistic effectiveness in the biological control of roots and crown rots by P. nicotianae, confirming the good effectiveness of Trichoderma spp. in integrated pest management strategies of Phytophthora diseases.
First report of Fusarium nodosum (L. Lombard \& Crous) on durum wheat (Triticum turgidum subsp. durum) in Italy

\section{Felici, S. Francesconi, G.M. Balestra}

Department of Agriculture and Forest Sciences (DAFNE), University of Tuscia, Via S. Camillo de Lellis snc, 01100 Viterbo, Italy.E-mail:felici@unitus.it; francesconi.s@unitus.it; balestra@ unitus.it

Fusarium nodosum (L. Lombard \& Crous), previously identified as $F$. sporotrichioides, was recently recognized as a new species. Different $F$. nodosum strains were isolated around the world (Portugal, France, Turkey and Iran) from different hosts (Arachis hypogaea, Arundo donax, Solanum lycopersicum, Triticum aestivum). In May and June 2021 two sampling campaigns were carried out in durum and soft wheat fields located in Viterbo (central Italy). Different fungal organisms were isolated from plants showing Fusarium head blight (FHB) symptoms and from asymptomatic plants. Considering morphological traits, colonies resembling Fusarium spp. were selected for molecular identification. The translation elongation factor 1 alpha (TEF-1 $\alpha$ ) DNA sequence was amplified and sequenced by Sanger sequencing. Two isolates, one from soft wheat cultivar Cadenza and one from durum wheat cultivar Svevo, were identified as F. nodosum using the NCBI BLAST Search Tool and showed a percentage of identity higher than $99 \%$ with several $F$. nodosum TEF-1 $\alpha$ sequences deposited in the database and fungal collection. Moreover, a phylogenetic tree of the $T E F-1 \alpha$ sequence of the isolates and strains in culture collection was constructed based on the neighbor-joining method in MEGAX software. To the best of our knowledge, this is the first report of isolation of $F$. nodosum from durum wheat in Italy. Very few is known about $F$. nodosum pathogenicity, mycotoxin production and its role in FHB species complex. For these strains, pathogenicity test is needed and Koch's postulates must be completed. Further research is required to verify if it could be a threat to cereal crops.

Exploiting the synergist properties of chitosan and gallic acid functionalized with cellulose nanocrystals and starch to manage main Italian fungal and bacterial plant diseases

\section{S. Francesconi, V. di Lorenzo, D. Schiavi, G.M. Balestra}

Dipartimento di Scienze Agrarie e Forestali (DAFNE), Università degli Studi della Tuscia, Via San Camillo de Lellis snc, 01100 Viterbo,Italia.E-mail:francesconi.s@unitus.it; balestra@unitus.it 
Fusarium graminearum $(\mathrm{Fg})$ and $F$. culmorum $(\mathrm{Fc})$, main causal agents of Fusarium head blight and crown rot, and Pseudomonas syringae pv. actinidiae (Psa), P. syringae pv. tomato (Pst) and P. savastanoi pv. savastanoi (Psav), causal agents of bacterial canker of kiwifruit, tomato bacterial speck, and olive knot, cause enormous yield losses. Such plant diseases are managed by the preventive application of triazoles and strobilurins based fungicides ( $\mathrm{Fg}$ and $\mathrm{Fc}$ ) or application of cupric salts (Psa, Pst, Psav). However, such compounds accumulate in soil and water, posing an effective risk for the environment. For such reasons, they must be replaced by innovative and eco-sustainable formulations, such as natural derived compounds with antimicrobial properties, and employment of nanotechnologies to optimize their functions by functionalize them with plantderived nano-carriers (cellulose nanocrystals and starch). The aim of the research was to identify natural compounds with antimicrobial properties against Fg, Fc, Psa, Pst and Psav. In vitro experiments demonstrated that the synergistic effect of chitosan and gallic acid at $0.05 \%$ inhibited the growth and development of Fg, Fc, Psa, Pst and Psav from 60 to $100 \%$. Moreover, following the principles of circular economy, such active compounds have been functionalized with cellulose nanocrystals and starch extracted from the waste biomass of the wheat milling process, to optimize the release, uptake and systemic diffusion into the plant. Such nanocomposites will have a double function on the main Italian crops (wheat, kiwifruit, tomato, olive): protection against Fg, Fc, Psa, Pst, Psav and biostimulant of the systemic acquired resistance.

UAV-based thermal, RGB imaging and gene expression analysis allowed detection of Fusarium head blight and gave new insights into the physiological responses to the disease in durum wheat

\section{S. Francesconi ${ }^{1}$, M. Maesano ${ }^{2}$, A. Harfouche ${ }^{2}$, G.M. Balestra ${ }^{1}$}

${ }^{1}$ Dipartimento di Scienze Agrarie e Forestali (DAFNE), Univer-
sità degli Studi della Tuscia, Via San Camillo de Lellis snc, 01100
Viterbo, Italia; ${ }^{2}$ Dipartimento per l'Innovazione nei Sistemi Bio-
logici, Agroalimentari e Forestali (DIBAF), Università degli Studi
della Tuscia,Via San Camillo de Lellis snc,01100 Viterbo, Italia.
E-mail: francesconi.s@unitus.it; balestra@unitus.it

Fusarium head blight (FHB) is considered a major threat to wheat and is managed by the application of fungicides at anthesis. However, fungicides are applied when FHB symptoms are clearly visible, by when it is too late to control FHB. For this reason, farmers often perform repeated fungicide treatments that cause a waste of money and pose significant risks to the environment and non-target organisms. We used unmanned aerial vehicle (UAV)-based thermal infrared (TIR) and red-green-blue (RGB) imaging for FHB detection in T. turgidum under natural field conditions. TIR and RGB data coupled with ground-based measurements such as spike's temperature, photosynthetic efficiency and molecular identification of FHB pathogens, detected FHB at anthesis half-way. Moreover, in greenhouse experiments the transcripts of the key genes involved in stomatal closure were mostly up-regulated in F. graminearum-inoculated plants, demonstrating that the physiological mechanism behind the spike's temperature increase and photosynthetic efficiency decrease could be attributed to the closure of the guard cells in response to $F$. graminearum. In addition, preliminary analysis revealed a differential regulation of genes between drought-stressed and $F$. graminearum-inoculated plants, suggesting that there might be a possibility to discriminate between water stress and FHB infection. This study shows the potential of UAV-based TIR and RGB imaging for field phenotyping of wheat in response to environmental stresses. This is anticipated to have enormous promise for the detection of FHB disease and tremendous implications for optimizing the application of fungicides, since global food crop demand is to be met with minimal environmental impacts.

\section{Biocontrol of soil born forest pathogens with local Tricho- derma spp. and Clonostachys rosea}

A. Frascella ${ }^{1}$, F. Venice $^{2}$, S. Barberini ${ }^{1}$, G. Emiliani ${ }^{1}$, R.

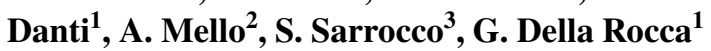

${ }^{1}$ CNR-IPSP, Via Madonna del Piano 10, 50019 Sesto Fiorentino (FI), Italy; ${ }^{2}$ CNR-IPSP, Viale P.A. Mattioli 25, 10125 Turin, Italy; ${ }^{3}$ Department of Agriculture, Food and Environment, University of Pisa, Via del Borghetto 80, 56124 Pisa, Italy.E-mail: angela.frascella@ipsp.cnr.it

In forest environment, the spread of pathogens compromises the ecosystem stability affecting biodiversity and forest services. A new frontier to successfully control forest pathogens is the application of locally selected biocontrol agents (BCAs).

In Italy, the project LIFE MycoRestore is dealing with the biocontrol of the causal agent of Ink Disease (Phytophthora cambivora) in a chestnut orchard and of Annosum and Armillaria Root Rot in a pure silver fir stand (Heterobasidion abietinum and Armillaria ostoyae) in Tuscan Apennines. Thirthy-five Trichoderma isolates belonging to 5 different species and a Clonostachys rosea isolate have been isolated from both diseased areas and tested as BCAs. The inhibitory activity of each isolate against the target pathogens has been evaluated in vitro setting up mycoparasitism, antibiosis and competition for nutrients tests and observations. The effect of secondary metabolites secreted by each BCAs candidate 
have been tested in vitro and the BVOCs emitted detected and characterized by SPME. Dual-cultures, sporulation test and metabolic profiling by Biolog technology have been conducted on the selected isolated and the chitinase, glucanase and cellulase activities have been determined. The biocontrol effectiveness of selected BCAs is being evaluated in planta on chestnut and silver fir seedlings through seasonal measurements of physiological performances (gas exchanges, chlorophyll fluorescence and greenness).

This work was supported by LIFE 18/CCA/ES/001110 "MycoRestore".

Insect vectors proteins interact with the immunodominant membrane protein Imp of Flavescence dorée phytoplasma

\section{Galetto, S. Abbà, L. Cerone, S. Palmano, M. Rossi, C. Marzachì}

CNR, Istituto per la Protezione Sostenibile delle Piante, Torino, Italia. E-mail: luciana.galetto@ipsp.cnr.it

Phytoplasmas are plant pathogenic bacteria that cause diseases and severe economic losses to crops worldwide. Phytoplasmas are transmitted by Hemipteran insect species to the phloem of host plants, and they multiply in both hosts. As these unculturable bacteria are wall-less, the involvement of different cell membrane proteins in promoting pathogen internalization within the host cell has been hypothesized. Here we present the results on the interactome of the immunodominant membrane protein (Imp) of Flavescence doree phytoplasma (FDp) with insect vector proteins. FDp is a grapevine quarantine pest and a major threat to European viticulture. Affinity chromatography and pull-down procedures combined with mass spectrometry were employed to identify host proteins interacting with synthetic Imp C-terminus domains of two FDp strains (16SrV-C and -D). The leafhopper species Scaphoideus titanus, the FDp natural vector, and Euscelidius variegatus, the laboratory vector, were the hosts of this study. Interacting protein fractions were trypsin-digested before being analysed by mass spectrometry and identified by bioinformatic analyses. Five E. variegatus proteins interacting with Imp were further characterized, by measuring expression of the corresponding transcripts in different insect tissues as well as in healthy vs. infected insects. RNA interference was exploited to silence these five gene and evaluate the effects on phytoplasma acquisition. As the control of phytoplasma diseases is based on insecticides to reduce vector populations, this work is an initial step to identify key stages of FDp transmission specificity and vector infection, as potential targets to disrupt FD epidemiological cycle.
Enhancement of agri-food oil by-products using beneficial microorganisms

L. Gioia ${ }^{1}$, S. Lanzuise ${ }^{1}$, A. Bottiglieri ${ }^{1}$, A. Sicari ${ }^{2}$, E.

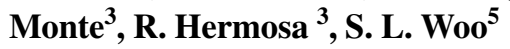

${ }^{1}$ University of Naples Federico II, Department of Agricultural Sciences, Via Università 133, 80055 Portici (NA), Italy; ${ }^{2}$ Santa Rita srl, Via F. Imparato 27/29, 80146 Naples, Italy; ${ }^{3}$ University of Salamanca, Instituto Hispano-luso de Investigaciones Agrarias (CIALE), C/ del Duero 12, 37185 Villamayor (Salamanca), Spain; ${ }^{4}$ National Research Council, Institute for Sustainable Plant Protection, Via Università 133, 80055 Portici (NA), Italy; ${ }^{5}$ University of Naples Federico II, Department of Pharmacy, Via D. Montesano 48,80131 Naples, Italy.E-mail: laura.gioia@unina.it

The agro-food chain represents one of the production sectors most responsible for the release of industrial wastes creating problems as pollutants in water and soil, the emission of greenhouse gases, with potential risks to human and environment health. The disposal of such wastes constitutes an economic cost to producers. However, agri-food by-products can be an economic resource when converted to new products, useful in a multitude of manufacturing sectors, with additional social and environmental benefits. The aim of this work was the development of a microbial biotechnological process to reduce the phytotoxicity of byproducts produced from the extraction of food oils from rapeseed (RS) and sunflower (SF), using them as substrates to produce cultures of the plant beneficial fungi, Trichoderma harzianum and T. asperellum, for applications as soil admendments and biostimulants in diverse plant cultivation systems. In vivo assays were conducted on tomato plants to evaluate the effect on plant growth after soil integrations with the oil by-products, after pretreatments in Solid State Fermentation (SSF) with three different Trichoderma strains. The culturing of Trichoderma on the oil by-products, contributed to the bioremediation of SF or RS by decreasing the phytotoxicity effects when they were added to the soil at high concentrations. Furthermore, the SSF of SF and RS wastes with Trichoderma treatments enhanced the positive effects on plant epigeal-hypogeal growth and development in comparison to treatments receiving only the by-products or the fungal applications; the combination of SF or RS with Trichoderma strain T22 were found to be the most effective biostimulant treatments. The byproducts also favored the colonization and persistence of Trichoderma in the soil, thus enhancing and prolonging its effects on the plant. The use of beneficial microorganisms is a promising method to recycle agro-food wastes, contributing to the green economy and environmental sustainability. 
This work was supported by Ministero dell' Università e della Ricerca, Dottorati Innovativi con caratterizzazione industriale; Asse I "Capitale Umano”, Azione I.1 del Programma Operativo Nazionale "Ricerca e Innovazione 2014-2020”.

Fusarium verticillioides and Aspergillus flavus co-occurrence influences plant and fungal gene expression in maize kernels and in vitro

\section{P. Giorni, A. Lanubile, A. Marocco, P. Battilani}

Department of Sustainable Crop Production, Università Cattolica del Sacro Cuore, Via Emilia Parmense 84, 29122 Piacenza, Italy. E-mail: paola.battilani@unicatt.it

Climate change will increase the co-occurrence of Fusarium verticillioides and Aspergillus flavus, so as of their mycotoxins, in European maize. In this study, the expression profiles of two pathogenesis-related $(P R)$ genes and four mycotoxin biosynthetic genes, FUM1 and FUM13 (fumonisin pathway) and $A F L R$ and AFLD (aflatoxin pathway), were examined in kernels and in artificial medium after a single inoculation with $F$. verticillioides or A. flavus or with the two fungi in combination, in different temperature regimes (20, 25 and $30{ }^{\circ} \mathrm{C}$ ) over a time-course of 21 days. In maize kernels, $P R$ genes showed the strongest induction at $25{ }^{\circ} \mathrm{C}$ in the earlier days post inoculation (dpi) with single fungi. A similar behavior was maintained with fungi co-occurrence, but with enhanced defense response at 9 dpi under $20{ }^{\circ} \mathrm{C}$. Regarding FUM genes, in the kernels inoculated with $F$. verticillioides the maximal transcript levels occurred at $6 \mathrm{dpi}$ at $25^{\circ} \mathrm{C}$, decreased with the co-occurrence of A. flavus, while the highest gene induction was detected at $20{ }^{\circ} \mathrm{C}$. Similar results were observed in fungi grown in vitro. Concerning $A F L$ genes, considering both A. flavus alone and in combination, enhanced up-regulation levels were reached at $30{ }^{\circ} \mathrm{C}$ during all time-course both in infected kernels and in fungi grown in vitro. Regarding mycotoxin production, no significant differences were found among temperatures for kernels contamination; in vitro the highest production was registered at $25^{\circ} \mathrm{C}$ for AFBs and at $20^{\circ} \mathrm{C}$ for FBs in case of single inoculation. In fungal co-occurrence, both mycotoxins resulted reduced at all the temperatures considered compared to the amount produced with single inoculation.

This work was supported by MycoKey project "Integrated and Innovative Key Actions for Mycotoxin Management in the Food and Feed Chain" (EU Project H2020-GA 678,781.U.3.2-678,781).

Draft genome sequence of a new Fusarium isolate collected from hazelnut in central Italy

\author{
A. Grottoli ${ }^{1}$, S. Turco ${ }^{2}$, L. Faino ${ }^{3}$, M. Reverberi ${ }^{3}$, V. Cris- \\ tofori $^{2}$, A. Mazzaglia ${ }^{2}$
}

${ }^{1}$ Consiglio per la ricerca in agricoltura e l'analisi dell'economia agraria, Centro di ricerca difesa e certificazione (CREA-DC), Via C.G. Bertero 22, 00156 Roma; ${ }^{2}$ Dipartimento di Scienze Agrarie e Forestali, Università degli Studi della Tuscia, Via S. Camillo de Lellis snc, 01100 Viterbo, Italy; ${ }^{3}$ Dipartimento di Biologia Ambientale, Sapienza, Università di Roma, Piazzale Aldo Moro 5, 00185 Roma. E-mail: angmazza@unitus.it

Fusarium lateritium, already known as the causative agent of hazelnut twig cankers and fruit rot on walnuts and olives, since 2000 has been also associated in Italy to a serious disease, the nut grey necrosis as well (NGN). Indeed, in several hazelnut orchards located in the Latium Region, in central Italy, symptoms like brown greyish necrotic patch on the nutshell, bracts, and less frequently on the petioles, have been observed together with a severe fruit drop. The disease impacts the Italian hazelnut production cultivation, which is the second largest world hazelnut producer, after Turkey.

To date, the only genome of $F$. lateritium available on the public database is an American strain isolated from elm tree with canker and dieback of branches, arranged in 1,404 contigs. Thus, a more complete representation of an Italian strain isolated from hazelnut could represent a first important step towards a better understanding of the biology, epidemiology, and infection mechanisms of this pathogen. Here we evaluated different de novo assembly algorithms, and a combined approach that takes advantage of the long but quite inexact reads obtained by Oxford Nanopore Technology, and of the precision of the short reads obtained by Illumina technology, to reach a complete and precise genome sequence. This resource could be a milestone to further disentangle the phylogeny of the $F$. lateritium complex and to develop a focused and specific control disease strategy.

This research was supported by the European Commission under the Grant Agreement number 774571 (project PANTHEON - "Precision farming of hazelnut orchards") and carried out in the frame of the Italian MIUR (Ministry for education, University and Research) initiative "Department of Excellence" (Law 232/2016).

\section{Evolution of mini chromosomes in Fusarium verticillioides}

A. Grottoli ${ }^{1,2}$, L. Faino ${ }^{1}$, M. Beccaccioli ${ }^{1}$, V. Scala ${ }^{2}$, N. Ferrante $^{1}$, B. Massimo ${ }^{3}$, M. Aragona ${ }^{2}$, R.S. Fratini ${ }^{1}$, M. Reverberi $^{1}$

${ }^{1}$ Department of Environmental Biology, University of Rome "La Sapienza”, p. le Aldo Moro 5, 00185 Rome, Italy; ${ }^{2}$ Research Centre for Plant Protection and Certification, Council for Agricultural Research and Economics (CREA), Via C.G. Bertero 22, 00156 Roma, Italy ; ${ }^{3}$ Department of Agricultural, Forest and Food Science, 
University of Turin, largo Braccini 2, 10095 Grugliasco (TO).

E-mail: luigi.faino@uniromal.it

The maize pathogen Fusarium verticillioides causes huge economic losses per year due to the production of fumonisins. Fusarium verticillioides ITEM 10027 (Fv10027) isolated in Italy shows a reduced fumonisins synthesis when compared to the $F$. verticillioides reference strain 7600 (Fv7600). Although the difference in fumonisins production, the pathogenicity tests on maize stalk did not show any difference in infection levels. Additionally, using knock-out mutant in FUM1 gene did not show any compromised virulence in stalk rot assay. To better understand $F v$ virulence, the genome of $F v 10027$ was sequenced and assembled. Comparative genomics between $F v 7600$ and $F v 10027$ showed a difference in genome size of about $1.4 \mathrm{Mb}$ despite $99 \%$ nucleotide identity. Genome assembly of $F v 10027$ showed that two mini-chromosomes of about $1 \mathrm{Mb}$ and $750 \mathrm{~Kb}$ were unique to $F v 10027$ while a mini-chromosome of about $400 \mathrm{~Kb}$ to $F v 7600$. To determine the presence of these mini chromosomes in the Italian $F v$ population, 24 strains, sampled in the Po valley, were sequenced; presence/absence analysis showed that only three $F v$ strains had those chromosomes. The analysis of $F v 10027$ dispensable chromosomes showed an enrichment of secreted proteins and a higher level of repetitive elements. Intriguingly, BLAST analysis on the Fv10027 proteome showed that proteins codified on mini chromosomes have the best identity to $F$. oxysporum proteins located at dispensable chr3 and chr6. Moreover, synonyms substitution analysis suggests that mini chromosomes of $F$. verticillioides were not probably acquired through a horizontal chromosomal transfer from $F$. oxysporum but rather originated before the split of the two species.

\section{First report of Venturia asperata in Trentino Region (north- ern Italy)}

\section{Gualandri ${ }^{1,2}$, D. Prodorutti ${ }^{1,2}$, L. Delaiti ${ }^{1}$, M. Zaffoni ${ }^{1}$, C. Panizza ${ }^{1}$, F. Pedrazzoli ${ }^{1}$, G. Angeli ${ }^{1}$ \\ ${ }^{1}$ Fondazione Edmund Mach, Center for Technology Transfer, Via E. Mach 1, 38010 S. Michele all'Adige, Trento; ${ }^{2}$ Center of Agricul- ture, Food and Environment (C3A), University of Trento, I-38010 San Michele all'Adige, Italy. E-mail: valeria.gualandri@fmach.it}

Venturia inaequalis (Cooke) G. Winter is known to be responsible for apple scab, a very harmful disease reported in almost all apple-growing regions worldwide. Apple industry constitutes an important cornerstone for the economy of Trentino (northern Italy). As the demand for a reduction of chemical treatments in agriculture is increasing, the development of resistant cultivars plays a crucial role. During the late summer of 2018 and 2019, atypical symptoms of apple scab were observed on a resistant cultivar carrying the $V f$ resistance gene to $V$. inaequalis. Symptoms were observed in a commercial orchard in Adige Valley. To identify the pathogen involved in this symptomatology, small pieces of brownish suberose patches (collected from fruits) and dusty patches (collected from leaf tissue) were plated on potato dextrose agar. DNA was extracted from mycelia originated from monoconidial cultures and the ITS region was amplified using the primer Vasp (5'-GTCTGAGAAACAAGTAAT AG-3'), specific for Venturia asperata Samuels \& Sivan., in combination with ITS4. Amplicons of the expected size were generated, gel purified, and sequenced (MT459450 and MT459451). A BLAST search was performed in the NCBI database and one isolate showed $100 \%$ of identity with $V$. asperata. These data suggest that, besides $V$. inaequalis, another species of Venturia may occur in Trentino region, confirming what has already been reported in France, Emilia Romagna and Piedmont. The presence of $V$. asperata, which causes a minor disease so far, might represent an emerging problem on apple tree. Epidemiological studies on a wider scale could improve the knowledge of this Ascomycetes, leading to specific control strategies aimed reducing fruit losses especially in sustainable and organic orchards, where treatments against apple scab are usually reduced.

\section{Fusarium oxysporum hyphal penetration depends upon} physical rather than chemical stimuli

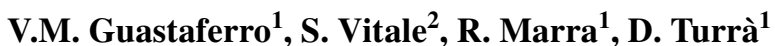

${ }^{1}$ Department of Agricultural Sciences, University of Naples "Federico II", Via Università 100, 80055 Portici (Na), Italy; ${ }^{2} I P S P$, Istituto per la Protezione Sostenibile delle Piante, sede secondaria di Portici, Piazzale Enrico Fermi 1, 80055 Portici (NA), Italy. E-mail: valentinomaria.guastaferro@unina.it

Fusarium oxysporum (Fo) is a soil dwelling fungal ascomycete and the causal agent of wilt disease in a large number of economically important crops. A crucial step for plant infection relies on hyphal-mediated penetration of epidermal root cells. In order to identify if chemical or physical stimuli trigger $F o$ invasive growth we characterized $F_{O}$ penetration using different nutrient sources, plate orientations or cellulose-based poreless membranes (cellophane) or chemically inert membranes of known pore size (nylon; $0.45 \mu \mathrm{m}$ and $0.22 \mu \mathrm{m}$ ). Here we show that while gravity or nutrient sources do not alter $F o$ penetration, pore size does affect hyphal invasive growth. In $F o$ there exist three mitogen-activated protein kinase (MAPK) signalling cascades responsible for invasive growth (FMK1) and cell wall integrity (MPK1) or high osmolarity (HOG1) responses. Interestingly, we observed that while Mpkl $\Delta$ or $\operatorname{Hog} 1 \Delta$ knock-out mutants did not show differential growth and 
penetration compared to the wt strain, the Fmkl $\Delta$ MAPK mutant poorly penetrated through $0.22 \mu \mathrm{m}$ pores and failed to penetrate poreless membranes, suggesting that the FMK1 MAPK pathway might be involved in hyphal differentiation. Fo invasion was not altered on cellophane membranes in a Clrl $\Delta$ mutant, lacking a major cellulase regulator, or on membranes laid on both poor or rich media. Moreover, Fo could efficiently penetrate artificial membranes irrespective of plate orientation (upright, vertical or upside-down position). Our preliminary findings suggest that while chemical perception of membrane or medium components is dispensable for Fo penetration, surface perception and/or hyphal differentiation might represent crucial mechanisms for successful Fo infection.

\section{Emerging fungal pathogens causing foliar diseases of blueberry in Italy}

\section{Guarnaccia ${ }^{1,2}$, I. Martino ${ }^{1}$, A. Garibaldi ${ }^{1}$, M.L. Gul- lino ${ }^{1}$}

${ }^{1}$ Centro di Competenza per l'Innovazione in campo agro-ambientale, AGROINNOVA, Università di Torino, Largo Braccini 2, 10095 Grugliasco (TO), Italia; ${ }^{2}$ Dipartimento di Scienze Agrarie, Forestali e Alimentari (DISAFA), Università di Torino, Largo Braccini 2, 10095 Grugliasco (TO), Italia. E-mail: vladimiro.guarnaccia@unito.it

During the last decade, blueberry cultivation increased worldwide. In Piedmont, one of the major blueberry growing areas in Italy, the production achieved high quantities due to the establishment of new selected cultivars, the intensification of cultural systems and the adoption of innovative agricultural practices. However, emerging diseases occurred. Several surveys were conducted in this region during 2019-2021 to monitor and investigate the fungal pathogens associated with stem blight, dieback, leaf anthracnose and defoliation of blueberry. Neofusicoccum parvum, Diaporthe eres, D. rudis, Cadophora luteoolivacea and Peroneutypa scoparia were found in association with severe stem blight on the commercial cultivars 'Last Call', 'Blue Ribbon' and 'Top Shelf'. Moreover, Colletotorichum helleniense was isolated from leaf spots of the blueberry cultivar 'Blue Ribbon'. The identification of the above mentioned species was reached through robust multilocus phylogeny analyses. Three different genetic markers were considered for the stem blight and dieback pathogens, whilst eight regions were used to identify the isolates of $C$. helleniense, causal agent of leaf anthracnose. Pathogenicity tests were conducted to assess the virulence of all the fungal species found. Neofusicoccum parvum has revealed the most aggressive species causing considerable necrotic lesions on plant stems of the representative cultivar 'Duke'. Colletotrichum helleniense showed variable virulence, based on different cultivars. Further epidemiological analyses are in progress to provide additional information for the adoption of effective integrated control strategies.

\section{Detection of Phytophthora spp. in walnut orchards}

\section{A. Haegi, M. Scarpari, L. Luongo, S. Vitale, A. Belisario}

Consiglio per la Ricerca in Agricoltura e l'Analisi dell'Economia Agraria (CREA)- Centro di Ricerca Difesa e Certificazione (DC), Via C. G. Bertero 22, 00156 Roma, Italy.E-mail: anita.haegi@ crea.gov.it

Phytophthora is considered an important pathogen on walnut, on which it causes severe losses. Several Phytophthora spp. are known to attack walnut, causing root and collar rot followed by die-back, among these Phytophthora cinnamomi is considered the most virulent and widespread in southern Europe. Accurate pathogen identification has critical implications for control and host management. For tree cultivation, for which diagnosis in plant is usually tardive, pathogen identification in soil could be very useful for an early detection since this could allow control of primary sources of infection. A series of different protocols has been set up for identification of Phytophthoras in soil at different levels: from generic identification to specific identification and quantification. A first PCR-based method has been set up for identification of Phytophthora spp. in soils of walnut orchards: studies have been performed on different depths and distances from walnut tree for the most significant conditions for soil sampling. Another method was used to identify different species of Phytophthora present in soil, based on nested-PCR. In soil of walnut orchards in northern Italy, this method confirm the predominant presence of Phytophthora cinnamomi. Finally, a real-time quantitative PCR (qPCR) method has been set up for direct detection and quantification of $P$. cinnamomi on plant tissue, and soil samples. This method allows the detection of P. cinnamomi in soil prior to plantation/cultivation to prevent future damage. In addition, the assessment of the pathogen quantity may contribute to estimate disease potential risk and to set up adequate control strategies.

This work was supported by Italian Ministry of Agriculture (MiPAAF) through the research project PORT.NOC focused on sources of resistance to Phytophthora in Juglans and mechanism of virulence and host pathogen interaction between P. cinnamomi and walnut.

Double-stranded RNA targeting Dicer-like genes compromises the pathogenicity of Plasmopara viticola on grapevine

Z.M. Haile ${ }^{1,2}$, D. Endale Gebremichael ${ }^{1}$, L. Capriotti ${ }^{3}$, B. Molesini ${ }^{4}$, F. Negrini ${ }^{1}$, M. Collina ${ }^{1}$, S. Sabbadini ${ }^{3}$, B. Mezzetti $^{3,5}$, E. Baraldi ${ }^{1}$ 
${ }^{1}$ Department of Agricultural and Food Sciences (DISTAL), University of Bologna, Bologna, Italy ${ }^{2}$ Ethiopian Institute of Agricultural Research (EIAR), Addis Ababa, Ethiopia; ${ }^{3}$ Department of Agricultural, Food and Environmental Sciences, Polytechnic University of Marche, Ancona, Italy; ${ }^{4}$ Department of Biotechnology, University of Verona, Verona, Italy; ${ }^{5}$ Research Group on Food, Nutritional Biochemistry and Health, Universidad Europea del Atlántico, Santander, Spain.E-mail: elena.baraldi@unibo.it

Downy mildew caused by Plasmopara viticola is one of the most devastating diseases of grapevine, attacking all green parts of the plant. The damage is severe when the infection at flowering stage is left uncontrolled. P. viticola management consumes a significant amount of classical pesticides applied in vineyards, requiring efficient and environmentally safe disease management options. Spray-induced gene silencing (SIGS), through the application of exogenous double-stranded RNA (dsRNA), has shown promising results for the management of diseases in crops. Here, we developed and tested the potential of dsRNA targeting $P$. viticola Dicer-like (DCL) genes for SIGS-based crop protection strategy. The exogenous application of $P v D C L 1 / 2$ dsRNA, a chimera of $P v D C L 1$ and $P v D C L 2$, highly affected the virulence of $P$. viticola. The reduced expression level of $P v D C L 1$ and $P v D C L 2$ transcripts in infected leaves, treated with $P v D C L 1 / 2$ dsRNA, was an indication of an active RNA interference mechanism inside the pathogen to compromise its virulence. Besides the protective property, the $P v D C L 1 / 2$ dsRNA also exhibited a curative role by reducing the disease progress rate of already established infection. Our data provide a promising future for $P v D C L 1 / 2$ dsRNA as a new generation of RNA-based resistant plants or RNA-based agrochemical for the management of downy mildew disease in grapevine.

This work was supported by COST (European Cooperation in Science and Technology), www.cost.eu

\section{Biological control of rice blast pathogen, Pyricularia oryzae by Bacillus spp.}

\section{A. Kunova, E. Magni, M. Pasquali, C. Pizzatti, M. Sarac- chi, P. Cortesi}

Environmental and Nutritional Sciences, University of Milan, Italy. E-mail: andrea.kunova@unimi.it

Rice blast, caused by Pyricularia oryzae, is one of the most important rice diseases worldwide. Each year it causes globally $30 \%$ yield losses, threatening thus global food security. Rice blast management relies heavily on fungicides, however, due to more and more restrictive legislation and increasing problems with fungicide resistance, a very limited spectrum of chemical control means is available. Therefore, there is an urgent need to search for and develop new efficient control strategies.

Biological control is nowadays well accepted alternative to control plant pathogens in agriculture and among different biological control agents (BCA), Bacillus spp. have been among the most successful microorganisms in disease management. Here, two strains of Bacillus spp., BCA20 and BCA21, were isolated as plate contaminants inhibiting fungal growth. Their activity was tested by dual-culture assay against 15 strains of Pyricularia oryzae. BCA20 showed overall higher activity, it inhibited the radial growth of the tested strains on average by $85 \%$ and the mycelium growth area by almost $52 \%$. The activity of BCA 21 was approximately $20 \%$ lower than that of BCA20. The multi-locus gene identification based on eight genes (16S, ilvD, glpF, pta, purH, pycA, rpoD and tpiA) identified BCA20 as $B$. subtilis and BCA21 as $B$. halotolerans. The activity of the two strains on the germination and growth of rice plants as well as their biocontrol activity in vivo is being investigated.

Do the frequency and severity of citrus diseases incited by latent fungal pathogens increase as a consequence of climatic change?

F. La Spada ${ }^{1}$, M. Riolo ${ }^{1,2,3}$, F. Aloi ${ }^{4}$, M. Cara ${ }^{5}$, R. Parlas-

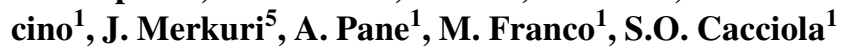

${ }^{1}$ Department of Agriculture, Food and Environment, University of Catania, 95123 Catania, Italy; ${ }^{2}$ Council for Agricultural Research and Agricultural Economy Analysis, Research Centre for Olive, Citrus and Tree Fruit - Rende CS (CREA-OFA), 87036 Rende, Italy; ${ }^{3}$ Department of Agricultural Science, Mediterranean University of Reggio Calabria, 89122 Reggio Calabria, Italy; ${ }^{4}$ Department of Agricultural, Food and Forest Sciences, University of Palermo, 90128 Palermo, Italy; ${ }^{5}$ Department of Plant Protection, Faculty of Agriculture and Environment, Agriculture University of Tirana (AUT), 1029 Tirana, Albania.E-mail: olga.cacciola@unict.it

Several families and genera of fungal plant pathogens, such as Botryosphaeriaceae and Colletotrichum, encompass species behaving as saprobes, endophytes or latent pathogens and shifting to a pathogenic lifestyle when environmental conditions are favorable or the host-plant is stressed, which often occurs as a consequence of traumatic events or extreme weather conditions. Usually, these fungi are generalist pathogens and can be regarded as opportunistic yet aggressive invaders. In particular, for the Botryosphaeriaceae, it was demonstrated they produce an arsenal of non host-specific phytotoxins which act as virulence factors. It is expected that the frequency and severity of diseases, caused by these fungi, will increase as a consequence of climate change and several evidence confirmed this trend. Two case-studies are here reported which exemplify well this type of plant diseases, bot gummosis and twig and shoot dieback of citrus, whose causal 
agents in southern Italy were identified as Neofusicoccum parvum and Colletotrichum spp., respectively.

The good, the bad and the ugly: how volatile organic compounds (VOCs) produced by Trichoderma spp. protect grapevine plants against downy mildew

\section{Lazazzara ${ }^{1}$, B. Vicelli ${ }^{1,2}$, C. Bueschl ${ }^{3}$, A. Parich $^{3}$, I. Pertot $^{1,2}$, R. Schuhmacher ${ }^{3}$, M. Perazzolli ${ }^{1,2}$}

\begin{abstract}
${ }^{1}$ Department of Sustainable Agro-ecosystems and Bioresources, Research and Innovation Centre, Fondazione Edmund Mach, San Michele all'Adige, Italy; ${ }^{2}$ Center Agriculture Food Environment (C3A), University of Trento, San Michele all'Adige, Italy; ${ }^{3}$ Institute of Bioanalytics and Agro-Metabolomics, Department of Agrobiotechnology (IFA-Tulln), University of Natural Resources and Life Sciences, Vienna (BOKU), Tulln, Austria. E-mail: valentina.lazazzara@fmach.it
\end{abstract}

Trichoderma spp. are among the most widespread soil microorganisms and have been widely used as biological control agents against phytopathogens. Trichoderma spp. are known to produce volatile organic compounds (VOCs) that play crucial roles in the inter-kingdom communications and biological control mechanisms. Several studies highlighted the importance of Trichoderma spp. as an alternative strategy against grapevine pathogens, but no information is available on the possible biological control mechanisms mediated by Trichoderma VOCs against grapevine downy mildew (caused by Plasmopara viticola). The aim of this study was to characterize VOCs produced by three Trichoderma strains and to investigate their effects against grapevine downy mildew. VOCs produced by Trichoderma asperellum $\mathrm{T} 34$, T. harzianum $\mathrm{T} 39$, and $T$. atroviride $\mathrm{SC} 1$ reduced downy mildew symptoms on grapevine leaf disks. A head space-solid phase microextraction gas chromatographymass spectrometry analysis revealed 31 VOCs in two independent experiments, including alkenes, ketones, pyrones, furanes and terpenes. Five reduced downy mildew symptoms on grapevine leaf disks. In particular, 6-pentyl-2Hpyran-2-one and 2-pentylfuran increased the accumulation of callose and enhanced the modulation of defense-related genes after $P$. viticola inoculation, indicating an induction of grapevine defense mechanisms. Moreover, one 6-pentyl2H-pyran-2-one activated the hypersensitive response after $P$. viticola inoculation to reinforce the grapevine defense reaction. These results indicate that Trichoderma VOCs can induce grapevine resistance and these molecules will be further characterized to better clarify the mode of action against grapevine downy mildew.

\section{Use of microbial extracts to control postharvest fungal rots}

V.T. Librizzi, S. Pangallo, M.G. Li Destri Nicosia, G.E. Agosteo, L. Schena

Dipartimento di Agraria, Università Mediterranea, Località Feo di Vito, 89124 Reggio Calabria, Italy. E-mail: lschena@unirc.it

Several microbial alcoholic extracts from isolates of Pseudomonas spp. proved a strong in vitro antifungal activity by inhibiting the mycelial growth of typical postharvest pathogens including Penicillium digitatum, Penicillium expansum, Colletotrichum acutatum s.s., and Botrytis cinerea. On artificially inoculated fruit, infections of these pathogens were almost completely inhibited on citrus, apples, olives and grape, respectively. The most effective extracts (B1, B5 and B9) also exhibited a curative activity and reduced the incidence of rots caused by $B$. cinerea on tomatoes and by Monilinia fructigena on apricots, when applied 6 and $24 \mathrm{~h}$ after inoculation of the pathogens. Furthermore, a significant reduction of rots caused by $B$. cinerea on tomatoes and $M$. fructigena on apricots was achieved on artificially inoculated fruits without a direct contact between extracts and pathogens, indicating the activation of defence responses in treated host tissues. In both host/pathogen combinations rots were completely inhibited by extracts at $12 \mu \mathrm{g} /$ $\mathrm{ml}$ dry matter when applied 12 and $24 \mathrm{~h}$ before the pathogen but a significant reduction of rots was also achieved by inoculating the pathogen immediately after the extract $(0 \mathrm{~h})$, suggesting a very quick host response. Finally, extracts significantly reduced natural rots under semi-commercial conditions on both olives and sweet cherries. Although further investigations are needed to evaluate the composition and safety of tested extracts their high efficacy, direct antifungal activity, induction of resistance, and both preventive and curative activity are important features suggesting a possible implementation as natural preparations to control postharvest diseases.

First detection of Colletotrichum acutatum and C. cigarro in a germplasm olive collection in Sicily and analysis of cultivar susceptibility in open field and in vitro

\footnotetext{
G. Licciardello' ${ }^{1}$,J. Moral ${ }^{2}$, M.C.Strano ${ }^{1}$, P. Caruso ${ }^{1}$, M. Sciara $^{1}$, P. Bella ${ }^{3}$, G. Sorrentino ${ }^{1}$, S. Di Silvestro ${ }^{1}$

${ }^{1}$ Consiglio per la Ricerca in agricoltura e l'analisi dell'Economia Agraria-Centro di ricerca Olivicoltura, Frutticoltura e Agrumicoltura (CREA), Corso Savoia 190, Acireale (CT), Italy; ${ }^{2}$ Department of Agronomy, Maria de Maeztu Excellence Unit, University of Córdoba. Edif. C4, Campus de Rabanales, 14071 Córdoba, Spain, ${ }^{3}$ Dipartimento di Scienze Agrarie, Alimentari e Forestali, Università degli Studi di Palermo, Viale delle Scienze, Ed 4, Palermo, Italy.E-mail: grazia.licciardello@crea.gov.it
} 
The quality of Sicilian olive oils is worldwide recognized. This region produces about $16 \%$ of the Italian production of olive oil. Anthracnose, caused by species of Colletotrichum, is considered the most serious worldwide olive fruit disease and compromises oil quality. Anthracnose has been sporadically detected in Sicily; however, the climatic changes and new agronomic practices are increasing this disease's risk. In each olive-growing region control measures depend on identifying the species of Colletotrichum and the resistance of local cultivars to the pathogen. During 2018 and 2019, 137 Colletotrichum strains were isolated on rotten fruits from olive trees grown in the International Olive Germplasm Collection (IOGC) of Villa Zagaria (Enna). The isolates were morphologically separated into two species complexes: $C$. acutatum or C. gloeosporioides. Subsequently, eight isolates were phylogenetically identified as C. acutatum (P77, P185, B13-16, 105B, 177B, 237-5), C. gloeosporioides (C2.1) and C. cigarro (Perg6B) using a multilocus analysis approach (loci ITS, GAPDH, ACT, and TUB2). In fruit pathogenicity assays, the three Colletotrichum species caused the typical fruit rot symptoms in 11 Sicilian cultivars, although there were significant differences among species, cultivars, and their interaction. Overall, the virulence of the pathogen species was C. acutatum $>$ C. gloeosporioides $>C$. cigarro. Cultivar response under field conditions showed that the disease severity and fruit-rot incidence were positively correlated. The Sicilian olive cvs. Cavaliera, Carolea, Calatina, and Nocellara del Belice were the most susceptible, while Biancolilla and Nocellara etnea were the most resistant.

The work has been financially supported by SALVAOLIVI project (MIPAAFT, DM 59 del 10/01/2018).

In vitro and in vivo activity of copper-alternative products and their efficacy to control citrus anthracnose in preand post-harvest conditions

\section{Lombardo ${ }^{1}$, S. Panebianco ${ }^{1,2}$, A. Azzaro ${ }^{1}$, A. Anza- lone $^{1}$, V. Catara ${ }^{1}$, G. Cirvilleri ${ }^{1}$ \\ ${ }^{2}$ Dipartimento di Agricoltura Alimentazione e Ambiente, Università degli Studi di Catania; ${ }^{2}$ Dipartimento di Fisica e Astronomia, Uni- versità degli Studi di Catania, Italy.E-mail: monia.lombardo@phd. unict.it}

Citrus production is world-wide threatened by Colletotrichum gloeosporioides, causal agents of pre- and postharvest anthracnose of citrus fruit. The limitation on the use of copper, for its demonstrated noxious effect on the environment, makes control of this pathogen difficult; thus the research of alternatives becomes a priority. In this study, the efficacy of alternative products was evaluated in vitro, in growth chamber, in open field and in postharvest at cold and ambient temperature. Mineral fertilizers, basic substances, plant extracts and biological control agents were able to inhibit in vitro the mycelial growth with variable efficacy. Products, evaluated in growth chamber trials on citrus fruit, significantly reduced disease incidence and severity, but showed lower efficacy than copper. Two mineral fertilizers, one citrus essential oil and chitosan were tested in open field on oranges cultivar Tarocco Scirè. Products, applied 3 times, were as effective as copper in reducing disease incidence, and chitosan gave the best results showing to be more effective than copper. Healthy fruits were collected after the second and third field treatment and stored 20 days at $6{ }^{\circ} \mathrm{C}$ and 10 days at $20^{\circ} \mathrm{C}$. Field treatments exerted prolonged efficacy after cold and ambient temperature, and the higher prolonged efficacy was observed in fruits treated 3 times. Although under high disease pressure conditions, field applications of alternative products significantly reduced the incidence of citrus anthracnose in pre-harvest and post-harvest. On the whole, tested products can represent a good alternative to copper compounds in the view of the future limitation on its use.

This work was supported by H2020 project Organic plus, grant agreement No. 774340, 2018-2021.

Transgenic strawberry (Fragaria $x$ ananassa) plants with a mannose binding lectin gene (FaMBL1) showed resistance to strawberry fungal diseases

\section{Ma, F. Negrini, Z. Haile, D. Gebremichael, E. Baraldi}

University of Bologna, DISTAL (Department of Food and Agricultural Science), Viale Fanin 46, 40127, Bologna, Italy. E-mail: elena. baraldi@unibo.it

FaMBL1 is a strawberry G-type lectin gene, which was found to be the most upregulated gene during the interaction of strawberry (Fragaria $\times$ ananassa) white fruit with Colletotrichum acutatum. Taking into consideration that white strawberry is more resistant to $C$. acutatum than red fruit, $F a M B L 1$ was of big interest in plant resistance. Hence, stable transgenic strawberry plants with FaMBLI gene silenced and overexpressed were generated. Transformed strawberry lines were screened on selective media and via PCR. Copy number of transgenes in the selected lines was determined by droplet digital PCR. Four overexpressing and three silencing lines albeit with various copy number were obtained. For overexpressing lines and wild type plants, expression level of FaMBL1 in leaves and stolons was measured by RT-PCR, revealing that overexpressing lines have significantly higher expression of FaMBLI compared with wild type in both leaves and stolons, and FaMBLI expression level is not correlated with copy numbers. Disease-related phytohormones content was measured as well using ultrahigh pressure liquid chromatography-tandem mass spectrometry analysis. Contents of phytohormones tested were not changed due 
to higher expression of $F a M B L 1$ except for jasmonic acid content, which was significantly lower in overexpressing lines than wild type plants. The resistance of overexpressing lines to fungal diseases was evaluated by infecting detached leaves with Botrytis cinerea and petioles with $C$. fioriniae, respectively. Leaves of overexpressing lines challenged by B. cinerea showed remarkably smaller lesion diameters compared with wild type. Petioles inoculated by $C$. fioriniae of overexpressing lines had lower disease incidence than wild type.

Analysis of volatilome and proteome responses of two differently resistant Phaseolus vulgaris genotypes interacting with Colletotrichum lindemuthianum

\section{Mancini ${ }^{1}$, M.M. Monti ${ }^{2}$, L. Gualtieri ${ }^{2}$, G. Domingo ${ }^{1}$, M. Beccaccioli ${ }^{3}$, M. Heil ${ }^{4}$, M. Bracale ${ }^{1}$, F. Loreto $^{2,5}$, M. Ruocco $^{2}$}

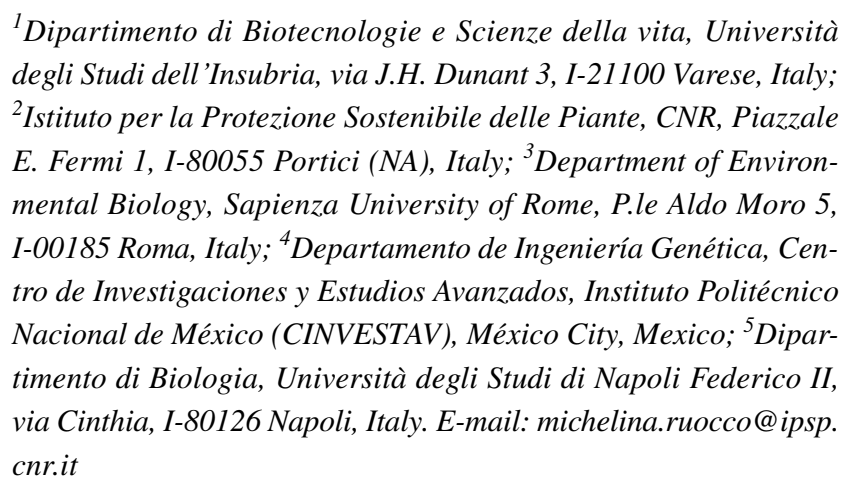

Plants produce and emit a large variety of Volatile Organic Compounds (VOCs) that play multiple roles including interactions with other organisms. The role of emitted VOCs in insect-plant interaction is widely studied, whereas information on VOCs role in plant-pathogen interaction is more elusive. We measured changes in volatilome and proteome in two different bean (Phaseoulus vulgaris L.) genotypes, the susceptible Negro San Luis (NSL) and the moderately resistant Flor de Junio Marcela (FJM), infected by the anthracnose agent Colletotrichum lindemuthianum, an hemibiotrophic fungus and a major bean pathogen damaging leaves, stems and pods. Our results confirm the high susceptibility of NSL and a good resistance of FJM to $C$. lindemuthianum strain 1088 , and indicate differences at both proteome and volatilome levels between the two genotypes, before and after the infection, and possibly different strategies of defence. The moderately resistant genotype contrasted pathogen invasion mainly by maintaining epidermal and cell wall structure and, probably, by reducing stomatal gas-exchanges. The susceptible genotype did not limit early stages of pathogen infection. Rather, this genotype activated a wide range of defensive biochemical responses, involving release of VOCs and induction of hypersensitivity, as indicated by enhanced synthesis of Green Leaf Volatiles (GLVs) and salicylic acid. Proteomic investigation provided a general framework for these evidences, whereas observed changes in the volatilome suggested that VOCs may principally represent stress markers rather than defensive compounds per se.

This work has been supported by the EPIC-XS project number 3695, funded by the Horizon 2020 programme of the European Union and by the bilateral CNR (Italy)/CONACYT (Mexico) project CUP:B72F16001460005.

Hyperspectral and thermal imaging to oversee the Trichoderma biocontrol efficacy against Fusarium oxysporum f. sp. lactucae

G. Manganiello ${ }^{1}$, N. Nicastro ${ }^{1}$, L. Ortenzi ${ }^{2}$, C. Costa $^{2}$, F. Pallottino $^{2}$, T. Cardi ${ }^{1}$, C. Pane ${ }^{1}$

${ }^{1}$ Consiglio per la Ricerca in Agricoltura e l'Analisi dell'Economia Agraria, Centro di ricerca Orticoltura e Florovivaismo, via Cavalleggeri 25, 84098, Pontecagnano Faiano, Italy; ${ }^{2}$ Consiglio per la Ricerca in Agricoltura e l'Analisi dell'Economia Agraria, Centro di ricerca Ingegneria e Trasformazioni Agroalimentari, via della Pascolare 16,00015 Monterotondo,Italy.E-mail: catello.pane@crea.gov.it

Fusarium oxysporum f. sp. lactucae ( $F o l$ ) is a feared soilborne pathogen of baby-lettuce (Lactuca sativa var. acephala) causing wilting disease. Infected plants appear chlorotic, stunted and, in the advanced disease stages, vascular tissues retain a pinkish discoloration, older leaves die and plant collapses. Here, hyperspectral and thermal imaging was applied to follow up Fol wilting developing on babylettuces treated with two biocontrol Trichoderma harzianum strains. Plant seedlings were infected by root-dipping into Fol conidia suspension $\left(10^{5}\right.$ conidia $\left.\mathrm{mL}^{-1}\right)$, transplanted in sterile Trichoderma-amended peat-soil and incubated at $26^{\circ} \mathrm{C}$ for 18 days. Control plants were soaked in sterile distilled water. Hyperspectral, thermal and phyto-pathological assessments were carried out every three days during the time-course and, at the end, additional biometric parameters (root and stem fresh and dry weight and foliar area) were recorded. In comparison to the infected control, Trichoderma treatments significantly decreased disease severity (-44\%, on average). Furthermore, Trichoderma bio-treated uninfected plants resulted more vigorous than both infected and untreated controls, with a remarkable increase in the measured biometric parameters. Infected plant hyperspectral signatures showed a dramatic decrease of reflectance in the region of near infrared (NIR), currently related to water stress occurrence. Nevertheless, reflectance curve of infected plants treated with Trichoderma showed a general 
behavior close to those of uninfected controls, confirming promptness in stress overcome. Thermal imaging accords the hyperspectral outlook, and the construction of a data fusion-based previsional model able to early detect disease is currently undergoing.

This research was funded by the Italian Ministry of Agriculture, Food and Forestry Policies (MiPAAF), project AgriDigit-AGROFILIERE DM 36,503.7305.2018 of 20/12/2018.

Monitoring wild rocket Fusarium wilting by applying deep learning model to hyperspectral data

\section{G. Manganiello ${ }^{1}$, F. Carotenuto ${ }^{2}$, N. Nicastro ${ }^{1}$, T. Cardi $^{1}$, C. Pane ${ }^{1}$}

${ }^{1}$ Consiglio per la Ricerca in Agricoltura e l'Analisi dell'Economia Agraria, Centro di ricerca Orticoltura e Florovivaismo, via Cavalleggeri 25, 84098 Pontecagnano Faiano, Italy; ${ }^{2}$ Dipartimento di Scienze della Terra, dell'Ambiente e delle Risorse, Università degli Studi di Napoli Federico II, Monte Sant'Angelo, Via Cinthia, 21, 80126 Napoli, Italy.E-mail: gelsomina.manganiello@crea.gov.it

Fusarium oxysporum f. sp. raphani (For) is responsible of wilting in wild rocket (Diplotaxis tenuifolia L. [D.C.]), causing stunted growth, yellowing and complete desiccation of affected cultivations. The aim of this research was to build a hyperspectral data-based deep learning model by Machine Learning (ML) algorithm, in order to monitor the wild rocket Fusarium wilting progression. To this scope, plant roots were dipped into a For conidial suspension $\left(10^{6}\right.$ conidia $\left.\mathrm{mL}^{-1}\right)$ and disease incidence (DI), disease severity (DSI) and the pathogen quantification (qPCR) were assessed on plants 5, 10 and 15 days post infection (dpi). At the end of the experiment, the total number of infected plants resulted symptomatic (DI $=100 \%$ ) with DSI average $=80 \%$. Due to the disease, a slight reflectance decrease in the near-infrared region (700-1,000 nm) at $5 \mathrm{dpi}$ and a dramatic decline along the $400-1,000 \mathrm{~nm}$ range in the next time-points, were observed. Consistently with the phenotypic and hyperspectral observations, a scaling up of pathogen DNA was detected over time. Hyperspectral dataset, consisting of 27,000 pixel-observations randomly sampled on healthy and infected plants at different infection stages, was equally split between calibration and testing. Then, it was submitted to the ML algorithm Extreme Gradient Bosting. High predictive performance in discriminating healthy from infected individuals was found, providing non-invasive detection of the infection. Interestingly, on the bases of few most informative bands from the 5 dpi dataset, the predictive model was able to early detect the disease, allowing timely curative treatments.
This research was funded by the Italian Ministry of Agriculture, Food and Forestry Policies (MiPAAF), project AgriDigit-AGROFILIERE DM 36,503.7305.2018 of 20/12/2018.

Investigation of a plant-derived extract as an alternative for grapevine protection against Plasmopara viticola

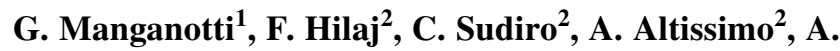 \\ Polverari $^{1}$, E. Vandelle ${ }^{1}$
}

${ }^{1}$ Department of Biotechnology, University of Verona, Strada Le Grazie 1537134 Verona, Italy; ${ }^{2}$ Landlab srl, Via Quintarello 12/A, 36050 Quinto Vicentino, Italy. E-mail: elodiegenevieve.vandelle@ univr.it; a.altissimo@landlab.net

Grapevine (Vitis vinifera $\mathrm{L}$ ) is one of the most important fruit crops and is estimated to be cultivated on over 7.6 millions of land hectares worldwide. Commercial cultivars are susceptible to a number of pathogenic microorganisms that cause diseases, affecting grape and wine quality. One of the most important diseases in V. vinifera is the downy mildew, caused by Plasmopara viticola, the control of which currently requires the repeated application of chemicals. In some cases, unsuitable agricultural practices result in level of pesticide residues in or on grapes at the moment of harvest higher than the level authorized by regulation. Even the use of the permitted formulations containing copper-based compounds causes several negative effects on the environment and have resulted in copper level increase in vineyard soil and grape berry, thus affecting wine quality. The development and use of novel natural compounds in vineyard to control pathogens can address many environmental and social concerns and offer innovative and economically viable opportunities for growers, consumers, policymakers in the entire wine system. In the frame of the EU Life project Plants4Plants, Landlab srl developed a natural extract, obtained directly from plants, which showed a significant efficacy in protecting tomato, potato and grapevine plants in the field. This study thus aims to evaluate the possibility of extract application on leaves of Vitis vinifera cv. Merlot to protect from the infection by $P$. viticola. Extract mode of action is currently being investigated in terms of plant molecular defence response activation and direct antimicrobial activity.

An alliance for the protection of plants: The Thematic Group "Plant Health" - DISTAL - UNIBO

P. Minardi, A. Prodi, A. Masetti, F. Sgolastra, M. Maccaferri, R. Tuberosa, P. Mattarelli, L. Baffoni, T. Gallina Toschi, A. Minelli, D. Viaggi 
Department of Agricultural and Food Sciences (DISTAL), Alma Mater Studiorum - University of Bologna, Viale G. Fanin 42, 40127 Bologna, Italy.E-mail: paola.minardi@unibo.it

The Thematic Group "Plant Health" (TG-PH) of DISTAL, established as part of the "Departments of Excellence" project, has been active since October 2020. To date, 13 research groups with over 40 people including teaching staff, researchers, technicians, postdocs and doctoral students have joined the TG-PH. The common goal of the TG's activities is to protect and enhance the role of "Plant Health" with a plurality of approaches and specific activities which include: (i) the development of strategies to prevent, monitor and control plant pests; (ii) new agronomic practices and plant nutrition approaches to reduce the impact on ecosystems; (iii) the selection and characterization of new varieties more resilient to biotic/abiotic stresses; (iv) the implementation of sustainable agricultural and food policies. Most of these activities are consistent with initiatives to effectively address major global policy issues such as reducing the use of pesticides and fertilizers, increasing biodiversity in order to ensure healthy, affordable and sustainable food supply to society compliant with food quality and safety. The high interdisciplinarity of the TG-PH is ensured by the wide range of scientific sectors to which the research groups involved belong. The common commitment is to pursue the sustainability objectives of the European Green Deal by bridging the gap between research and practice, accelerating the process of transferring research results and following up with networking. Moreover, TG-PH members share the common belief that only a stronger synergy between this knowledge and expertise coupled with a strong publicprivate partnership (PPP) will allow for the translation of the results of basic research into concrete solutions useful for the various stakeholders and society at large.

\section{First report and characterization of citrus vein enation virus in Italy}

\section{Minutolo ${ }^{1}$, M. Cinque ${ }^{1}$, F. Di Serio ${ }^{2}$, D. Alioto $^{1}$, B.} Navarro $^{2}$

${ }^{1}$ Dipartimento di Agraria, Università degli Studi di Napoli Federico II, Portici (NA), Italy; ${ }^{2}$ Istituto per la Protezione Sostenibile delle Piante, Consiglio Nazionale delle Ricerche, Bari, Italy. E-mail: beatriz.navarro@ipsp.cnr.it

Citrus vein enation virus (CVEV) belongs to the genus Enamovirus (family Solemoviridae) and has been proposed as the causal agent of citrus vein enation (VE) and woody gall (WG) diseases. CVEV, first described in Spain, is reported in several citrus growing areas of Asia, America and Australia and it is considered as a quarantine pest in several Mediterranean and American countries. A high-throughput sequencing-based study of the virome associated with citrus trees in the Campania region (southern Italy) allowed the identification of this virus, for the first time in Italy, in a nonsymptomatic Citrus sinensis tree. The full-genome sequence of the CVEV Italian isolate was determined and the sequence variability of the infecting virus population characterized. Phylogenetic relationships according with their geographic origin were observed between the currently sequenced CVEV isolates. The presence of CVEV was further confirmed by RT-PCR and by graft-transmission to indicator plants. A field survey revealed the presence of CVEV in different areas of Campania region, mainly in lemon trees, and allowed the identification of kumquat ( $C$. japonica) as a novel natural host of the virus. Symptoms of VE and WG reported to be induced by CVEV in some citrus species were not observed in the surveyed plants, opening a relevant question of the role of symptomless hosts in the epidemiology of the virus. This point is even more relevant if the transmission of the virus mediated by aphids in a persistent manner is taken into consideration.

Identification by serological detection methods and molecular characterization of citrus concave gum-associated virus in citrus and apple trees in Italy

\section{Minutolo ${ }^{1}$, M. Cinque ${ }^{1}$, B. Navarro $^{2}$, D. Alioto ${ }^{1}$, F. Di Serio ${ }^{2}$}

${ }^{l}$ Dipartimento di Agraria, Università degli Studi di Napoli Federico II, Portici (NA), Italy; ${ }^{2}$ Istituto per la Protezione Sostenibile delle Piante, Consiglio Nazionale delle Ricerche, Bari, Italy. E-mail: minutolm@unina.it

Citrus concave gum-associated virus $(\mathrm{CCGaV})$ is the type member of the genus Coguvirus (family Phleboviridae). This negative-stranded RNA virus with a bipartite genome, first identified in citrus trees in southern Italy, was closely associated with concave gum, a citrus virus-like disease. In 2018, CCGaV has been reported in apple trees, in a germplasm collection in USA and in a field in Brazil, respectively. The association of $\mathrm{CCGaV}$ with symptoms in apple trees remains unclear, as well as the questions about the virus variability, prevalence and distribution, both in field and in vegetative propagation material. To conclusively answer to these questions, fast, reliable and cost-effective detection methods are needed. We previously proposed methods based on RT-PCR to detect CCGaV. Here, data on sensitivity, specificity and reliability of serological tests (doubleantibody-sandwich assay, DAS-ELISA, and direct tissue blot immunoassay, DTBIA), performed using a polyclonal 
antibody against a fragment of the $\mathrm{CCGaV}$ nucleocapsid protein, are presented. Field surveys, carried out comparing serological and molecular assays, further validated DASELISA tests for both citrus and apple trees and DTBIA for citrus trees, thus showing that they could be used for further implementing citrus and apple certification programs. This study also allowed identifying $\mathrm{CCGaV}$ in several apple cultivars in Italy for the first time. The full length genomic sequence of one $\mathrm{CCGaV}$ apple isolate was determined by high-throughput sequencing and the sequence variability of the proteins encoded by several apple and citrus CCGaV isolates was investigated, providing an overview on the phylogenetic relationships between the viral isolates.

Toward innovation in plant health management via an eco-evolutionary perspective on the life history of plant pathogens

\section{C.E. Morris}

INRAE, Pathologie Végétale, F-84140, Montfavet, France . E-mail: cindy.morris@inrae.fr

Concepts about the plant-pathogen interactions and coevolution have overwhelmingly focused on an arms race at scales of time that are not always well specified. Microorganisms have co-existed with plants since plants have colonized landmasses over 450 million years ago - and even earlier. However, little research on plant-microbe interactions has addressed that scale of time. If we took a long-term evolutionary perspective of the life history of plant pathogens into account, what new insight could we have for managing plant health? In this talk I will explore these questions. Firstly, I will present a short reminder of the main evolutionary events of life on Earth that led up to the colonization of landmasses by plants. Then I will address the questions of the progress of plant microbe interactions - if they have evolved towards more intimate or more peripheral interactions and if this has involved a loss or gain of functions. I will highlight the major biological outcomes of plant-microbe interactions including the origin of roots, creation of soil, access to habitats and recalcitrant nutrients, and genetic diversification of plants. To illustrate the insights into epidemiology, emergence and management of plant disease procured from a long-term evolutionary perspective I will present 3 cases: 1 ) The emergence of several important diseases in the Myrtaceae family suggests how phylogenetic signals in the host range of pathogens and their closest relatives could help establish precautions when expanding the range of crops. 2) The time of divergence and host range of Xylella fastidiosa suggest that life history across the full evolutionary age of a pathogen can orient strategies for anticipating its emergence, giving a greater window of time to intervene with prophylactic measures rather than eradication. 3) The evolutionary age of traits that shape the basic ecology of pathogens, such as ice nucleation activity in Pseudomonas syringae, can explain the inherent adaptability and ubiquity of a pathogen and orient surveillance toward habitats to which it has been linked for much longer than its association with agriculture. I conclude by proposing that "arms race" might not be the most useful framework for understanding the molecular evolution of plant-pathogen interactions and that "diplomacy" might be a more robust concept.

The barley immune receptor Mla recognizes multiple pathogens and contributes to host range dynamics

J. Bettgenhaeuser ${ }^{1 *}$, I. Hernández-Pinzón ${ }^{1 *}$, A.M. Dawson $^{1}$, M. Gardiner ${ }^{1}$, P. Green ${ }^{1}$, J. Taylor ${ }^{1}$, M. Smoker ${ }^{1}$, J.N. Ferguson ${ }^{1}$, P. Emmrich ${ }^{1}$, A. Hubbard ${ }^{2}$, R. Bayles ${ }^{2}$, R. Waugh ${ }^{3}$, B.J. Steffenson ${ }^{4}$, B.B.H. Wulff ${ }^{1}$, A. Dreiseitl ${ }^{5}$, E.R. Ward ${ }^{1}$, M.J. Moscou ${ }^{1}$

${ }^{1}$ The Sainsbury Laboratory, University of East Anglia, Norwich Research Park, Norwich, NR4 7UK, England, UK; ${ }^{2}$ NIAB, Huntingdon Road, Cambridge, CB3 OLE, England, UK; ${ }^{3}$ The James Hutton Institute, Invergowrie, Dundee, DD2 5DA, Scotland, UK; ${ }^{4}$ Department of Plant Pathology, University of Minnesota, St. Paul, Minnesota 55108, USA; ${ }^{5}$ Department of Integrated Plant Protection, Agrotest Fyto Ltd, Havlíčkova 2787, CZ-767 01 Kroměř́ž, Czech Republic.E-mail: matthew.moscou@tsl.ac.uk

Crop losses caused by plant pathogens are a primary threat to stable food production. Stripe rust (Puccinia striiformis) is a fungal pathogen of cereal crops that causes significant, persistent yield loss. Stripe rust exhibits host species specificity, with lineages that have adapted to infect wheat and barley. While wheat stripe rust and barley stripe rust are commonly restricted to their corresponding hosts, the genes underlying this host specificity remain unknown. We show that three resistance genes, $R p s 6, R p s 7$, and $R p s 8$, contribute to immunity in barley to wheat stripe rust. $R p s 7$ cosegregates with barley powdery mildew resistance at the Mla locus. Using transgenic complementation of different Mla alleles, we confirmed allele-specific recognition of wheat stripe rust by Mla. Our results show that major resistance genes contribute to the host species specificity of wheat stripe rust on barley and that a shared genetic architecture underlies resistance to the adapted pathogen barley powdery mildew and non-adapted pathogen wheat stripe rust.

This work was supported by Biotechnology and Biological Sciences Research Council Doctoral Training Programme BB/F017294/1 and Institute Strategic Programme BB/J004553/1, BB/P012574/1, BBS/E/ J/000PR9795, Human Frontier Science Program Long-term Fellowship 
LT000218/2011-L, 2Blades Foundation, and Gatsby Charitable Foundation.

\section{Study of rapid alkalinization factor (RALF) genes as plant susceptibility agents during plant pathogen interaction in strawberry}

\section{F. Negrini ${ }^{1}$, K. O'Grady ${ }^{2}$, M. Hyvönen ${ }^{3}$, K.M. Folta ${ }^{2}$, E. Baraldi ${ }^{1}$}

\begin{abstract}
${ }^{1}$ Department of Agriculture and Food Sciences (DISTAL), University of Bologna, Viale Fanin 46, 40127 Bologna, Italy; ${ }^{2}$ Horticultural Sciences Department, University of Florida, 2550 Hull Rd, Gainesville, FL 32611, United States of America; ${ }^{3}$ Department of Biochemistry, University of Cambridge, Tennis Court Road, CB2 1QW Cambridge, United Kingdom.E-mail: elena.baraldi@unibo.it
\end{abstract}

Rapid Alkalinization Factor (RALF) are cysteins-rich peptides ubiquitous in plant kingdom. They play multiple roles as hormone signals and recently their involvement in hostpathogen crosstalk as negative regulator of immunity in Arabidopsis has also been recognized. In addition, RALF homologue peptides are secreted by different fungal pathogens as effectors during early stages of infections. The aim of this work was to characterize RALF genes as susceptibility factors during plant pathogen interaction in strawberry. For this, the genomic organization of the RALF gene families in the octoploid and diploid strawberries were described, identifying 13 member in Fragaria vesca (FvRALF) and 50 members in $F$. $\mathrm{x}$ ananassa (FaRALF). The changes in expression of fruit FaRALF genes was investigated upon infection with Colletotrichum acutatum and Botrytis cinerea showing that, among RALF genes expressed in fruit, FaRALF3 was the only one upregulated by fungal infection in the ripe stage. A role of FaRALF3 as susceptibility gene was then assessed trough Agrobacterium-mediated transient FaRALF3 overexpression and silencing in fruits, revealing that FaRALF3 expression promotes fungal growth and hyphae penetration in host tissues. In silico analysis was used to identify distinct pathogen inducible elements upstream of the FaRALF3 gene. Agroinfiltration of strawberry fruit with deletion constructs of the FaRALF3 promoter identified a 5' region required for FaRALF3 expression in fruit, but failed to identify a region responsible for fungal induced expression. Furthermore, FaRALF3 and strawberry receptor FERONIA (FaMRLK47) were heterologously expressed in Escherichia coli in order to purify active proteins forms and study RALF-FERONIA interaction in strawberry.

This work was supported by EMBO Short Term Fellowship number 7779 .
Wheat rusts monitoring in Tuscany: re-emergence of stem rust on both durum and common wheat cultivars

\section{Nocentini ${ }^{1}$, B. Randazzo ${ }^{2}$, M.S. Hovmoller ${ }^{3}$, M. Pat- pour $^{3}$, A. F. Justesen ${ }^{3}$, F. Mascher ${ }^{4}$, L. Mugnai ${ }^{1}$}

${ }^{1}$ Department of Agriculture, Food, Environment and Forestry (DAGRI), University of Florence, Piazzale delle Cascine 28, I-50144 Firenze (Italy); ${ }^{2}$ As.A.R. - Ciminna, Palermo (Italy); ${ }^{3}$ Department of Agroecology, Aarhus University, Forsoegsvej 1, DK-4200 Slagelse, (Denmark); ${ }^{4}$ Agroscope, Department of Crop Sciences (Switzerland). E-mail: marconoce@gmail.com

Wheat stem rust caused by Puccinia graminis f. sp. tritici, was eradicated in Western Europe during the last half of twentieth century by breeders' work, but in the second decade of the new millennium an outbreak occurred in middle Europe first, especially in Germany and with sporadic infections in Denmark, Sweden and UK. Only in 2016, an epidemic outbreak was recorded in Sicily. During the last three years, stem rust symptoms were reported also in Tuscany, initially only on some cultivars with low incidence and low severity, but in 2021 all the cultivars monitored showed stem rust symptoms with an incidence ranging from 25 to $100 \%$. For this reason we started a collaboration with the RustWatch project, a consortium of researchers and plant pathologists led by the Global Rust Reference Center at Aarhus University in Denmark, to contribute setting up an early-warning system of wheat rusts by monitoring and sampling wheat cvs to provide a better understanding of the epidemic and determine the rust races present in the different countries and regions respectively. For this purpose some cvs were sown both in Tuscany and Sicily 1) to follow the appearance of rust symptoms in different climatic and soil conditions, 2) to evaluate the perspectives of an early warning system coordinated between Sicily and Tuscany, and 3) to assess the races present on the same cvs in so different region.

The research was funded by the European Union's Horizon 2020 research and innovation program under grant agreement No 773311 (RustWatch) and the study was carried out as part of the wheat fungal diseases monitoring program of the Phytosanitary Service of Regione Toscana.

First report of Fusarium brachygibbosum on cultivated host in Europe

\author{
S. Oufensou ${ }^{1,2}$, V. Balmas ${ }^{1}$, Q. Migheli ${ }^{1,2}$ \\ ${ }^{1}$ Dipartimento di Agraria, Università degli Studi di Sassari, \\ Viale Italia 39, 07100 Sassari, Italy; ${ }^{2}$ Nucleo di Ricerca sulla
}


Desertificazione, Via E. De Nicola 9, 07100 Sassari, Italy. E-mail: soufensou@uniss.it

We report the presence of Fusarium brachygibbosum on quinoa (Chenopodium quinoa Willd.) and durum wheat (Triticum turgidum subsp. durum) isolated in 2018 and 2019, respectively. The isolates were obtained from quinoa (cv. Regalona) seeds harvested in Sardinia (S. Lucia, ZeddianiOristano, Italy) and durum wheat (cv. Marco Aurelio) grain sampled in Campobasso (Molise, Italy). A preliminary identification based on morphological traits was performed and based on the shape of macroconidia, microconidia, presence of chlamydospores and the aspect of the colony on PDA. The isolates were provisionally classified as members of Fusarium incarnatum-equiseti species complex. Genomic DNA of two isolates (one from quinoa and one from durum wheat) was extracted and amplification of the translation elongation factor 1-a was performed. The PCR products were purified and then sequenced by BMR Genomics (Padova, Italy). Blast results on FUSARIUM-ID database, showed $97.4 \%$ identity of the quinoa isolate to the sequence of $F$. brachygibbosum strain NRRL 34,033 (USA TX), while the strain obtained from durum wheat showed $98 \%$ identity to the same NRRL strain. F. brachygibbosum has been previously recovered from undisturbed and cultivated soils, and from a marine sediment contaminated by oil spill in Italy. This is the first report of the presence of $F$. brachygibbosum on cultivated host in Europe.

Fusarium oxysporum (sequence type) associated with corm rot and wilt on saffron in Sardinia, Italy

\section{S. Oufensou ${ }^{1,2}$, V. Balmas ${ }^{1}$, M.A. Dettori ${ }^{3}$}

${ }^{1}$ Dipartimento di Agraria, Università degli Studi di Sassari, Viale Italia 39, 07100 Sassari, Italy; ${ }^{2}$ Nucleo di Ricerca sulla Desertificazione, Via E. De Nicola 9, 07100 Sassari, Italy; ${ }^{3}$ Istituto CNR di Chimica Biomolecolare, Traversa La Crucca 3, 07100 Sassari, Italy.E-mail: mariaantonietta.dettori@cnr.it

Saffron (Crocus sativus L.) is an ancient crop cultivated in Sardinia in an area of almost 35 hectares out of an Italian total of 50 hectares. Saffron is generally grown on a small scale under family-run and organic farming conditions Several pathogens infect saffron plants and corms, however, Fusarium corm rot and wilt caused by Fusarium oxysporum $\mathrm{f}$. sp. gladioli are reported to cause huge yield losses in Italy.

In late 2020, sampling was carried out in four different fields: three in Central Sardinia (two in S. Gavino Monreale and one in Turri) and one in North Sardinia (Arzachena). Basal stem of corm and plants showing browning or wilt, were used for fungal isolation. Morphological and molecular characterisations were performed. Several Sequence Type (ST) of $F$. oxysporum were identified using FUSARIUM-ID (http://www.fusariumdb.org/) database. ST 191 and ST 22 were found in the S. Gavino Monreale area, while ST 63 was detected in Arzachena area.

As a preliminary analysis, these results show that there is a genetic differentiation among $F$. oxysporum f. sp. gladioli strains on saffron samples from different locations in Sardinia.

This work has been supported by CNR, bilateral project Italy/ Morocco 2021-2022.

Grapevine Leaf Stripe Disease and white decay: new insights from the remission of symptoms induced by trunk surgery

\section{A. Pacetti ${ }^{1,2}$, S. Moretti ${ }^{2}$, R. Pierron ${ }^{2}$, S. Farine ${ }^{2}$, C. Bertsch $^{2}$, L. Mugnai ${ }^{1}$}

${ }^{1}$ Department of Agricultural, Food, Environmental and Forestry Science and Technology (DAGRI), Plant pathology and Entomology section, University of Florence, P.le delle Cascine 28, 50144 Firenze, Italy; ${ }^{2}$ Laboratoire Vigne Biotechnologies et Environnement EA-3991, Université de Haute Alsace, 33 rue de Herrlisheim, 68000 Colmar Cedex, France. E-mail: andrea.pacetti@unifi.it

Esca is recognized by many authors as a complex of diseases. In the field, vines older than 3 years can show the typical foliar symptoms, characterized by chloro-necrotic interveinal discoloration, which in older vines is usually associated with white rot, in Europe mainly caused by Fomitiporia mediterranea. Trunk surgery, i.e. the removal of rotten tissue by a precision chainsaw, has been recently confirmed to be able to reduce the appearance of foliar symptoms in vines affected by Esca proper (foliar symptoms + white rot). Metagenomic studies on microbiome changes following trunk surgery showed that $F$. mediterranea was the only species significantly reduced in the remaining sound tissue following removal of the decayed tissue. Based on this observation an in-depth study was developed on the wood degradation mechanisms implemented by the fungus that could also be shared by other fungi associated with the foliar symptoms in young vines without wood rot. With the aim of shedding light on these mechanisms, several $F$. mediterranea strains have been studied for their enzymatic activity such as laccase, manganese peroxidase, and lignin peroxidase also relating them to laccase and manganese peroxidase gene expression. Analysis of the residual polymers by acid digestion of degraded wood and a SEM analysis of the wood samples supported the data on enzymatic activity.

The microbiome-root-shoot axis of induced systemic resistance 
A. Pascale ${ }^{1}$, M.J.J. Stassen ${ }^{1,2}$, S.H. Hsu ${ }^{3}$, C. Dubos ${ }^{2}$, C.M.J. Pieterse ${ }^{1}$, I.A. Stringlis ${ }^{1}$

${ }^{1}$ Plant-Microbe Interactions, Department of Biology, Science4Life, Utrecht University, 3508 TB Utrecht, The Netherlands; ${ }^{2}$ BPMP, CNRS, INRAE, Institut Agro, University of Montpellier, Montpellier, France; ${ }^{3}$ Department of Agronomy, National Taiwan University, No. 1, Sect. 4, Roosevelt Road, 10617, Taipei, Taiwan. E-mail: a.pascale@uu.nl

Plants interact with a plethora of microbes both aboveground and belowground. The totality of these microbes and their activities are referred to as plant microbiome. Many of these microbes can provide the plants with benefits such as nutrient uptake, growth promotion and disease resistance. An imbalance in microbial load and composition along the plant, known as dysbiosis, can result in pathogen proliferation and disease. Plants can modulate their microbiome through the biosynthesis of secondary metabolites, such as coumarins. Production of coumarins relies on the activity of the root specific transcription factor MYB72 that is also indispensable for the onset of induced systemic resistance (ISR). Another component of ISR, BGLU42 is important for coumarin exudation in the rhizosphere where a beneficial microbiome is assembled. Arabidopsis plants overexpressing BGLU42 display a constitutive ISR phenotype. Therefore, coumarins seem to have a role both in roots but also in leaves where ISR is expressed. Here, we aim to study their role in the bidirectional communication between roots and shoots and in shaping the phyllosphere microbiome during ISR (microbiome-root-shoot axis). Our preliminary results show that coumarins are not produced only in roots but also in leaves of plants colonized by beneficial rhizobacteria. It is possible therefore that presence or absence of coumarins in the leaves could affect microbiome assembly and the resistance output of ISR. Therefore, our goal is to study the role of coumarins as signaling molecules during ISR and their involvement in preventing dysbiosis by modulating the microbial homeostasis in the phyllosphere.

This work is supported by the European Commission Marie Skłodowska-Curie Actions. -Individual Fellowship(MSCA-IF), GRANT NUMBER: 893366.

\section{Comparative efficacy of new and traditional stump treat- ments against Heterobasidion spp. in Norway spruce, sil- ver fir and pine stands}

\section{Pellicciaro, G. Lione, S. Ongaro, P. Gonthier}

University of Turin, Department of Agricultural, Forest, and Food Sciences (DISAFA), Largo Paolo Braccini 2, I-10095 Grugliasco, Italy.E-mail: paolo.gonthier@unito.it
The destructive Heterobasidion annosum species complex includes in Europe four species, one of which, i.e. H. irregulare, introduced from North America. The three native Heterobasidion species attack preferentially Norway spruce (Picea abies), silver fir (Abies alba) and pines (Pinus spp.), while $H$. irregulare is associated with Italian stone pine (Pinus pinea). The efficacy of stump treatments with Proradix ${ }^{\circledR}$ (based on Pseudomonas protegens strain DSMZ 13,134), the cell-free filtrate (CFF) of Pseudomonas protegens (strain DSMZ 13,134), Rotstop ${ }^{\circledR}$ (based on Phlebiopsis gigantea), a native strain of Phlebiopsis gigantea and urea was investigated in Abies alba, Picea abies, Pinus pinea and Pinus sylvestris stands against airborne infections by all Heterobasidion species present in Europe. All tested treatments reduced significantly infection rates compared to controls on stumps of all tree species. The performances of treatments varied depending on the tree species. While urea was the most effective treatment regardless of the tree species, the CFF of Pseudomonas protegens resulted very promising.

Authors are grateful to the staff of the Parco della Gallinara (Rome, Italy) and the Corpo Forestale/Corps Forestier of Regione Autonoma Valle d'Aosta/Région Autonome Vallée $d$ 'Aoste for helping with treatments and field samplings. A special thanks to Jean-Claude Haudemand, Giancarlo Zorzetto and Alessandro Porru.

Rep-PCR fingerprinting of Xanthomonas arboricola strains isolated in Chile from Corylus avellana symptomatic plants

\section{S. Perez Fuentealba ${ }^{1}$, E. Biondi ${ }^{2}$, J. Giuliani ${ }^{2}$, P. Minardi $^{2}$}

${ }^{1}$ Institute of Agri-Food, Animal and Environmental Sciences (ICA3), Universidad de O'Higgins, Ruta 90 km. 3, 3070000 San Fernando, Chile; ${ }^{2}$ Department of Agricultural and Food Sciences (DISTAL), Alma Mater Studiorum - University of Bologna, Viale G. Fanin 42, 40127 Bologna, Italy.E-mail: enrico.biondi3@unibo.it

In Xanthomonas genus, which includes Gram-negative bacteria mainly phytopathogenic against various host plants, the Xanthomonas arboricola species has a high genetic variability and, among the current 9 pathovars, pv. corylina causes the halzenut bacterial necrosis which is the main disease present in all hazelnut cultivation areas. In this study, 19 X. arboricola and $21 X$. arboricola pv. corylina strains isolated in Chile, during 2018, from Corylus avellana symptomatic plants were characterised by Rep-PCR analysis (ERIC, BOX, REP). The genetic profiles of all 
strains were transformed into binary matrices which were processed by UPGMA method in single or concatenated way using Jaccard similarity coefficient. Thirteen $X$. arboricola reference strains belonging to the pathovars celebensis, pruni, juglandis and populi were used as controls, while the DISTAL 9081 strain of $X$. axonopodis pv. vitians was used as outgroup. The UPGMA cluster analysis of RepPCR fingerprints divided the $51 \mathrm{X}$. arboricola strains into 5 statistically significant groups corresponding to the relative pathovars: pruni, corylina, juglandis, celebensis and populi. The $X$. arboricola pv. corylina strains showed a high genetic variability (approx. 45\%). The Rep-PCR fingerprints of the $X$. arboricola strains isolated from symptomatic hazelnut shoots and leaves gave similar results with a similarity value of approx. 50\% among strains which were included in the corylina pathovar.

This work was partially funded by the National Agency for Research and Development (ANID) / FONDECYT Posdoctorado /3180629

\section{A novel strategy to obtain Trichoderma beneficial strains}

\section{A. Pironti ${ }^{1}$, R. Marra ${ }^{1}$, A. Staropoli ${ }^{1,2}$, G. Manganiello ${ }^{1}$, N. Lombardi $^{1}$, F. Vinale ${ }^{2,3}$, S.L. Woo ${ }^{2,4}$, M. Lorito ${ }^{1,2}$}

${ }^{1}$ Department of Agricultural Sciences, University of Naples Fed-
erico II, Via Università 100, 80055 Portici (NA), Italy; ${ }^{2}$ Institute
for Sustainable Plant Protection, National Research Council, Piaz-
zale Enrico Fermi 1, 80055 Portici (NA), Italy; ${ }^{3}$ Department of
Veterinary Medicine and Animal Productions, University of Naples
Federico II, Via Delpino 1, 80137 Naples, Italy; ${ }^{4}$ Department of
Pharmacy, University of Naples Federico II, Via D. Montesano 49,
80131 Naples, Italy. E-mail: angela.pironti@ unina.it

Trichoderma beneficial strains may be obtained from suppressive soils or using genetic manipulation techniques, such as transformation, mutagenesis or protoplast fusion (PF). In filamentous fungi PF may represent an effective technique for producing genetic recombination and developing superior hybrid strains. In this work, we used PF to produce Trichoderma hybrids showing improved properties compared to parental strains in terms of biocontrol ability, production of bioactive metabolites and/or promotion of plant growth (PGP). The progeny obtained from two intra-specific hybridizations among beneficial Trichoderma species was screened by using a "high throughput" phenotype-assisted selection for biocontrol and PGP activities. Eight hybrids were isolated from the rhizosphere of tomato plants inoculated with the fusant mixture $T$. harzianum strain $\mathrm{M} 10+T$. virens strain GV41 and showing no disease symptoms caused by Rhizoctonia solani. Hybrids displayed PGP activity on tomato plants and were further characterized by morphological, genetical and metabolomic analyses. In co-culture experiments with Fusarium graminearum on maize, hybrid A3 reduced the pathogen growth and the production of the mycotoxin deoxynivalenol (DON) as observed by GC-MS. Moreover, 4 hybrids obtained by PF between $T$. harzianum strain T22 and T. asperellum strain KV906 inhibited in vitro the growth of Botrytis cinerea. Major secondary metabolites produced in liquid cultures by Trichoderma hybrids were detected by LC-MS q-TOF analysis. Interestingly, several hybrids produced the volatile 6-pentyl-alpha-pyrone (6PP), not found in parental strain cultures. Our results may offer novel opportunities to develop improved beneficial microbes to be used as plant protection products or pant biostimulants.

Type III secretion system enhancement by plant extracts drives host vs non-host plant-bacteria interaction outcome

M-R. Puttilli ${ }^{1}$, C. Correia ${ }^{1,2,3}$, D. Danzi ${ }^{1}$, F. Spinelli ${ }^{2}$, C. Santos $^{3}$, A. Polverari ${ }^{1}$, E. Vandelle ${ }^{1}$

${ }^{1}$ Department of Biotechnology, University of Verona, Strada Le Grazie 15, 37134 Verona, Italy; ${ }^{2}$ Department of Agricultural and Food Sciences, Alma Mater Studiorum-University of Bologna, 40127 Bologna, Italy; ${ }^{3}$ Department of Biology and LAQV/ REQUIMTE, Faculty of Sciences, University of Porto, Rua Campo Alegre, 4169-007 Porto, Portugal. E-mail: elodiegenevieve.vandelle@univr.it

The outcome of host-pathogen interactions is assumed to be largely dictated by offensive or defensive capabilities of both players. A huge effort has been made to provide advances in the study of bacterial host specificity and virulence through the comparative analysis of bacterial genomes and, in plantPseudomonas syringae interactions, several virulence factors contributing to early bacterial pathogenicity have been studied in great details, including the type III secretion system (T3SS), which requires an activating signal before it can be competent for the secretion of virulence effectors, in particular plant signal(s) and multiple physiological and environmental factors. However, the scenario seems more complexed since we recently demonstrated that different biovars of the kiwifruit pathogen Pseudomonas syringae pv. actinidiae (Psa) display a different transcriptional responsiveness in apoplast-like medium, directly correlated to biovar aggressiveness. The further transcriptome profiling of Psa biovar 3 (Psa3) incubated in minimal medium showed the enhancement of TTSS-related gene expression in presence of kiwifruit or tomato leaf extracts after only $1 \mathrm{~h}$, suggesting that the interaction with host plants anticipates TTSS stimulation. In accordance with the necessity of phytopathogenic bacteria to overcome TTSS restriction by plant basal defenses, we showed that TTSS enhancement by plant extracts allows Psa3 to induce TTSS activity in planta, as 
revealed by the induction of a temperature-dependent hypersensitive response in the non-host plant Arabidopsis thaliana Col-0. Overall, our results indicate that in the plant-bacteria arms race, one fundamental parameter governing interaction outcome is likely the timing of bacterial virulence vs. plant defense induction.

\section{Beauveria bassiana field-isolates have varying degrees of rhizosphere competence}

\section{Ranesi ${ }^{1}$, S. Vitale ${ }^{2}$, L. Di Costanzo ${ }^{1}$, S.L. Woo ${ }^{3}$, D. Turrà̀}

${ }^{1}$ Department of Agricultural Sciences, University of Naples "Federico II", Via Università 100, 80055 Portici (NA), Italy; ${ }^{2}$ CNR - Istituto per la Protezione Sostenibile delle Piante (IPSP-CNR), Piazzale Enrico Fermi 1, 80055 Portici (NA), Italy; ${ }^{3}$ Department of Pharmacy, University of Naples "Federico II", Via Domenico Montesano 49, 80131 Naples, Italy.E-mail: marta.ranesi@unina.it

Beauveria bassiana $(B b)$ is a soil-borne entomopathogenic and endophytic fungus able to colonize plant roots and stems. In their interaction with plants, Endophytic Fungi (EF) may stimulate plant growth promotion and protection to both biotic and abiotic threats. EF isolates with crop production enhancement ability are thus increasingly sought for their potential. Although direct/indirect EF-plant interactions are important in triggering plant defence responses to pathogens or pests, little is known on the mechanisms used by $B b$ to outcompete other soil-inhabiting fungi or to penetrate host plant tissues. Here we characterize the acidifying ability of ten $B b$ field-isolates in vitro. While all tested $B b$ isolates were capable of lowering substrate $\mathrm{pH}$ when grown alone, only a few isolates were able to counteract Fusarium oxysporum-mediated alkalinisation, a renowned pathogenicity mechanism of several plant pathogens. Notably, both growth inhibition of $F$. oxysporum and presence of crystals were selectively associated with high-acidifying $B b$ isolates. In order to identify crystal chemical composition, single crystal analysis and X-ray fluorescence measurements were performed at the Elettra Synchrotron (Trieste), identifying a tetragonal form of hydrate calcium oxalate. Our findings suggest that different $B b$ isolates might have varying degrees of rhizosphere competence and plant protection ability as a result of the acidifying and chelating activity of oxalic acid, a major secondary metabolite produced by $B b$. Further experiments will be performed to determine if there is a correlation between oxalic acid production and $B b$ biocontrol activity on $F$. oxysporum, a potentially novel EF biocontrol mechanism.
Prospecting algae and cyanobacteria as bioprotectans for plant disease control

\section{H. Righini ${ }^{1}$, O. Francioso ${ }^{1}$, M. Di Foggia ${ }^{2}$, A. Martel Quintana $^{3}$, R. Roberti ${ }^{1}$}

${ }^{1}$ Department of Agricultural and Food Sciences, University of Bologna, Viale G. Fanin 40, 40127 Bologna, Italy; ${ }^{2}$ Department of Biomedical and Neuromotor Sciences, University of Bologna, Via Irnerio 48, 40126 Bologna, Italy; ${ }^{3}$ Banco Español de Algas, Universidad de Las Palmas de Gran Canaria, 35214 Telde, Gran Canaria,Spain.E-mail: roberta.roberti@unibo.it

The European Directive 2009/128 on sustainable use of pesticides promotes the use of alternative approaches to synthetic products for plant disease control to reduce human, animals and environmental risks. Among alternatives, natural products based on cyanobacteria and algae are gaining attention. Our studies demonstrated that application of water extracts from Anabaena minutissima, Ecklonia maxima and Jania adhaerens controlled powdery mildew caused by Podosphaera xanthii on cucumber detached cotyledons and seedlings and induced the expression of PR genes related to plant-induced resistance. In addition, tomato seed treatment with the same extracts increased germination, seedling dry weight, calibre, and reduced root rot caused by Rhizoctonia solani on tomato plants. Seed treatment also increased chitinase activity and lignin compound contents in tomato seedlings. A deeper investigation on the possible bioactive compounds of $A$. minutissima, E. maxima and $J$. adhaerens, revealed the antifungal activity of polysaccharides against Botrytis cinerea, agent of grey mould, in vitro and in vivo on strawberry fruits. Latest research pointed out that application of phycobiliproteins from A. minutissima, Arthrospira platensis and Hydropuntia cornea on tomato fruits before $B$. cinerea challenge reduced grey mould disease. In particular, FT-IR and FT-Raman spectroscopies have shown that phycobiliproteins from A. minutissima preserved cutin and pectine structures of tomato fruit from $B$. cinerea infection. In conclusion, our research demonstrate the potentialities of algae and cyanobacteria as a bioprotectans for plant disease control.

Is genetic resistance of olive cultivars to anthracnose still effective after a shift of the Colletotrichum population associated to the disease?

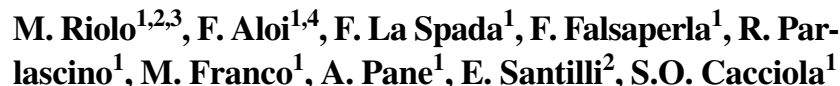


${ }^{1}$ Department of Agriculture, Food and Environment, University of Catania, 95123 Catania, Italy; ${ }^{2}$ Council for Agricultural Research and Agricultural Economy Analysis, Research Centre for Olive, Citrus and Tree Fruit-Rende CS (CREA-OFA), 87036 Rende, Italy; ${ }^{3}$ Department of Agricultural Science, Mediterranean University of Reggio Calabria, 89122 Reggio Calabria, Italy; ${ }^{4}$ Department of Agricultural, Food and Forest Sciences, University of Palermo, 90128 Palermo, Italy. E-mail: olga.cacciola@unict.it

Olive anthracnose (OA) is the most damaging disease of olive fruit worldwide. It is endemic, with frequent severe epidemic outbreaks in some areas of southern Italy with disease-conducive environmental conditions. So far 13 Colletotrichum species were reported to be associated with OA worldwide. Since recently $C$. godetiae was the prevalent species causing OA in southern Italy. However in the last decade $C$. acutatum has prevailed on $C$. godetiae and presently is by far the most prevalent species associated to the disease in this area. In this study nine olive cultivars of worldwide origin were tested for their susceptibility to four different species of Colletotrichum. Colletotrichum acutatum was significantly more virulent than the other three Colletotrichum species and also cultivars that were resistant to $C$. godetiae, such as 'Dolce Agogia', were very susceptible to C. acutatum. Only the Italian cultivars 'Frantoio' and 'Leccino' were resistant to all the four Colletotrichum species tested.

Field monitoring of olive knot in germplasm bank in Southern Italy

\section{Riolo ${ }^{1}$, V.D. Pellicori ${ }^{1}$, S. Bregaglio ${ }^{2}$, S. Zelasco ${ }^{1}$, E.} Santilli $^{1}$

${ }^{1}$ Council for Agricultural Research and Economics, Research Centre for Olive, Fruit and Citrus Crops, 87036 Rende, Italy; ${ }^{2}$ Council for Agricultural Research and Economics, Research Centre for Agriculture and Environment, 40128 Bologna. E-mail: elena. santilli@crea.gov.it

Olive knot disease, caused by Pseudomonas savastanoi pv. savastanoi, is one of the most damaging disease to olive trees. The epidemiological cycle of the bacterium is characterized by a saprophytic phase on olive tree phylloplane, from which it can be disseminated at short distances by splashing rain, windblown aerosols, insects and agronomic practices. However, the mechanisms of pathogen spread and the subsequent appearance of the symptoms on olive trees is poorly understood yet. To date, no olive cultivars have been proved to be completely resistant to olive knot, and only few olive cultivars have been investigated for their susceptibility to this disease. The aim of this study was to assess the incidence of olive knot disease on the accessions of the field collection of Mirto Crosia (Cosenza province, Italy), where 458 olive cultivars and 138 accessions are grown on 9 ha. Field monitoring was conducted on four consecutive years on all cultivars of the collection. The incidence of olive knot was visually assessed with an ordinal disease scale quantifying the intensity of tubercles, ranging from 0 (no symptoms) to 4 (tubercles widespread on the entire plant of an undetectable extension). Preliminary results indicated that most susceptible cultivars were 'Gentile dell'Aquila', 'Moresca', and 'Giarraffa', whereas 'Coratina', 'Nocellara etnea' and 'FS17' did not show any symptoms of olive knot throughout the assessment period.

This work was supported by MIPAAF-D.M. n. 0,033,437 del 21/12/2017" Project 2018-2022 "Salvaguardia e valorizzazione del patrimonio olivicolo italiano con azioni di ricerca nel settore della difesa fitosanitaria"- SALVAOLIVI.

Feeding behavior of Scaphoideus titanus varies on grapevine cultivars differentially susceptibles to Flavescence dorée

M. Ripamonti ${ }^{1,2}$, F. Maron ${ }^{1}$, D. Cornara ${ }^{3,4}$, C. Mar-

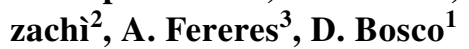

${ }^{l}$ Department of Agriculture, Forest and Food Sciences (DiSAFA), University of Turin, Grugliasco (TO), Italy; ${ }^{2}$ Institute for Sustainable Plant Protection - National Research Council of Italy, IPSP-CNR, Torino, Italy; ${ }^{3}$ Instituto de Ciencias Agrarias, Consejo Superior de Investigaciones Cientificas, ICA-CSIC, Madrid, Spain; ${ }^{4}$ CIHEAM Bari, Italy.E-mail:matteo.ripamonti@unito.it

Scaphoideus titanus Ball is an ampelophagous leafhopper (Cicadellidae: Deltocephalinae), mainly known as the vector of the Flavescence dorée (FD) phytoplasma throughout most viticultural European countries. Considering its efficient ability to sustain FD epidemics and spread, an experimental design was set up to investigate differences in its probing behavior, putatively ascribed to different grapevine varieties. In order to reach this aim, the Electrical Penetration Graphs (EPG) technique was applied. EPG permits a fine description of leaf-hidden probing behavior of sap-sucking insects, enabling a fine dissection of the nutrition of these herbivorous insects. Three grapevine cultivars were selected for their evident differential susceptibility to FD: Barbera as FD-highly susceptible, Brachetto and Moscato as FDpoorly susceptible. Results showed significant differences in the duration of the overall phloem sap ingestion, with a considerable fraction of time spent in phloem nutrition on Barbera. Interestingly, no main differences were highlighted in the phases previous to the reach of the phloem. Moreover, phloematic salivation events were less frequent but numerically higher in Barbera. These results suggest a preference for Barbera, and pair with Barbera higher susceptibility to 
FD. As Barbera was found as the most suitable cultivar, $S$. titanus Moscato-related probing behavior showed the most disturbed profile. In particular, less durable phloem ingestions and more frequent salivations may suggest the presence of antixenotic compounds that actively interfere with $S$. titanus nutrition. The implications of the results could lead to a focused resistance to the leafhopper, opening more sustainable ways for these pest limitations.

Resistance / tolerance to Flavescence doreè of grapevine: a first approach towards the identification of the genes involved

\section{Rossi, L. Galetto, S. Abbà, C. Marzachì, S. Palmano \\ Istituto per la Protezione Sostenibile delle Piante, CNR, Torino, Italy.E-mail: marika.rossi@ipsp.cnr.it}

Flavescence dorée (FD) is a quarantine disease of grapevines caused by a phytoplasma representing one of the most serious limiting factors to viticulture in many European areas. So far, as no genes involved in resistance to FD have been yet identified, the management of FD is based exclusively on preventive control strategies, such as mandatory insecticide treatments and replacement of infected plants with certified plant material. The knowledge of plant defense mechanism response to phytoplasma infection would help identify new sustainable strategies for FD control. To this goal, in the present work, the model system Arabidopsis thaliana/FD phytoplasma/Euscelidius variegatus have been used to identify the plant metabolic pathways altered by phytoplasma infection. A set of genes involved in defense to FD phytoplasma was identified, and their role was further investigated by using knockout mutants in a reverse genetics approach.

Several A. thaliana mutants, defective for genes putatively involved in response to FD, were infected to investigate the role of different metabolic pathways in resistance / tolerance to phytoplasma infection. Infection and phytoplasma multiplication rates were measured in comparison with wild type plants. Identifying genes involved in the susceptibility to infection in a model system represents a preliminary step for the characterization of genes potentially involved in the resistance to FD in grapevine.

An effective low environmental impact strategy for controlling citrus green mould by a new natural biostimulant and reduced doses of Imazalil

\section{E.I. Rovetto ${ }^{1}$, F. La Spada ${ }^{1}$, S. El boumlasy ${ }^{1,2}$, A. Pane ${ }^{1}$,} F. Aloi ${ }^{1}$, M. Riolo ${ }^{1,3,4}$, S.O. Cacciola ${ }^{1}$

\footnotetext{
${ }^{1}$ Department of Agriculture, Food and Environment (Di3A), University of Catania, Via Santa Sofia 100, 95123 Catania, Italy;
}

${ }^{2}$ Laboratory of Materials-Catalysis, Chemistry Department, Faculty of sciences, University Abdelmalek Essaadi, B.P. 2117 Tetouan, Morocco; ${ }^{3}$ Council for Agricultural Research and Agricultural Economy Analysis, Research Centre for Olive, Citrus and Tree Fruit- Rende CS (CREA- OFA), 87036 Rende, Italy; ${ }^{4}$ Department of Agricultural Science, Mediterranean University of Reggio Calabria 89122 Reggio Calabria, Italy. E-mail: olga.cacciola@ unict.it

This study aimed to investigate the potentialities of the application of a mixture made of a natural biostimulant and a fungicide at a reduced dose for the managing of post-harvest citrus green mold by Penicillium digitatum. The natural biostimulant is a new formula based on seaweed (Ascophyllum nodosum) extract and plant (alfalfa and sugarcane) derivatives, while the fungicide is an Imazalil formula. The following aspects related to the application of the mixture were investigated: (i) the fruit-resistance to citrus green mold induced by post-harvest fruit treatments; (ii) the differential expression of resistance genes ( $\beta$-1,3-glucanase-, peroxidase- and PAL-encoding genes) in fruits; (iii) the in vivo post-infectional activity in the control of citrus green mold. The residue of fungicide in peel of mixture-treated citrus fruits was also evaluated.

Results indicated that the mixture provided the best effectiveness in terms of both induction of resistance and postinfectional antifungal activity with as a significant reduction of both incidence and severity of green mold. The expression of defense-related genes also suggested that the mixture was able to elicit a long-lasting resistance. Finally, the residual concentration of Imazalil in peel of fruits treated with mixture was far below the limit established by EU and, quite surprisingly, significantly lower than the residual concentration in fruits treated with the fungicide alone. This study provides new insight into the genetic mechanisms of disease resistance induction in citrus fruit by biostimulants and also offers new perspectives for the improvement of postharvest management strategies of citrus green mold.

\section{The International Committee on Taxonomy of Viruses (ICTV) adopts a binomial nomenclature for virus species}

\section{Rubino ${ }^{1}$, S. Sabanadzovic ${ }^{2}$, F.M. Zerbini ${ }^{3}$}

${ }^{1}$ Istituto per la Protezione Sostenibile delle Piante, CNR, Bari, Italy, Chair of the Plant Viruses Subcommittee of the ICTV; ${ }^{2}$ Mississippi State University, Mississippi State, Mississippi, USA, Chair of the Fungal and Protist Viruses Subcommittee of the ICTV; ${ }^{3} U n i-$ versidade Federal de Viçosa, Viçosa, Minas Gerais, Brazil, President of the ICTV. E-mail: luisa.rubino@ipsp.cnr.it

The International Committee on Taxonomy of Viruses (ICTV) is responsible for developing and maintaining an 
internationally agreed system of hierarchical classification of viruses and naming of taxa, available to the scientific community through a website (https://talk.ictvonline.org) and published reports/papers.

The taxonomic framework has been adapted over the years to reflect current knowledge on the evolution of global virosphere. The ICTV now allows the classification of viruses known only from genomic data. The expansion of taxonomic ranks beyond orders allows studies on evolutionary connections of viruses. In other biological taxonomies, species naming follows a Latinized binomial format first introduced by Carl Linnaeus in 1753, consisting of two italicized words indicating the genus and the species epithet (Arabidopsis thaliana, Saccharomyces cerevisiae, Homo sapiens, Escherichia coli). In contrast, viral species names did not follow a uniform format, except for a requirement to be italicized and to have the first letter of the first word capitalized. Embracing the need for a standardized format, a binomial nomenclature for virus species was ratified by the ICTV in 2021. Thus, a virus species name will consist of two italicized words, the first one being the genus name and the second one consisting of a "free-form" species epithet, composed using the standard Latin-script English alphabet containing 26 letters and/or Arabic numbers. Linnaean-style, Latinized virus species are permitted, but not mandated. Importantly, this change in nomenclature will apply to virus species only. Common virus names will not be affected and will remain unchanged.

\section{Survey on the persistence of Plenodomus tracheiphilus inoculum in of lemon groves during summer}

M. Russo ${ }^{1}$, G. Scuderi ${ }^{1}$, M.C. Bazzano ${ }^{1}$, S. Leocata ${ }^{2}$, A.

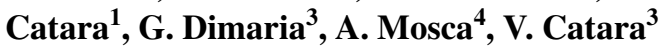

${ }^{1}$ Agrobiotech Soc. Coop., Stradale V. Lancia 57, Catania, Italy;

${ }^{2}$ Studio Tecnico ASA, Stradale V. Lancia 57, Catania, Italy;

${ }^{3}$ Università degli Studi di Catania, Dipartimento di Agricoltura, Alimentazione e Ambiente, Via Santa Sofia 100, 95123 Catania;

${ }^{4}$ Università degli Studi di Catania, Dipartimento di Fisica e Astronomia, Via Santa Sofia 64, 95123 Catania, Italy.E-mail:mrusso@ agrobiotech.it

Plenodomus tracheiphilus is the causal agent of the most destructive lemon disease. The importance and frequency of root infections have been investigated since long time, mostly in growth chamber. By DNA hybridization and later by real-time PCR the fungal inoculum was detected in the soil. The highest fungal DNA concentrations have been detected in March-April, whilst the DNA was nearly undetectable in July and August and increased again in the period September-November. To investigate the actual persistence of the inoculum in the soil during summer a survey was carried out in southern Syracuse, the most important lemon area of Italy. Soil samples were collected on June-July 2019 , in 10 orchards, under the canopy of 53 lemon trees or in the area where the dead trees were grubbed. Lemon trees of different cultivar/rootstock combinations and age were sampled. In each site four subsamples were collected, 232 in total, at $10-20 \mathrm{~cm}$ depth where the soil temperature was between $26-32{ }^{\circ} \mathrm{C}$, assembled per tree or site and stored in a refrigerator $\left(4{ }^{\circ} \mathrm{C}\right)$ until analyzed. Total soil genomic DNA was extracted, using the kit DNeasy PowerSoil (QIAGEN). Detection of $P$. tracheiphilus by Real-time PCR was positive in approximately the $77 \%$ of the tests. Variable fungal DNA concentrations were quantified as DNA per gram of soil. Soil aliquots were plated on a semi selective medium to confirm the number of viable propagules. Metabarcoding of fungal communities recognized the presence of the $P$. tracheiphilus in pilot samples.

This work was supported by the project S.I.R.P.A. funded by PO FESR 2014-2020 Sicilia action 1.1.5.

\section{Phytosanitary evaluation of commercial maize hybrids in Italy in 2019 and 2020}

\section{Sanna ${ }^{1}$, M.L. Gullino ${ }^{1}$, M. Mezzalama ${ }^{1,2}$ \\ ${ }^{1}$ AGROINNOVA, University of Torino, Italy, Largo Paolo Braccini 2, 10095 Grugliasco (TO), Italy; ${ }^{2}$ DISAFA, Largo Paolo Braccini 2, 10095 Grugliasco (TO), Italy. E-mail: monica.mezzalama@ unito.it}

Seed health evaluation is one of the quality characteristics that must be assessed during the seed certification process. Maize (Zea mays L.) is a cereal crop of great economic importance; in Italy its production is currently of 62,591,881 tons on 604,001 ha. Various seed borne pathogens, among them fungi belonging to the genus Aspergillus and Fusarium, affect maize causing biosafety and phytosanitary problems.

We evaluated the phytosanitary quality, and the presence of potentially mycotoxigenic fungi in maize seed samples of commercial hybrids available on the Italian market, produced by eight companies in five countries in Europe and one in North America, treated with different fungicide mixtures. With the freezing blotter method, we detected fungi present in 102 and 75 maize seed lots produced in 2019 and 2020 respectively. The analysis of the seed produced in 2019 showed significant differences among companies and countries in the percentage of infection with Aspergillus spp. and Fusarium spp. The results obtained with the samples produced in 2020 were not statistically different. PCR-based tests were carried out on 90 isolates to identify the A. flavus, $F$. graminearum and $F$. verticillioides and differentiate the mycotoxigenic isolates with with species-specifics primers designed from specific DNA 
sequences. The results showed that Fusarium verticillioides and Aspergillus flavus were the most common species infecting seed and that $46.5 \%$ of $F$. verticillioides and $57.1 \%$ of $A$. flavus were toxigenic. Among the commercial seed treatments, the mixture of fludioxonil and metalaxyl-M was less effective than the ones containing azoxystrobin and prothioconazole in controlling Aspergillus spp. and Fusarium spp.

\section{Tomato fruit: friend or foe? Lessons learnt on emerging safety issues}

S.M. Sanzani ${ }^{1}$, F. Djenane ${ }^{1 *}$, T. Gallone ${ }^{2 *}$, N. Admane ${ }^{1}$, G. Cavallo ${ }^{1}$, O. Incerti $^{1}$, F. Garganese ${ }^{3}$, A. Mincuzzi ${ }^{3}$, A.G. Caruso ${ }^{3}$, M. Amenduni ${ }^{3}$, A. Ippolito ${ }^{3}$

${ }^{1}$ CIHEAM Bari, Via Ceglie 9, 70010 Valenzano (BA), Italy; ${ }^{2}$ Agro. Biolab Laboratory s.r.l., Rutigliano, Italy; ${ }^{3}$ Dipartimento di Scienze del Suolo, della Pianta e degli Alimenti, Università degli Studi di Bari Aldo Moro, Via Amendola 165/A, 70126 Bari,Italy.E-mail: sanzani@iamb.it

\section{*Authors equally contributed}

Tomatoes are a star ingredient of the Mediterranean diet and evoke a powerful association with health benefits related to the content of beneficial compounds as lycopene. However, their consumption might hide some threats related to the contamination by fungi able to produce toxic metabolites. In fact, in a recent investigation, samples of fresh and dried tomatoes produced in the Apulia region (southern Italy) and sent to European markets proved to be contaminated by Alternaria spp. and related mycotoxins. These finding prompted the assessment of the contamination by mycotoxigenic fungi of tomatoes cultivated in a conducive (warm and humid) environment as the greenhouse, which is growing in popularity to counteract seasonality and extreme weather events. It was found that Alternaria, Aspergillus, and Penicillium were the most represented genera. Particularly, Alternaria strains were mostly A. alternata morphotype alternata, able to produce alternariol and alternariol monomethyl ether. Aspergillus strains included species A. westerdijkiae, A. ochraceus, and A. occultus, able to produce ochratoxin A (OTA), and A. welwitschiae, able to produce OTA and fumonisins. The majority of Penicillium strains was represented by $P$. olsonii, not able to produce regulated mycotoxins. Commercial formulations were tested in order to control those pathogens and related decays. Potassium bicarbonate and the combination peracetic acid+hydrogen peroxide proved to prevent fungal growth completely. The same formulations applied by dipping on tomato fruit against $A$. alternata, the most aggressive pathogen, were effective against disease incidence and severity. These promising results support their use in larger-scale trials.
Do insect pollinators transport plant pathogens in urban environments?

\section{A. Saporiti, A. Heinzl, A. Kunova, L. Degradi, M. Sarac- chi, C. Pizzatti, P. Cortesi, D. Lupi, M. Pasquali}

Department of Food, Environmental and Nutritional Sciences, University of Milan, Italy.E-mail: matias.pasquali@unimi.it

The spread of plant pathogens may be facilitated also by insects. In this study, a population of urban pollinators in the city of Milan was sampled and, using a metabarcoding approach based on long sequence reads, the presence of fungal plant pathogens in different insect populations was assessed.

Four locations were sampled in 2020 in the territory of the city of Milan collecting populations of Apis mellifera, Bombus terrestris, Anthidium sp., Bombus pascuorum, and Megachile sculpturalis. The ribosomal operon, the Elongation factor 1-alpha and the RPB2 genes from each population and locality were amplified using a long-range Taq polymerase with fungal-kingdom specific primers. The PCR product libraries were sequenced using Minion Nanopore platform. Fungal identity was attributed by a specific bioinformatic pipeline. Our study preliminary suggests that some plant pathogens may be associated to urban pollinators indicating that these insects can act as transporters of pathogen spores. This result confirms recent literature findings, which suggest a possible role of pollinators as spreaders of plant diseases.

Role of lipid signals in the bacterial-plant pathogen Xylella fastidiosa dual state and during the interaction with the host

V. Scala ${ }^{1}$, N. Pucci ${ }^{1}$, M. Salustri ${ }^{2}$, V. Modesti ${ }^{1}$, S. Lucchesi $^{1}$, A. L'Aurora ${ }^{1}$, M. Scortichini ${ }^{3}$, M. Zaccaria ${ }^{4}$, B. Momeni $^{4}$, M. Reverberi ${ }^{2}$, S. Loreti ${ }^{1}$

${ }^{1}$ Research Centre for Plant Protection and Certification, Council for Agricultural Research and Economics (CREA), Via C.G. Bertero 22, 00156 Roma, Italy ; ${ }^{2}$ Sapienza University, Dept. of Environmental Biology, P.le Aldo Moro 5, 00185 Roma, Italy; ${ }^{3}$ Research Centre for Olive, Fruit Trees and Citrus Crops, Council for Agricultural Research and Economics (CREA), Via di Fioranello 52, 00134 Roma, Italy ; ${ }^{4}$ Department of Biology, Boston College, Chestnut Hill MA, United States of America. E-mail: valeria.scala@crea.gov.it

The global plant exports have augmented the probability for phytopathogens to rapidly reach new countries and infect new agroecosystems. One of the most notorious examples 
is provided by the causal agent of Olive Quick Decline Syndrome (OQDS): Xylella fastidiosa subsp. pauca (Xfp). The first association record of Xfp/olive groves showing twig and branch wilting in Europe, was reported on 2013.

Results achieved by projects XF-ACTORS, SALVAOLIVI and OLIDIXIIT are presented. The studies were focused on the role of lipid molecules. Lipids modulate pathogens virulence, plant defenses and are signals in cell-to-cell communication. Specifically, oxylipins have been extensively studied in plantpathogen interaction even if no studies dealing with phytopathogenic bacteria have been raised.

Xfp was characterized in vitro for uncovering its lipid profile. Starting from this we performed our study: artificial inoculation of a model plant (Nicotiana tabacum) and sampling olive in Xfp-infected and not infected olive orchards (Apulia, Salento). It was confirmed the presence and the alteration in OQDS trees of lipids involved in the Pierce's diseases caused by $X$. fastidiosa subsp. fastidiosa in grapevine, i.e. the diffusible signaling factors such as myristoleic, palmitoleic and oleic acids. Moreover, oxylipins derived by the action of bacterial dioxygenase (e.g., 10-HpOME) and plant lipoxygenase (e.g., 9-HODE) shape in vitro the lifestyle of Xfp (i.e., motility versus sessile status) and are profoundly modified in vivo. More efforts are under way to unveil the role of this lipids in Xf pathogenicity. Lipids can be employed as hallmarks of OQDS and/or for developing control strategies.

This work was supported by Regione Puglia ("Strategie di controllo integrato per il contenimento di Xylella fastidiosa in oliveti pugliesi ed analisi epidemiologiche del complesso del disseccamento rapido dell'olivo (CoDiRO), MIPAAF (SALVAOLIVI D.M. 33,437 del 21-12- 2018 and Oli.Di.X.I.It D.M. 23,773 del 6/09/2017), H2020 (XF-ACTORS grants agreement no. 727987).

\section{Analysis of Vermentino plants with symptoms of chlorotic mottling and leaf deformation disease by molecular test and fluorimetric indices}

\section{N. Schianchi ${ }^{1}$, A. Deidda ${ }^{2}$, V.A. Prota ${ }^{1}$, S. Serra ${ }^{1}$, A. Sassu $^{2}$, L. Ghiani ${ }^{2}$, F. Gambella ${ }^{2}$}

\footnotetext{
${ }^{1}$ Dipartimento di Agraria, Sezione di Patologia Vegetale ed Entomologia, Università degli Studi di Sassari, Viale Italia 39, 07100 Sassari, Italia; ${ }^{2}$ Dipartimento di Agraria, Sezione di Meccanizzazione ed Impiantistica, Università degli Studi di Sassari, Viale Italia 39,07,100 Sassari, Italia.E-mail:nschianchi@uniss.it
}

Grapevine Pinot gris virus (GPGV; genus Trichovirus) is a single-stranded, positive-sense RNA virus infecting grapevine and associated with stunting, chlorotic mottling and leaf deformation. Symptomatic (S) and asymptomatic (A) plants are usually identified by visual approach in the field, while the virus detection is carried out by molecular test (RT-PCR). To detect out infected plants with an early and non-destructive analysis, the use of fluorescence analysis by a proximal sensor was tested. Monitoring was performed in a Vermentino vineyard (Olmedo, Sardinia, Italy) Guyot trained to characterize GPGV disease symptoms. In the summer 2021, 50 leaves by respective plants were tested by RT-PCR (Invitrogen) and classified in two groups: 20 plants $\mathrm{A}$ and $30 \mathrm{~S}$. The same leaves were tested by a fluorometric proximal sensor, Multiplex 3.6 (FORCE-A, Orsay, France) using these indices: Sample Fluorescence Ratio (SFR_RG), linked to chlorophyll content; FLAV, linked to flavonols content; FER_RG, correlated to anthocyanins content devoid of chlorophyll. These indices were analysed in a statistical software (RStudio) by analysis of variance (ANOVA). Statistical differences between the $\mathrm{A}$ and $\mathrm{S}$ plants were found using only the FER_RG index. It has been observed that this index is significantly higher in S plants, indicating a lower chlorophyll content than in the A plants. By performing the inverse of the FER_RG index (FER_RG ${ }^{\wedge-1}$ ), the corresponding index relating to the content of chlorophyll was obtained, which identifies a higher index in asymptomatic plants than in symptomatic ones.

\section{Potential application in crop protection of lignocellulosic nanocarriers obtained from hazelnut residues}

\section{Schiavi, V. Di Lorenzo, M. Salustri, C. Petrucci, G. M. Balestra}

Department of Agricultural and Forestry Sciences (DAFNE), University of Tuscia, Via S. Camillo de Lellis snc, 01100 Viterbo, Italy. E-mail: schiavi@unitus.it; balestra@unitus.it

Hazelnut tree (Corylus avellana) cultivation is quickly diffusing in Italy and in many areas of Mediterranean region. Most common agricultural practices associated to hazelnut orchards management are suckering and pruning, while shelling is required in post-harvest phase to process fruits. Results of these cultural practices consist in huge amount of lignocellulosic biomasses, whose only enhancement today is the energetic one. Many researchers have already highlighted how agroindustrial wastes can be exploited to obtain novel sustainable compounds. Due to their antimicrobial and antioxidants properties, as well as the possibility of acting as carriers for bioactive molecules, engineered organic nanomaterials could open new scenarios in defining innovative green strategies in crop diseases management. Among them lignocellulosic nanocarriers, such as cellulose nanocrystals and lignin nanoparticles, are some of the most promising in terms of potential utilization in sustainable plant protection strategies. The aim of our work was to investigate the 
possibility of extracting cellulose and lignin from hazelnut pruning residues and shells, in order to synthetize cellulose nanocrystals through chemical bleaching followed by acid hydrolysis, and lignin nanoparticles through ethanolic fractionaction followed by solvent exchange protocol. Obtained nanocarriers were morphologically characterized while, at the same time, their biocompatibility on hazelnut plants and their antimicrobial activity was in vitro assessed respect to the causal agent of the hazelnut bacterial blight of hazelnut, Xanthomonas arboricola pv. corylina. Results confirm the possibility of obtaining lignocellulosic nanocarriers from both pruning residues and fruit shells, showing no harmful effects on vegetative growth of hazelnut plants when foliar-applied.

\section{Mapping viruses associated with century old "psorosis group" diseases of citrus}

\section{G. Scuderi ${ }^{1}$, M. Russo ${ }^{1}$, S. Leocata ${ }^{2}$, M. Bazzano ${ }^{1}$, A.F.

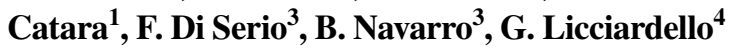

${ }^{1}$ Agrobiotech Soc. Coop., Blocco Palma I, Via V. Lancia 57, 95131
Catania,Italy; ${ }^{2}$ Studio Tecnico ASA, Blocco Palma I, Via V. Lan-
cia 57, 95131 Catania, Italy; ${ }^{3}$ Consiglio Nazionale delle Ricerche,
Istituto per la Protezione Sostenibile delle Piante, Sede di Bari, Via
Amendola 122/D, 70126 Bari, Italy; ${ }^{4}$ Consiglio per la Ricerca in
agricoltura e l'analisi dell'Economia Agraria-Centro di ricerca
Olivicoltura, Frutticoltura e Agrumicoltura (CREA), Corso Savoia
190, Acireale (CT), Italy. E-mail: grazia.licciardello@ crea.gov.it

The development of high-throughput sequencing (HTS) technologies has revolutionized the research on plantassociated pathogens. Several citrus virus and viroids have been fully sequenced by HTS, and many are still pending. Recently, two negative-stranded RNA, bipartite viruses, citrus concave gum-associated virus $(\mathrm{CCGaV})$ and citrus virus $\mathrm{A}$ (CiVA) have been associated with citrus concave gum and citrus impietratura diseases, respectively, whilst other virus sequences similar to $\mathrm{CCGaV}$ and $\mathrm{CiVA}$ have been detected in citrus trees affected by cristacortis and impietratura. Each of these diseases induce typical symptoms on trunk and/ or fruits and all of them induce leaf flecking and mosaiclike symptoms resembling psorosis, Hence, in the past all of them where considered member of the "psorosis group" diseases. Officially, EU legislation on regulated non quarantine pests (RNQP) indicates only citrus cristacortis and citrus impietratura should be absent in the mother trees of certified propagation material, while the "Qualità Italia" certification program of citrus includes also concave gum. To investigate systematically on such group of diseases, we have surveyed old citrus orchards in eastern Sicily and collected several clones affected by clear symptoms of concave gum, blind pocket, psorosis, ringspot, impietratura and cristacortis. All of them have been propagated in a glasshouse repository to better correlate symptoms with bioassays and molecular testing. Testing of symptomatic accessions has revealed some samples are singly infected by citrus psorosis virus, citrus concave gum associated virus, or citrus virus $\mathrm{A}$, and some carry mixed virus infections. The full sequencing could be useful to clarify the association with specific symptoms and/ or their relationship (if any).

This research is part of the project "Novarancia", funded by the Rural Program of Sicily 2014-2020.

Peptides obtained by targeted modifications of a natural Trichoderma peptaibol protect plants from grey mold disease and downy mildew

\section{Sella ${ }^{1}$, M. De Zotti ${ }^{2}$, A. Bolzonello ${ }^{1}$, S. Tundo ${ }^{2}$, S. Luti $^{3}$, R. Bernardi ${ }^{4}$, F. Favaron ${ }^{1}$, I. Baccelli ${ }^{3}$}

${ }^{1}$ Department of Land, Environment, Agriculture and Forestry, University of Padova, Legnaro (Padova), Italy; ${ }^{2}$ Department of Chemistry, University of Padova, Padova, Italy; ${ }^{3}$ Institute for Sustainable Plant Protection, National Research Council, Florence, Italy; ${ }^{4}$ University of Pisa, Department of Agricultural, Food and Agro-environmental Sciences, Via del Borghetto 80, Pisa. E-mail: luca.sella@unipd.it; ivan.baccelli@ipsp.cnr.it

Fungal species belonging to the Trichoderma genus are commonly used as biocontrol agents against several crop pathogens. Among their secondary metabolites, peptaibols are helical, antimicrobial peptides structurally stable even under extreme $\mathrm{pH}$ and temperature conditions. The promise of peptaibols as agrochemicals is however hampered by poor water solubility, which inhibits efficient delivery for practical use in crop protection. Using a versatile synthetic strategy, based on green chemistry procedures, we produced water-soluble peptaibol analogs of the 11-mer lipopeptaibol trichogin GA IV, naturally produced by Trichoderma longibrachiatum.

These newly synthesized peptides were tested against the important plant pathogens Botrytis cinerea and Plasmopara viticola. Compared to native trichogin, which was inactive against the tested pathogens, some peptide analogs resulted particularly effective at low micromolar concentrations against both pathogens, while others were effective only against one of them.

The most effective peptides significantly reduced disease symptoms by $P$. viticola on grapevine leaves and by $B$. cinerea on grapevine leaves, ripe grape berries and tomato leaves. Our results suggest that trichogin-derived peptides do not prime plant defenses but protect plant tissues by inhibiting spore germination on the host surface. An in-depth conformational analysis featuring a 3D-structure-activity relationship study indicated that the relative spatial position 
of cationic residues in the sequence is crucial for increasing peptide fungicidal activity. Besides, effective peptides maintain the right-handed helical structure even in the presence of the pathogen. Further studies will help clarify the mode of action of these antimicrobial peptides.

This research is funded by the Italian Ministry for University and Research, PRIN 20173LBZM2.

Endophytic Beauveria bassiana as a dual biocontrol agent for the control of tomato pests or pathogens and plant biostimulant

\section{Sinno ${ }^{1}$, I. Di Lelio ${ }^{1}$, M. Ranesi ${ }^{1}$, G. Iacomino ${ }^{1}$, F. Pen- nacchio $^{1}$, M.C. Digilio ${ }^{1}$, S.L. Woo ${ }^{2}$}

${ }^{1}$ Department of Agricultural Sciences, University of Naples "Federico II", Via Università 100, 80055 Portici (NA), Italy; ${ }^{2}$ Department of Pharmacy, University of Naples "Federico II", Via Domenico Montesano 49, 80131, Naples, Italy.E-mail: martina.sinno@ unina.it

Many beneficial microorganisms (BM) interactions with plants establish mutualistic symbiosis that confers reciprocal advantages to each component. Among BM, endophytic fungi are a valuable resource, offering the possibility to improve crop protection and/or plant growth, representing a valid alternative to the use of chemical pesticides or fertilizers in modern agriculture. Beauveria bassiana is a well-recognized entomopathogenic fungus, that has attracted further attention due to its ability to grow as an endophyte within the plant tissues thus conferring plant resistance to pests and pathogens.

In this work, we evaluated ten strains of B. bassiana and selected promising isolates able to both endophytically colonize tomato and demonstrated a dual biocontrol ability against two foliar fungal pathogens: Botrytis cinerea and Alternaria alternata, as well as an important insect pest: the aphid Macrosiphum euphorbiae. Along with their capacity for biocontrol, the impact of the fungal endophytes on plant growth stimulation was also assessed. Four of the tested strains offered a significant reduction in disease symptoms and decreased the pest infestations without negatively affecting the plant growth. Indeed, in some cases, the endophytic fungi were able to improve the overall vegetative development. Finally, a useful workflow protocol was designed for the selection of such beneficial fungal endophytes of tomato. This work provides evidence that $B$. bassiana is an excellent candidate as both a biological control agent and plant biostimulant, able to improve crop protection and production without the use of chemical products that can be used in the management of ecosustainable farming systems.

This work was supported by European Union Horizon 2020 Research and Innovation Program, ECOSTACK (grant agreement no. 773554) and by PRIN 2017 [grant number PROSPECT 2017JLN833].

\section{New soilborne pathogens of hemp in Campania region}

\author{
R. Sorrentino, V. Battaglia, G. Piccirillo, F. Raimo, M. \\ Sicignano, E. Lahoz
}

CREA-Council for Agricultural Research and EconomicsResearch Centre for Cereal and Industrial Crops, Via Torrino 2, 81100 Caserta, Italy.E-mail: roberto.sorrentino2@gmail.com

Hemp is a species whose cultivation has a long history in Italy. In fact, it was cultivated until several years later the Second World War but, subsequently, its cultivation was abandoned due to the cultivation of other economically advantageous crops such as tobacco in southern Italy. Since 2016 the cultivation of industrial hemp progressively came back because the publication of Law n. 242 of 2016 by the Italian legislator that allows hemp cultivation in full legal capacity. During some surveys carried out in the years 2018-2020, hemp plants (cv. Uso-31 and Kompolty) with symptoms attributable to soilborne pathogens were observed in the province of Naples both in outdoor and indoor cultivation systems. ( $\mathrm{ca}$. $10 \%$ of plants showing symptoms). Symptoms consisted in severe foot and root rot symptoms observed on hemp plants grown for flowers and fiber production. Fusarium solani and Rosellinia necatrix were isolated from the plants and appropriate pathogenicity and virulence tests were carried out. Since 2017, the return of hemp cultivation in Campania has been accompanied by the recurrence of some diseases that have compromised crops in certain areas and for certain varieties. Together with these two new pathogens, infections by F. oxysporum f. sp. cannabis and Sclerotium rolfsii are also recurrent. Nevertheless, our activities showed us the many other soil-borne pathogens can severely affect the hemp cultivations. Studies on eco-friendly agrochemicals could be the way for sustainable and profitable farming of hemp.

This work was supported by Project PSR PROHEMPIL B21 I1800029002.

Spray application of $\mathrm{BcBmp3-dsRNA}$ delivered by layered double hydroxide (LDH) clay nanosheets reduces virulence of Botrytis cinerea on Lactuca sativa: first results

\footnotetext{
M. Spada' ${ }^{1}$, A. Viviani ${ }^{1}$, C. Pugliesi ${ }^{1}$, M. Fambrini ${ }^{1}$, S. Pecchia $^{1,2}$

${ }^{1}$ Department of Agriculture Food and Environment, University of Pisa, Via del Borghetto 80, 56124 Pisa, Italy; ${ }^{2}$ Interdepartmental Research Center Nutrafood "Nutraceuticals and Food for Health", University of Pisa, Via del Borghetto 80, 56124 Pisa, Italy. E-mail: maria.spada@phd.unipi.it
} 
Recently novel strategies based on the use of RNA interference (RNAi) are rising up in the crop protection scenario. Spray-induced gene silencing (SIGS) is a potential strategy for plant disease management, whereby nucleotide sequence-specific double-stranded RNA (dsRNA) can be sprayed onto a crop and it could represent a potential alternative to conventional fungicides. SIGS could give rise to transient silencing without producing genetically modified organisms (GMO) neither requiring transformation method for plants. Nevertheless, the instability of naked dsRNA sprayed on plants is a major challenge towards its practical application. To overcome this limiting aspect, nanocarriers for dsRNA delivery can be used to extend its stability and durability. We previously shown that topical application of a $B c B m p 3$-dsRNA construct mediated both in vitro and in vivo knockdown of $B$. cinerea transcripts on Lactuca sativa. Our dsRNA construct was loaded on non-toxic, degradable, layered double hydroxide clay nanosheets for a sustained release on the leaf surface under ambient conditions. We prepared LDH by a modified non-aqueous method and the BcBmp3-dsRNA/LDH optimal ratio was assessed by the gel retardation assay. Lettuce plants were sprayed with either water, LDH, or $B c B m p 3$-dsRNA/LDH complex on day 0. $B$. cinerea was inoculated using a conidial suspension 7 days after spray treatment. A significant reduction of gray mould severity was observed as assessed by a rating scale and by calculating the McKinney index. Our results suggest a possible development of SIGS approach for the management of $B$. cinerea disease, although further experiments are needed to fully understand this potential.

The research was partially supported by the University of Pisa within the framework of a PhD research project entitled "Botrytis cinerea-Lactuca sativa L. pathosystem: nanoparticles-mediated delivery of dsRNA in Spray-Induced Gene Silencing (SIGS) for plant disease control".

Microbiome composition provides a powerful tool to elucidate the epidemiology of postharvest diseases of apples

\section{Spadaro ${ }^{1,2}$, M. Garello ${ }^{1,2}$, S. Prencipe ${ }^{1,2}$, E. Piombo ${ }^{1,2}$,} G. Schiavon ${ }^{1,2}$, M. Wisniewski ${ }^{3}$, S. Droby ${ }^{4}$

${ }^{1}$ Dept. Agricultural, Forest and Food Sciences (DISAFA), University of Torino, Largo Braccini 2, 10095 Grugliasco (TO), Italy; ${ }^{2} A G R O I N N O V A$ - Centre of Competence for the Innovation in the Agro-environmental Sector, University of Torino, Largo Braccini 2, 10095 Grugliasco (TO), Italy; ${ }^{3}$ Department of Biological Sciences, Virginia Polytechnic Institute and State University, $220 \mathrm{Ag}$ Quad Ln, Blacksburg, Virginia 24061, USA; ${ }^{4}$ Department of Postharvest Sciences, ARO, the Volcani Center, 68 HaMaccabim Road, Rishon LeZion 7, 505101, Israel.E-mail: davide.spadaro@unito.it
Apple fruits are susceptible to postharvest rots caused by different fungal genera. Some emerging diseases, such as white haze and dry lenticel rot, result in reducing fruit quality and their epidemiology is poorly understood. In recent years, metabarcoding has been extensively used to characterize microbial complexity in apple fruit, based on cultivar, tissue and phenological phase. In this work, we sequenced the ITS2 and V4 regions for both epiphytic and endophytic samples of apple cultivars 'Opal' and 'Ambrosia' to investigate the composition of fungal and bacterial communities, at different developmental stages in the orchard, at storage and shelf-life. Bioinformatic analyses of sequencing data showed significant differences in alpha diversity in the endophytic and epiphytic fungal and bacterial communities in the two apple cultivars. The differences were particularly pronounced for the fungal community samples from similar tissues over the same time points. Compositional and disease incidence data indicate that Golubevia spp. is the main causal agent of white haze and its presence in fruit tissue became significant from September. Ramularia spp., the causal agent of dry lenticel rot, is shown to have a relatively high abundance early during fruit development as part of endophytic microbiota, suggesting the earlier presence in the fruit tissue. This finding provides interesting information about the epidemiology of some postharvest pathogens, which is important to develop adequate management strategies for apple fruit pathogens.

Improvement of nutraceutical value of parsley (Petroselinum crispum) upon field applications of beneficial microorganisms

A. Staropoli ${ }^{1,2}$, A. Vassetti ${ }^{1}$, M.M. Salvatore ${ }^{3}$, A. Andolfi, $^{3,4}$, M.I. Prigigallo ${ }^{5}$, G. Bubici ${ }^{5}$, M. Scagliola ${ }^{6}$, P. Salerno $^{6}$, F. Vinale $^{2,4,7}$

${ }^{1}$ Department of Agricultural Sciences, University of Naples Federico II, 80055 Portici, Italy; ${ }^{2}$ Institute for Sustainable Plant Protection, National Research Council, 80055 Portici, Italy; ${ }^{3}$ Department of Chemical Sciences, University of Naples Federico II, 50125 Naples, Italy; ${ }^{4}$ BAT Center-Interuniversity Center for Studies on Bioinspired Agro-Environmental Technology, University of Naples Federico II, 80055 Naples, Italy; ${ }^{5}$ Institute for Sustainable Plant Protection, National Research Council, 70126 Bari, Italy; ${ }^{6}$ Spagro srl Barletta, Italy; ${ }^{7}$ Department of Veterinary Medicine and Animal Productions, University of Naples Federico II, 80137 Naples, Italy. E-mail: alessia.staropoli@unina.it

Parsley (Petroselinum crispum) is an important aromatic herb that has gained importance in food and cosmetic industry, and it is used as medicinal plant due to the presence 
of compounds with biological activity. Several studies have demonstrated antioxidant, antimicrobial or cancer chemopreventive activity of different parts of parsley. In this study, we focused on the improvement of nutritional value of parsley by using beneficial microorganisms that affect the chemical profile of crops. Streptomyces fulvissimus strain AtB-42 and Trichoderma harzianum strain T22 were applied to a parsley field crop either as single inoculants or a microbial consortium. Three months after transplanting (and inoculation), plants were harvested and subjected to a metabolomic analysis by LC-MS qTOF. Spectrometric analysis led to the identification of seven polar metabolites belonging to different chemical groups, such as coumarines, prenol lipids, flavonoids, carotenoids, fatty acids and cyclic polyols. Results showed a significant difference in relative abundance of these metabolites among treatments. The AtB-42 application, alone or in combination with T22, induced the production of petroselinic acid, while T22, alone or in combination, induced the accumulation of xanthotoxol/bergaptol and its derivative xanthotoxin/bergapthen. The microbial consortium increased the accumulation of capsanthone compared with the single treatments. Finally, all the treatments induced the accumulation of quinic acid, compared to the control. It can be concluded that S. fulvissimus and T. harzianum significantly induced metabolic profile change of parsley and the accumulation of metabolites with nutraceutical value.

This work was supported by PROTECTION Project (MISE CRESO grant number Protection no. F/050421/01-03/X32).

\section{LL017 - a novel plant extract fortifying plants: three case studies}

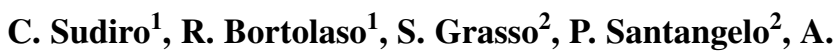
Altissimo $^{1}$

${ }^{1}$ LANDLAB srl, Via Quintarello 12/A, 36050 Quinto Vicentino -VI, Italy; ${ }^{2}$ LANDLAB South Europe srl.E-mail: c.sudiro@landlab.net

Phytophthora infestans (known as late blight) is a potentially devastating pathogen on potatoes, and it is also a serious pathogen on tomatoes in cooler climates. Plasmopara viticola is a highly destructive disease of grapevines in all grape-growing areas of the world with spring and summer rainfall at temperatures above $10{ }^{\circ} \mathrm{C}$. The use of plant protection products is fundamental for crop cultivation. However, as all pesticides, fungicides may cause point source or diffuse pollution of soils, ground and surface waters. Although very little is known on the factorial effect on human health, consumers and their retailers tend to required "Zero residues" food, only achievable by boosting the plant's selfdefences. LL017 is a novel plant extract that activates the primary and secondary metabolism of the plant leading to a strong enhancement of the crops comfort and therewith its defence systems called CFE (Crop Fortification Efficacy). We performed trials on tomatoes, potatoes and grapes, using the LL017 either alone or in strategy with conventional fungicides, and comparing the effect of the product towards the benchmarks. In all the cases, treatments with LL017 decreased both fungal incidence and severity, with an efficiency only slightly lower than the benchmarks. When it was used in strategy, it was possible to reduce the use of conventional fungicide by $33 \%$. These results are very promising, and suggest that a combined strategy with conventional fungicides may be used to effectively decrease the use of this chemicals (Plant Protection Products, PPP) in favour of a "greener" solution to plants diseases.

This work was supported by the EU Project LIFE18 ENV/ NL/000043 Plants for Plants.

Plant-microbe-environmental interaction under the soil: the case of kiwifruit vine decline in Italy

\section{G. Tacconi ${ }^{1}$, L. Tosi ${ }^{2}$, M. Giannini ${ }^{3}$, S. Serra ${ }^{3}$, V. Mich- elotti $^{1}$, A. Lamontanara ${ }^{1}$, L. Orrù ${ }^{1}$ \\ ${ }^{1}$ CREA, Centro Genomica e Bioinformatica, via San Protaso 302, 29017 Fiorenzuola d'Arda (Piacenza), Italy; ${ }^{2}$ Agrea Centro Studi, via Giuseppe Garibaldi 5, 37057 S. Giovanni Lupatoto (Verona,) Italy; ${ }^{3}$ Veneto Agricoltura, via Pradon 13, 45018 Porto Tolle (Rovigo) Italy.E-mail: gianni.tacconi@crea.gov.it}

Since 2012, kiwifruit vine decline (KVD) became the most serious disease of kiwifruit in Italy: over $25 \%$ of the cultivated area are affected. "The leaves wither and face down as if to escape the sun; the roots darken and rot. Then the leaves fall (...). Within one or two years, the plant dries up and dies. There is no cure." (The Guardian, 2020). These sentences well describe the syndrome: KVD is related to climate change, soil conditions and soil-borne diseases. Exceptional rainfall, high temperature for many days during the summer recorded in the last years was consider the main causes of KVD. Different pathogens were isolated since 2014 in many areas, but a common agent was not identified. Neither of these factors taken alone appears to be able to lead to KVD and their combination that must be studied. The control of predisposing factors, such as water excess with the adoption of raised-beds and the optimization of irrigation, help to reduce KVD but does not solve the problem over five years in field trials. The metagenomics approach was used to elucidate the differences in microbial community composition of the soil and the root, between affected and healthy orchards. This is one of the first example where the metagenomics approach was used in a broadwide field survey for a multifactorial diseases, in order to solve an "unclear" phenomenon that are destroying an important crop in one of the main production country. 
Virome reconstruction of Lamon bean through highthroughput sequencing (HTS) approach

\section{G. Tarquini, M. Martini, G. Firrao, P. Ermacora}

Department of Agriculture, Food, Environmental and Animal Sciences, University of Udine, Via delle Scienze 206, 33100 Udine, Italia.E-mail: paolo.ermacora@uniud.it

The Lamon bean is an agricultural product with protected geographical indication (PGI), whose peculiarities are specifically linked to the area of production, located in Belluno province in the Veneto region (N.E. of Italy). In the last decade, the Lamon bean has been subjected to severe epidemics caused by destructive viruses that heavily compromised its profitability. The emergence of new viruses and novel viral strain(s) has always represented the major cause of viral epidemics, causing huge crop losses and threatening crop production. In this work, the full virome of seven Lamon bean plants showing different symptoms was obtained by an HTS approach based on MinION (Oxford Nanopore Technologies; ONT) and analyzed in silico. Sequencing data were validated through RT-PCR and ELISA in a large number of herbaceous plants, including diverse wild species that may represent virus reservoir. Results demonstrated the presence of bean common mosaic virus (BCMV), cucumber mosaic virus (CMV) and peanut stunt virus (PSV), often detected as mixed infection. It is the first time that the presence of PSV was reported in common bean in the Mediterranean basin. Moreover, the Sanger sequencing and phylogenetic studies revealed a wide intraspecific variability of virus species detected in the Lamon area. Nanopore sequencing technology appeared to be a powerful tool in revealing the composition of virus population in Lamon beans. This would allow the development of more efficient and accurate strategies for controlling virus diseases, maintaining the economic sustainability of the Lamon bean cultivation in a context of low environmental impact.

Grapevine Pinot gris virus (GPGV) sequence and Grapevine Leaf Mottling and Deformation (GLMD) disease severity: searching for the link

\section{G. Tarquini, P. Ermacora, G. Firrao}

Department of Agriculture, Food, Environmental and Animal Sciences, University of Udine, Via delle Scienze 206, 33100 Udine, Italia.E-mail: giulia.tarquini@uniud.it

Sequence analysis of natural isolates suggested that the wide diversity in the severity of Grapevine Leaf Mottling and Deformation (GLMD) symptoms could be related with the sequence variation of the associated member of the genus Trichovirus, grapevine Pinot gris virus (GPGV). In particular, the sequence of 3'-end of the GPGV movement protein (MP) includes nonsynonymous single nucleotide polymorphisms (nsSNPs) that discriminate between isolates found in grapevines displaying different symptoms severity. Here, the 3'-terminus of the MP of the virulent infectious clone (pRI::GPGV $\mathrm{VIIR}_{\mathrm{V}}$ ) derived from a grapevine showing severe symptoms, was substituted with a 356-bp synthetic fragment having a sequence resembling that an infectious clone (pRI::GPGV $\mathrm{LAT}_{\mathrm{LAT}}$ ), obtained from an asymptomatic grapevine. The resulting construct ( $\mathrm{pRI}: \mathrm{GPGV}_{\mathrm{CHIMERA}}$ ) was root-inoculated in virus-free grapevines along with the parent clones. Significant differences in symptom expression, virus titre, accumulation of GPGV-derived small interfering RNAs (siRNAs) and alterations in the gene expression of boron transporters were recorded on plants inoculated with either one of the three constructs. The chimeric clone behavior was indistinguishable from that of the donor of the synthetic fragment ( $\mathrm{pRI}:: \mathrm{GPGV}_{\mathrm{LAT}}$ ) and significantly different from the other (pRI::GPGV $\mathrm{VIR}_{\mathrm{V}}$ ), confirming the critical role of the MP $\mathrm{C}$-terminus in determining the fate of the GPGV infection and the GLMD-d severity. Furthermore, quantification of GPGVderived siRNAs via RT-qPCR at the 6635-MP and 6992-CP loci, predicted as hotspots for siRNAs production, showed that the biogenesis of siRNA was more abundant at the 6635-MP locus. Therefore, this locus, which is within the MP 3 '-end fragment examined, contribute to antiviral RNA silencing to a large extent. The connections of specific siRNA biogenesis with symptoms severity deserve further investigations.

\section{Fusarium musae, agent of crown rot disease of banana infects plants and humans}

V. Tava ${ }^{1}$, L. Degradi ${ }^{1}$, M. Saracchi ${ }^{1}$, A. Prigitano $^{2}$, A. Kunova $^{1}$, M. Esposto ${ }^{2}$, P. Cortesi ${ }^{1}$, M. Pasquali ${ }^{1}$

${ }^{l}$ DeFENS, Università degli Studi di Milano, Milano, Italy; ${ }^{2}$ Dipartimento di Scienze Biomediche per la salute, Università degli Studi di Milano, Milano, Italy. E-mail: valeria.tava@unimi.it

Fusarium musae is one of the causal agents of crown rot on banana fruits, an important post-harvest disease of banana fruits. Recent studies suggested that $F$. musae can be isolated also from human patients where it causes nail and eye lesions as well as systemic infection in immunocompromised patients. A set of experiments was carried out to estimate the potential risk of this pathogen to spread from food to clinical settings. A worldwide collection of 19 strains isolated from banana fruits and human patients was classified using multigene phylogeny and infection behaviour on banana fruits. Moreover, the genomes of two representative strains of $F$. musae were sequenced using a using both short and long reads. Mitochondrial genome analysis confirmed the txonomic identity (100\% identity at the protein level) of 
the strains with different host origin. The susceptibility to eight widely used agricultural azole fungicides (prochloraz, tebuconazole, epoxiconazole, difenoconazole, propiconazole, tetraconazole, flusilazole, and fenbuconazole) was furthermore investigated. The strains of human origin, in most of the cases, showed comparable ability to those of plant origin to cause rot symptoms on banana fruits and similar susceptibility to azoles. Overall, our data confirm both taxonomically and physiologically that $F$. musae is a potential cross kingdom pathogen.

Phytosanitary problems of "Aglione della Val di Chiana" bulbs and related control strategies

\section{F. Tini, M. Quaglia, I. Bergamini, N. Terzaroli, G. Bec- cari, L. Covarelli}

Department of Agricultural, Food and Environmental Sciences, University of Perugia, Italy.E-mail: giovanni.beccari@unipg.it

"Aglione" (Allium ampeloprasum var. holmense) is a typical product of "Val di Chiana" (a valley between Umbria and Tuscany regions, Central Italy), which has been recently appreciated by an increasing number of consumers and has become a key economic resource for local farmers. In recent years, phytosanitary problems emerged in the above-mentioned cultivation area, making it necessary to understand the causes and find the related solution. For this reason, bulbils coming from six farms were divided into four portions (tunic, reserve tissue, root, shoot) and, for each of them, symptom observations and fungal isolations were performed. The obtained isolates were molecularly identified and, for a representative isolate of each identified species, pathogenicity was tested. Fungi belonging to the genera Penicillium [P. allii (92\%), P. citrinum (4\%), P. flavigenum (3\%), P. brevicompactum (1\%)] and Fusarium $[F$. oxysporum f. sp. cepae (56\%), F. oxysporum f. sp. dianthi (29\%), F. proliferatum (19\%), F. oxysporum f. sp. lactucae (5\%)] were identified. Fusarium spp. were mainly associated with tunic and root, while Penicillium spp. with root, reserve tissue and shoot. A correlation between isolated fungi and specific symptoms was noted, even if pathogens also developed from asymptomatic portions. $P$. allii was the species with the highest virulence. The planting of healthy bulbils is of fundamental importance for the success of "aglione" cultivation and the application of chemical or microbiological formulations as well as of surface disinfection with a water-sodium hypochlorite solution (2\%) showed promising effects for pathogens control.

Influence of infection timing on Fusarium poae colonization and secondary metabolite accumulation in bread wheat grain
F. Tini ${ }^{1}$, L. Covarelli ${ }^{1}$, C. Cowger ${ }^{2}$, M. Sulyok ${ }^{3}$, P. Benincasa $^{1}$, G. Beccari ${ }^{1}$

${ }^{1}$ Department of Agricultural, Food and Environmental Sciences, University of Perugia, Italy; ${ }^{2}$ U.S. Department of Agriculture-Agricultural Research Service, Department of Entomology and Plant Pathology, North Carolina State University, Raleigh, USA; ${ }^{3}$ Department of Agrobiotechnology, University of Natural Resources and Applied Life Sciences, Vienna, Austria.E-mail: giovanni.beccari@unipg.it

Fusarium poae (FP) is one of the most common Fusarium head blight (FHB) causal agents in wheat. It produces several mycotoxins, in particular nivalenol (NIV). In FHB epidemiology, infection timing is important for kernel development, symptom appearance and mycotoxin accumulation. For these reasons, this study aimed to explore, both in controlled environment and in a 2-year field plot experiment in central Italy, the influence of five different bread wheat infection timings (from early anthesis to medium milk growth stage) on FP colonization and mycotoxin accumulation in the grain. FHB symptoms on heads and kernels were visually evaluated. Grain yield were determined, as was FP biomass accumulation in the grain and the chaff (by qPCR). Finally, FP secondary metabolites in the grain were analyzed by LC-MS/MS. The climate chamber experiment showed that early infection timings (beginning to full anthesis) favoured FP colonization and mycotoxin accumulation (in particular NIV) in the grain. On the contrary, later infection timings (watery ripe kernel and medium milk growth stages) reduced FP development and mycotoxin accumulation. Differences were detected in symptom exoression in kernels as a consequence of infection timing. At each infection timing, FP biomass was higher in the chaff than in the grain. Field experiments confirmed these results. However, the time window of host susceptibility in the field was shorter than that observed in controlled conditions.

Exploitation of the resistance/susceptibility mechanism of Vitis vinifera for the control of grapevine downy mildew

S.L. Toffolatti ${ }^{1}$, D. Marcianò ${ }^{1}$, G. Maddalena ${ }^{1}$, E. Marone Fassolo $^{1}$, D. Maghradze ${ }^{2,3}$, D. Fracassetti ${ }^{4}$, A. Tirelli ${ }^{4}$, P.A. Bianco $^{1}$, O. Failla ${ }^{1}$, P. Casati ${ }^{1}$, A. Passera ${ }^{1}$, V. Ricciardi ${ }^{1}$, G. De Lorenzis ${ }^{1}$

${ }^{1}$ Department of Agricultural and Environmental Sciences, University of Milan, via Celoria 2, 20133 Milano, Italy; ${ }^{2}$ National Wine Agency of Georgia, Marshal Gelovani Avenue 6, 0159 Tbilisi, Georgia; ${ }^{3}$ Caucasus International University, Chargali str. 73, 0141 Tbilisi, Georgia; ${ }^{4}$ Department of Food Environmental and Nutritional Sciences, University of Milan, via Celoria 2, 20133 Milan, Italy.E-mail: silvia.toffolatti@unimi.it 
In a previous comparative transcriptome analysis, several genes involved in resistance to Plasmopara viticola, the grapevine downy mildew agent, have been identified in Mgaloblishvili, a Georgian cultivar of Vitis vinifera. Genes related to the synthesis of antimicrobial enzymes and compounds such as terpenes (e.g. valencene synthase and a cytochrome $\mathrm{P} 450$ ) were among the most frequently upregulated. The same transcriptome analysis highlighted a gene encoding for an LOB domain-containing (LBD) protein, $V v L B D p 1$, putatively involved in susceptibility to $P$. viticola in the Pinot noir $V$. vinifera cultivar.

In this study, the knowledge achieved on the resistance/ susceptibility features of $V$. vinifera was further deepened and exploited to set up the basis for the development of alternative means for the control of downy mildew. On the one hand, the analysis of volatile organic compound (VOC) profiles of leaf through solid-phase microextraction gas chromatography-mass spectrometry and the expression of six terpene synthases (TPSs) allowed to identify four terpenes (farnesene, nerolidol, ocimene and valencene) that, in leaf-disc assays, caused a significant reduction (53-100\%) in downy mildew severity compared to the untreated control. On the other hand, the knockdown of $V v L B D p l$ in Pinot noir through RNA interference (RNAi) triggered by exogenous double-stranded RNA (dsRNA) led to significant reductions in the disease severity in the experimental inoculations carried out seven days after the dsRNA treatment. Together, these results demonstrate the potential of natural bioactive molecules produced by grapevine and RNAi in silencing susceptibility factors in grapevine as innovative means for the downy mildew control.

This work was supported by University of Milan, DiSAA, Research Support Plan 2018, Line 2 A, project 'From phenotyping to genome editing: strategies to limit damage from downy mildew and bois noir in grapevine (ResVite)' and by the National Wine Agency of Georgia within the "Research project for the Study of the Georgian Grapes and Wine Culture".

\section{Targeting Penicillium expansum transporters with high affinity small molecules for reducing patulin production}

V. Tragni ${ }^{*}$, P. Cotugno ${ }^{2 *}$, A. De Grassi ${ }^{3,4 *}$, F. Massari $^{2}$, F. Di Ronzo ${ }^{3}$, A.M. Aresta ${ }^{5}$, M.M. Cavalluzzi $^{6}$, A. Mincuzzi ${ }^{1}$, G. Lentini ${ }^{6}$, C. Zambonin ${ }^{5}$, S.M. Sanzani ${ }^{7 \#}$, A. Ippolito ${ }^{1 \#}$, C.L. Pierri ${ }^{3,4 \#}$

${ }^{I}$ Department of Soil, Plant and Food Sciences, University of Bari Aldo Moro, Via Amendola 165/A, 70126 Bari, Italy; ${ }^{2}$ Biology Department, University of Bari Aldo Moro, Via Amendola 165/A, 70126 Bari, Italy; ${ }^{3}$ Department of Biosciences, Biotechnologies, Biopharmaceutics, University of Bari, Via E. Orabona, 4, 70125 Bari, Italy; ${ }^{4}$ BROWSer S.r.l., clo Department of Biosciences, Biotechnologies, Biopharmaceutics, University of Bari Aldo Moro, Via E. Orabona, 4, 70125 Bari, Italy;
${ }^{5}$ Chemistry Department, University of Bari Aldo Moro, Via Amendola 165/A, 70126 Bari, Italy; ${ }^{6}$ Pharmacy Department, University of Bari Aldo Moro, Via Orabona 4, 70125 Bari, Italy; ${ }^{7}$ CIHEAM Bari, Via Ceglie 9, 70,010 Valenzano (BA), Italy. * These authors are co-first. ${ }^{\#}$ These authors are co-corresponding. E-mail; sanzani@iamb.it; ciro. pierri@uniba.it; antonio.ippolito@uniba.it

Fruits and vegetables represent an important component of a healthy diet. However, almost a third of all food crops could be annually lost because of fungal pathogens. Furthermore, the increase in resistance phenomena in fungi pushed the search of new molecules for controlling infections and related mycotoxins. Some of the newly proposed small molecules target fungal proteins with transporter ability. However, most of mycotoxin-producing fungi, as patulin-producer Penicillium expansum, have few proteins with a solved structure to be used for identifying new inhibitors. Computational approaches for protein function analyses might help in overcoming the problem, by building 3D homology models to be used in virtual screening of chemical libraries. In the present investigation, on the basis of generated 3D comparative models, it was possible to highlight approved drugs/natural compounds/chemicals able to inhibit GMC oxidoreductase and organic acid mitochondrial transporters to control $P$. expansum growth and patulin production. In particular, 1,2,3-BTA and tannic acid, predicted to inhibit mitochondrial transporters, and meticrane and 6-hydroxycoumarin, predicted to inhibit GMC oxidoreductase, proved to be effective in vitro and/or in vivo. A mixture of the identified molecules could be used as disinfecting treatment in fruit washing water and storage rooms to prevent fungal infection and mycotoxin accumulation. Finally, the presented study might be extended to the identification of high affinity small molecules of species-specific protein targets of other pathogenic fungi for preventing pre- and postharvest losses as well as for reducing the contamination by mycotoxins in fruit and vegetables.

Alfalfa mosaic virus induces accumulation of defencerelated metabolites in Nicotiana tabacum

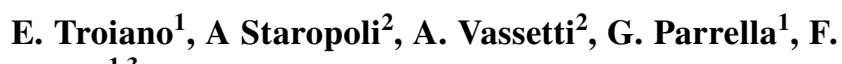
Vinale $^{1,3}$

${ }^{1}$ Institute for Sustainable Plant Protection, National Research Council, 80055 Portici, Italy; ${ }^{2}$ Department of Agriculture, University of Naples Federico II, Via Università 100, 80055 Portici, Italy; ${ }^{3}$ Department of Veterinary Medicine and Animal Productions, University of Naples Federico II, 80137 Naples, Italy. E-mail: elisa. troiano@ipsp.cnr.it

Plants reaction to abiotic and biotic stresses is often related to the production of several molecules including secondary 
metabolites (SMs), natural products with a significant role in plant defence mechanism against pest and pathogens. Aim of this work is to study the metabolism alterations of tobacco plants infected with alfalfa mosaic virus (AMV), through a metabolomic approach based on LC-MS-QTOF. Two AMV French isolates (subgroup II), differing for symptoms severity on host range (e.g. CarE16 necrotic on tomato, To80 causing only mosaic) were used. Two full expanded leaves were inoculated with the two AMV strains separately and subjected to SMs extraction at different days post inoculation. ELISA was used to determine the viral titre. Pronounced symptoms were observed on non-inoculated leaves as the infection progressed, in agreement with ELISA results. LC-MS data were used for PCA analysis and showed the presence of three clusters (noninoculated, CarE16-inoculated, To80-inoculated). Fourteen molecules (alkaloids, terpenes or phenols) were identified by comparison of mass spectra with an in-house database and showed different expression levels in inoculated plants vs controls or in CarE16-inoculated vs To80-inoculated plants. Up-regulation of metabolites related to defence (i.e. nicotine, isoraimonol, 2-ketoepimanool, 3beta,8alfa-dihydroxy-13E-labden-15-oic acid) was evident in plants infected with CarE16, that has shown to be more aggressive than To80, as expected. This approach, although preliminary, has proved to be a valid tool in improving the understanding of the complex mechanisms of viruses-plants interaction. Further investigations are underway to validate this approach in the study of the interactions of other plant-virus pathosystems.

This work was supported by PROTECTION Project (MISE CRESO grant number Protection no. F/050421/01-03/X32).

\section{Nematofauna and microbial communities as bio-indica- tors of vineyard soils health in Campania region (south- ern Italy)}

\section{E. Troiano ${ }^{1}$, G. d'Errico ${ }^{2,3}$, C. Vincenzo ${ }^{1}$, G. Parrella ${ }^{1}$, F.P. d'Errico ${ }^{2}$, F. Vinale ${ }^{1,4}$}

${ }^{1}$ Institute for Sustainable Plant Protection, National Research Council, 80055 Portici, Italy; ${ }^{2}$ Department of Agriculture, University of Naples Federico II, Via Università 100, 80055 Portici, Italy; ${ }^{3}$ Campania Region, Regional Phytosanitary Service, via Don Bosco 9/E, 80141 Naples, Italy, ${ }^{4}$ Department of Veterinary Medicine and Animal Productions, University of Naples Federico II, 80137 Naples, Italy.E-mail: elisa.troiano@ipsp.cnr.it

Soil microflora and microfauna are considered important factors for soil quality, to improve plant growth and resistance to biotic and abiotic stresses. In this study, we evaluated the quality of the soils of selected vineyards located in Avellino province (Campania region, southern Italy), through the identification of the associated nematofauna and microbial communities. Soil sampling was carried out at 30 and $60 \mathrm{~cm}$ depth in order to consider different nematode and microbial populations associated to grapevines rhizosphere. Isolated organisms were characterized and identified by using extensively both morphological and molecular techniques. Nematode population was characterized by a low percentage of plant-parasitic nematodes (PPNs) as Helycotylenchus spp., Rotylenchulus spp. and Xiphinema pachtaicum. Interestingly, the grapevine fanleaf virus nematode-vector, $X$. index, has been not detected while predators (Mononchida) have been isolated in several samples. Some phytopathogenic bacteria such as Agrobacterium tumefaciens and fungi such as Fusarium spp. and Neonectria spp. were detected. On the other hand, this area presents a high level of beneficial microbes known for their ability to suppress pests and pathogens and to degrade chemicals (including pesticides). In particular, Clonostachys rosea (nematicidal activity), beneficial species of Pseudomonas and Pseudaminobacter (plant protection against fungi and PPNs), Variovorax boronicumulans (plant growth promotion) and other rhizobacteria have been isolated. Preliminary in vitro bioassays indicate that $C$. rosea isolated in this work produces metabolites with a strong nematicidal activity. In conclusion, these data show that soil biodiversity is important in preserving soil quality and to control pests and/or pathogens on vineyard production.

This work has been supported by DIONISO Project (PSR Campania 2014-2020-Azione 2 "Sostegno ai POI"), 2019-2021.

\section{Looking at bacterial genomes through a nanopore-size lens}

\section{S. Turco, M.I. Drais, L. Zuppante, A. Mazzaglia}

Dipartimento di Scienze Agrarie e Forestali, Università degli Studi della Tuscia, Via S. Camillo de Lellis snc, 01100 Viterbo, Italy. E-mail: silvia.turco@unitus.it

During the last decade the Oxford Nanopore Technologies (ONT) sequencing methods have been revolutionizing the way to conduct genomic experiments, with significant reflections on plant pathogens identification and studies. The possibility to sequence single molecules in real time and obtain reads much longer than the common short Illumina reads, drastically increases the chance to reconstruct the complete circular chromosomal genome in one single step. This is also crucial when reconstructing the accessory plasmids, since the complete molecule could be already sequenced in one single long read, leading to straightforward assemblies. We tested the efficacy of this method on two pathogenic Pseudomonads with a relatively small genome size (around $6.5 \mathrm{Mb}$ ). First, the genome of a peculiar levan positive strain of Pseudomonas savastanoi pv. savastanoi (PVFi1) isolated in the 90's in central Italy was sequenced with both ONT 
and Illumina. Among other features, it was possible to identify within the assembled genome a functional levansucrase gene very similar to the one possessed by levan positive Pseudomonads, as well as a copy of a non-functional levansucrase gene, analogous instead to the one commonly present in the levan negative Pseudomonas savastanoi. Also, a comparative genomic analysis between Pseudomonas avellanae strains having different geographical origin and host plant was performed, aiming to identify traits specific to population clusters and give insights into the pathogen, host and environment interaction. These achievements provide evidence of the value of ONT approach in obtaining accurately reconstructed genomes, consequently depicting specific features of the pathogens and their population structure.

The research was carried out in the frame of the Italian MIUR (Ministry for education, University and Research) initiative "Department of Excellence" (Law 232/2016).

Quantification of Fusarium spp. in naturally infected Italian durum wheat kernels and correlation with mycotoxin contaminations

M.T. Valente ${ }^{1}$, G. Orlandi ${ }^{1}$, V. Balmas ${ }^{2}$, A. Prodi ${ }^{3}$, L. Covarelli ${ }^{4}$, M. Sulyok ${ }^{5}$, A. Haegi ${ }^{1}$, G. Manetti ${ }^{1}$, A. Infantino ${ }^{1}$

${ }^{1}$ Research Centre for Plant Protection and Certification, Via C.G.
Bertero 22, I-00156 Rome, Italy; ${ }^{2}$ Department of Agriculture,
University of Sassari, Via E. De Nicola 9, 07100 Sassari, Italy;
${ }^{3}$ Department of Agricultural and Food Sciences, Alma Mater Stu-
diorum University of Bologna, Viale G. Fanin 44,40127 Bologna,
Italy; ${ }^{4}$ Department of Agricultural, Food and Environmental Sci-
ences, University of Perugia, Borgo XX Giugno 74, O6121 Perugia,
Italy; ${ }^{5}$ Department of Agrobiotechnology (IFA-Tulln), University
of Natural Resources and Applied Life Sciences, Vienna (BOKU),
Konrad Lorenz Strasse 20, A-3430 Tulln, Austria. E-mail: ales-
sandro.infantino@crea.gov.it

Fusarium Head Blight is one of the most devastating diseases of wheat, in which several Fusarium spp. able to produce mycotoxins, harmful compounds for humans and animals, are involved. To allow for a fast and precise quantification of Fusarium biomass in wheat kernels, a primer pair (FModTCGTCGTCATCGGCCACGTCGAC and FusCerA-GGT AGATCAAGTGACCGGTCT) was designed on the EF-1a gene region. SybrGreen qPCR assays were used for their sensitivity and suitability for the detection and quantification of this genus. The specificity for Fusarium spp. was assayed in silico on 25 Fusarium species and confirmed in vivo on 23 Fusarium spp., 5 Cylindrocarpon spp., 2 Trichoderma spp., and 3 Colletotrichum spp. The analysis was able to detect all the Fusarium species but also Cylindrocarpon species. Seventy durum wheat samples, harvested in Italy in 2019, were analysed by qPCR for the quantification of Fusarium spp. DNA, that ranged from 0 to $0.038 \mathrm{ng} / 10 \mathrm{ng}$ of total DNA. The Pearson correlation coefficient (r) of Fusarium spp. DNA was significant for the total amount of Fusarium toxins $(\mathrm{r}=0.937)$, DON $(\mathrm{r}=0.745)$, enniatins $(\mathrm{r}=0.593)$, Fusarium incidence-Blotter test $(\mathrm{r}=0.511)$, Fusarium incidenceMPDA $(r=0.723)$ and for Fusarium incidence - qPCR $(\Sigma$ of 8 species $)(r=0.723)$, while it was not significant for $\mathrm{T} 2 /$ HT2 $(r=0.093)$. The obtained results are promising for the definition of Fusarium spp. DNA thresholds to speed up the evaluation of wheat samples before analyzing them for mycotoxin content.

Research funded by Lazio Rural Development Plan 2014-2020, Action 10.2.1 (Agro environmental Measure) supporting the "conservation of plants and animals genetic resources in agriculture.

\section{Subcellular responses of wheat epidermal cells to Zymoseptoria tritici}

F. Valente ${ }^{1}$, C. Rodrigues ${ }^{1}$, E. Wallington ${ }^{2}$, D. Herring ${ }^{1}$, G. Thomas ${ }^{1}$, J. Metz ${ }^{1}$, A. Greenland ${ }^{2}$, G. Romana ${ }^{1}$, K. Haynes $^{1}$, P.J. Hussey ${ }^{3}$, M.J. Deeks ${ }^{1}$

${ }^{1}$ Department of Biosciences, University of Exeter, Stocker Road, EX4
4QD, Exeter, United Kingdom; ${ }^{2}$ NIAB, Cambridge, 93 Lawrence
Weaver Road, CB3 OLE, Cambridge, United Kingdom; ${ }^{3}$ School of
Biosciences, Durham University, Stockton Road,DH1 3LE, Durham,
United Kingdom.E-mail: fv247@bath.ac.uk; M.Deeks@exeter.ac.uk

In 2009, the FAO suggested in a report that by 2050 agricultural production will have to increase to $70 \%$ to meet projected demand. Plant diseases caused by phytopathogenic fungi represent the main worldwide threats to food security. Zymoseptoria tritici (Z. tritici) is the main causal agent of the wheat foliar disease Septoria tritici blotch, characterised by a symptomless biotrophic phase lasting 7-11 days, followed by a necrotrophic period with development of fungal asexual sporulation structures called pycnidia throughout the leaf surface. However, several aspects of the first latent phase, including epidermal cell responses, and the spatiotemporal perception of the hyphae at the sub-cellular scale at the stomatal complex, remain still uncharacterised. Herein, we are testing the hypothesis that the wheat immune response galvanizes mechanisms of defence in the initial contact with $Z$. tritici prior to the host penetration via sub-stomata cavities. To address our biological question, we propose a model of host-microbe interaction using bio-imaging approaches based on live-cell imaging and fluorescent proteins labelling plant organelles to investigate early sub-cellular responses occurring in wheat during the early contact with $Z$. tritici. We used high-resolution fluorescence microscopy and automated quantitative bio-imaging approaches for object recognition to determine the presence of wheat focal immunity 
in response to $Z$. tritici invading hyphae in pre-penetration resistance. Subcellular responses in wheat epidermal cells in response to fungal pathogens occur at the stomatal complex via cell wall reinforcement and organelle re-distribution at the site of microbe interaction, with subsidiary cells playing a role in fungal detection.

\section{Geosmithia species associated with Liparthrum colchicum in central Italy}

\section{S. Vitale ${ }^{1}$, L. Luongo ${ }^{1}$, G.P. Barzanti ${ }^{2}$, F. Binazzi ${ }^{2}$, M. Petrucci $^{1}$, M. Galli ${ }^{1}$, F. Pennacchio ${ }^{2}$, V. Francardi ${ }^{2}$}

${ }^{1}$ CREA Research Centre for Plant Protection and Certification, Via C.G. Bertero 22, 00156 Roma (Italy); ${ }^{2}$ CREA Research Centre for Plant Protection and Certification, Via Lanciola 12A, 50125 Cascine del Riccio, Impruneta, Florence (Italy). E-mail: salvatore. vitale@crea.gov.it

Liparthrum colchicum Semenov (Coleoptera Curculionidae Scolytinae) is a relatively unknown monophagous insect species primarily associated with thin dried twigs (about $0.5-1 \mathrm{~cm}$ in diameter) of laurel (Laurus nobilis). Several recent records reported from different locations of Tuscany and Latium showed that the distribution of this beetle could be much wider than previously expected. In Autumn 2019, terminal twigs of bay trees with evident and widespread symptoms of L. colchicum attacks and fungal infections were observed in the park of Villa Salviati (Pisa), Tuscany. Samples of plant material were then collected in order to investigate possible association of this scolytid with phytopathogenic fungi. Adults of the scolytid obtained from the wood galleries were kept in Petri dishes for about 1-3 h on Potato Dextrose Agar (PDA) medium; dishes were afterwards incubated for 7 days at $24{ }^{\circ} \mathrm{C}$. After this period, fungal colonies were observed. Two different colonies of Geosmithia genus were identified according to macro-and micro-morphological criteria. For molecular identification, the DNA of two monosporic isolates (CREADC-F2469, CREADC-F2470) was extracted and the rDNA ITS region was amplified by conventional PCR using the primers ITS5 and ITS4. Morphological identification of the two isolates was confirmed by molecular sequence comparison with $100 \%$ identity with Geosmithia pallida (GenBank accession No. KF808305) and 99\% identity with Geosmithia langdonii (KF808297), respectively. These sequence data have been submitted to the GenBank databases (ncbi.nlm.nih.gov/genbank) under the accession numbers MW627331 and MW627364. To our knowledge this is the first report of Geosmithia pallida and G. langdonii associated with Liparthrum colchicum.

The study was performed within the project "Contributi per il controllo delle emergenze fitosanitarie determinate da Xylosandrus compactus, Xylella fastidiosa, Bortytis cinerea-(CO.XI.BO)" (D.M. 0,037,134 of 31/12/2018) funded by the Ministry of Agricultural, Food and Forestry Policies-MiPAAF.

\section{Selective bioherbicide activity of ginger (Zingiber officinale Roscoe) leaves}

\section{S. Vitalini, M. Iriti}

Department of Agricultural and Environmental Sciences, Università degli Studi di Milano, via G. Celoria 2, 20133 Milan, Italy. E-mail:marcello.iriti@unimi.it

The intensive use of plant protection products (PPPs) may represent a threat for the consumer health and the environment. Therefore, Directive 2009/128/EC establishes a sustainable use of pesticides by promoting the integrated pest management and alternative approaches such as the development of PPPs from plant extracts or microorganisms. In this context, the phytotoxic effects of the water leaf extract and powdered leaves of ginger (Zingiber officinale Roscoe) were assessed against weeds, both monocotyledonous (Echinochloa oryzoides (Ard.) Fritsch and Lolium multiflorum Lam.) and dicotyledonous (Sinapis alba L. and Trifolium incarnatum L.) species, as well as rice (Oryza sativa L.). Different concentrations of the extract and powder were assayed in pre- and post-emergence, in Petri dishes and pots, respectively. Inhibition of germination and emergence, root and shoot length and weight of seedlings, and phytotoxicity rating scale were recorded up to 7 days. In general, both extract and powder significantly inhibited the germination of all the weeds, showing a higher activity on L. multiflorum. In postemergence, the extract exhibited a significant phytotoxicity on all the weeds except for L. multiflorum. Noteworthy, rice seedlings did not show any appreciable lesion after treatment. Further studies are in progress to characterize the chemical constituents of the extract and powder as well as to investigate the mechanisms involved in the observed herbicidal activity and its selectivity. Ginger leaves are production waste that could be developed as a bioherbicide to reduce the PPP input in agriculture and the risk of selecting weed populations resistant to conventional herbicides.

\section{Cucumber mosaic virus is unable to self-assemble in tobacco plants when transmitted by seed}

\section{A. Vitti ${ }^{1,2}$, B. Bochicchio ${ }^{3}$, A. De Stradis ${ }^{4}$, P. Piazzolla ${ }^{2}$, M. Nuzzaci ${ }^{2}$}

${ }^{1}$ Department of Pharmacy, University of Salerno, Via Giovanni Paolo II 132, 84084 Fisciano, Salerno, Italy; ${ }^{2}$ School of Agricultural, Forestry, Food and Environmental Sciences, University of Basilicata, Viale dell'Ateneo Lucano 10, 85100 Potenza, Italy; 
${ }^{3}$ Laboratory of Protein Chemistry, Laboratory of Bioinspired Materials (LaBIM), Department of Science, University of Basilicata, Viale dell'Ateneo Lucano 10, 85100 Potenza, Italy; ${ }^{4}$ Institute for Sustainable Plant Protection, CNR, Via Amendola 122/D, 70126 Bari, Italy.E-mail: avitti@unisa.it

Cucumber mosaic virus (CMV) has great impact on agronomic production worldwide. The genome consists of three single-stranded RNAs, all necessary for infectivity, the coat protein $(\mathrm{CP})$ gene being present in the genomic RNA3 and subgenomic RNA4. CMV is transmitted by aphids, but seed transmission has been reported in legumes, pepper and Arabidopsis. The functions that control virulence, and hence the effect of infection on progeny production, are important for CMV seed transmission, and RNA1 is considered able to affect its efficiency.

Three viral forms [CMV-Fny strain (F); pseudorecombinant CMV-Fny/S (FS); chimeric CMV previously obtained (CS)], produced from the same RNA1, 2 components of CMV-Fny, were propagated in Nicotiana tabacum cv. Xanthi plants. Seed-growth tests on filter paper revealed the seed-borne infection only at embryo, but not integument level. RT-PCR and Immuno Dot Blot analyses on seedlings obtained from seed-growth tests in pots showed the presence, for all considered viruses, which were then purified, of replicase gene and $\mathrm{CP}$ (CMV polyclonal antiserum), with infection rate from 4 to $16 \%$. Electron microscopy revealed absence (CS) or viral particles (F and FS) without the typical central hole; structural characteristics of purified CMV particles, assessed by circular dichroism spectroscopy, showed anomalous spectra of nucleic acids rather than nucleoproteins. Our results suggest that during the first stages of germination and seedling development some tobacco seed factors may target, for example, viral CP N-terminal region, rich in basic amino acids and responsible for protein-RNA interactions, so interfering with the correct virion formation, self-assembling and architecture stability.
Searching for mycoviruses in two collections of Fusarium fungi using metagenomics

\section{J. Zhang, F. Cuppone, R. Baroncelli, A. Prodi, C. Ratti}

Department of Agricultural and Food Sciences, University of Bologna, Viale G. Fanin, 40127 Bologna, Italy. E-mail: claudio.ratti@ unibo.it

We know little about viruses compared to the other lifeforms but, recently, metagenomics has helped us to gain a better understanding of the virosphere. This research aims to discover the mycovirus diversity in two Fusarium poae and Fusarium proliferatum collections and to characterize the mycovirus that may have an effect on pathogenicity, in order to enrich the understanding of fungi viromes and provide potential materials for the biological control of Fusarium spp. pathogens.

Next Generation Sequencing (NGS) analyses of $30 \mathrm{~F}$. poae strains revealed an extreme diversity of mycoviruses; more than 40 putative viral species have been identified belonging to the genera Partitivirus, Betapartitivirus, Victorivirus, Totivirus, Betaendornavirus, Mitovirus, Megabirnavirus, Chrysovirus, Hypovirus and to the new genus Polymycovirus or to unclassified mycoviruses. Moreover, all the $F$. poae strains analysed are infected by four or more viruses. Using the same approach, the viruses identified in $F$. proliferatum collections resulted in lower diversity and abundance. Most of the mycoviruses identified in F. proliferatum belong to Mitovirus and Sclerotimonavirus genera. Interestingly, most $F$. proliferatum strains are not multiple infected. From results obtained so far it is interesting to further explore the differences between the two fungal collections.

Publisher's Note Springer Nature remains neutral with regard to jurisdictional claims in published maps and institutional affiliations. 